Estratégias de beaconing para comunicação em redes veiculares

\author{
Roberto Sadao Yokoyama
}



SERVIÇO DE PÓS-GRADUAÇÃO DO ICMC-USP

Data de Depósito:

Assinatura:

\title{
Estratégias de beaconing para comunicação em redes veiculares
}

\author{
Roberto Sadao Yokoyama
}

Orientador: Prof. Dr. Edson dos Santos Moreira

Tese apresentada ao Instituto de Ciências Matemáticas e de Computação - ICMC-USP, como parte dos requisitos para obtenção do título de Doutor em Ciências - Ciências de Computação e Matemática Computacional. VERSÃO REVISADA 
Ficha catalográfica elaborada pela Biblioteca Prof. Achille Bassi e Seção Técnica de Informática, ICMC/USP, com os dados fornecidos pelo(a) autor(a)

\begin{tabular}{|c|c|}
\hline \multirow[t]{3}{*}{ Y54e } & $\begin{array}{l}\text { Yokoyama, Roberto Sadao } \\
\text { Estratégias de beaconing para comunicação em } \\
\text { redes veiculares / Roberto Sadao Yokoyama; } \\
\text { orientador Edson dos Santos Moreira. -- São Carlos, } \\
2014 . \\
\quad 82 \mathrm{p} \text {. }\end{array}$ \\
\hline & $\begin{array}{l}\text { Tese (Doutorado - Programa de Pós-Graduação em } \\
\text { Ciências de Computação e Matemática Computacional) -- } \\
\text { Instituto de Ciências Matemáticas e de Computação, } \\
\text { Universidade de São Paulo, } 2014 .\end{array}$ \\
\hline & $\begin{array}{l}\text { 1. Redes Veiculares. 2. Beaconing. 3. Testbed. } \\
\text { 4. Localização. } 5 \text {. Posicionamento. I. Moreira, Edson } \\
\text { dos Santos, orient. II. Título. }\end{array}$ \\
\hline
\end{tabular}




\section{Agradecimentos}

Agradeço à Fundação de Amparo à Pesquisa do Estado de São Paulo (FAPESP) pelos auxilios financeiros deste trabalho (Processos \#2009/17720-0 e \#2011/19701-3).

À Coordenação de Aperfeiçoamento de Pessoal de Nivel Superior (CAPES) pelo auxilio financeiro concedido no inicio desta pesquisa.

Ao Instituto Nacional de Ciência e Tecnologia em Sistemas Embarcados Críticos (INCT$S E C)$ pela oportunidade de participar da rede de pesquisadores.

Ao professor orientador, Edson Moreira, pela orientação, amizade e atenção dedicada à realização deste trabalho.

Ao professor Claudio Casetti e o seu grupo de pesquisa por me receber na Politecnico di Torino durante o estágio no exterior.

Aos amigos Bruno Kimura e Roberto Lopes pelas pesquisas em conjunto.

Aos professores Alex Santos Roschildt Pinto, José Augusto Suruagy Monteiro, Juliana Freitag Borin, Kalinka Regina Lucas Jaquie Castelo Branco, pelos comentários e sugestões para a versão final desta tese. 
Em sistemas de transporte inteligentes, as redes veiculares têm um papel fundamental. Por meio da comunicação sem fio, veículos irão disseminar conteúdo nessas redes para melhorar a segurança e eficiência no transporte, prover aplicações de entretenimento etc. Beaconing, proposto originalmente para aplicações de segurança, é usado neste estudo como uma das maneiras de disseminação de conteúdo, onde o nó emissor insere uma informação em um quadro de beacon, que é propagado em broadcast. A maioria dos estudos da literatura focam na otimização de desempenho de beaconing e utilizam o método de simulação para validação e avaliação. Esta tese explora estratégias de beaconing com validação e avaliação usando método experimental em ambientes reais para resolver problemas relacionados a aplicações cooperativas de localização e posicionamento de veículos. Para tanto, foi implantado um testbed veicular para realização de testes tradicionais, como o de desempenho sobre os parâmetros de comunicação, mas principalmente de novos protocolos que transmitem informações adicionais nos beacons. Os principais resultados são: i) uma aplicação para inferência da distância entre os veículos por meio do sinal recebido de rádio frequência, ii) localização de pontos de interesse para motoristas e passageiros e por fim, iii) verificação da localização do veículo e disseminação de beacons anonimamente. Desta maneira, este estudo demonstrou, por meio de experimentos em ambientes reais, que estratégias de beacons podem ser aplicadas com sucesso para aplicações que usam cooperação para localização e posicionamento em redes veiculares.

Palavras-chaves: redes veiculares, beaconing, localização, posicionamento e testbed. 

Vehicular networks play an important role in intelligent transportation systems. Through wireless communication, vehicles can disseminate information to improve transportation safety and efficiency, and provide entertainment applications. Beaconing, first proposed for safety applications, is used in this study as one of the ways to disseminate information, in which the source node adds information to the beacon frame, which is finally propagated in broadcast. Most studies in the literature focus on beaconing performance and optimization using simulations. This thesis explores beaconing strategies, applying experimental methods to validate and evaluate beaconing in real environments, solving problems related to cooperative location applications and vehicles positioning. A vehicular network testbed was developed to perform traditional tests, such as the performance of the communication parameters and to specifically test novel protocols that transmit additional information in the beacons. The key contributions are: i) an application to infer the distance between vehicles via the radio frequency signal received; ii) location of points of interest for drivers and passengers; and iii) location verification of vehicle and anonymous beacon broadcast. In brief, this study demonstrated, through experiments in real environments, that beacon strategies can be successfully applied to problems of location and positioning in vehicular networks.

Keywords: vehicular network, beaconing, location, positioning and testbed. 

$\begin{array}{lll}\text { Abstract } & \text { v }\end{array}$

$\begin{array}{ll}\text { Lista de Figuras } & \text { xi }\end{array}$

Lista de Tabelas $\quad$ xv

Lista de Abreviaturas $\quad$ xvii

1 Introdução $\quad 1$

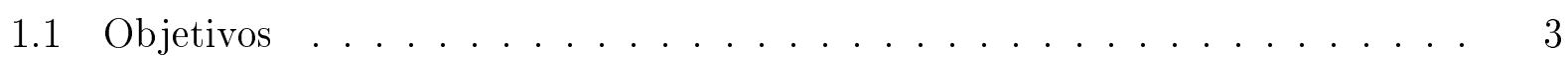

1.2 Organização do documento . . . . . . . . . . . . . . . 3

2 Redes veiculares $\quad 5$

2.1 Principais desafios . . . . . . . . . . . . . . . . . 6

2.2 Padrões de comunicação veicular . . . . . . . . . . . . . 8

2.3 Conceitos de beacons . . . . . . . . . . . . . . . . . . . 10

2.3.1 Beacons em redes WiFi. . . . . . . . . . . . 10

2.3.2 Beacons em redes veiculares .................. 12

2.4 Visão geral dos estudos da literatura . . . . . . . . . . . . . . . . 12

2.5 Testbeds de redes veiculares . . . . . . . . . . . . . . 13

2.6 Trabalhos relacionados . . . . . . . . . . . . . . . 16

2.7 Considerações finais . . . . . . . . . . . . . . . . . . 18

3 V-Beacon: Uma plataforma experimental para redes veiculares $\quad 19$

3.1 Implementação do middleware beaconing . . . . . . . . . . . . . . . . 20 
3.1 .1 Envio de beacon . . . . . . . . . . . . . . . . 21

3.1 .2 Recepção do beacon . . . . . . . . . . . . . . . . . . . 22

3.2 Hardware . . . . . . . . . . . . . . . . . . . 23

3.2 .1 Instalação do roteador no veículo $\ldots \ldots \ldots \ldots \ldots \ldots$

3.2 .2 Instalação do roteador na $\operatorname{RSU} \ldots \ldots \ldots \ldots . \ldots \ldots$

3.3 Experimentos de validação da plataforma . . . . . . . . . . . . . 25

3.3 .1 Testbed e aplicação . . . . . . . . . . . . . . . . 25

3.3 .2 Teste I - Comunicação V2V . . . . . . . . . . . . . . 25

3.3 .3 Teste II - Comunicação V2I . . . . . . . . . . . . . . . . 28

3.4 Visualização do RSSI . . . . . . . . . . . . . . . . . . . . . . . . . . . . . . 29

3.5 Considerações finais . . . . . . . . . . . . . . . . . . . . . . . . . . . 29

4 Caracterização do RSSI de beaconing para estimar distâncias 31

4.1 Descrição do experimento . . . . . . . . . . . . . . . . 33

4.1 .1 Configuração do testbed . . . . . . . . . . . . . . . 33

4.1 .2 Medições. . . . . . . . . . . . . . . . . . . . . 34

4.2 Caracterização do RSSI . . . . . . . . . . . . . . . . . . . . . 36

4.3 Formalização do problema . . . . . . . . . . . . . . . . . . . . . 39

4.4 Arquitetura da aplicação . . . . . . . . . . . . . . . . . . . . . 39

4.5 Resultados . . . . . . . . . . . . . . . . . 41

4.5 .1 Avaliação geral . . . . . . . . . . . . . . . . 42

4.5.2 Impacto do valor de $k$ vizinhos $\ldots \ldots \ldots \ldots \ldots . \ldots . \ldots 43$

4.5.3 Impacto da quantidade de amostras $m$ e do intervalo $\triangle \ldots \ldots .44$

4.6 Considerações finais . . . . . . . . . . . . . . . . . . 45

5 OSDP: Um protocolo de descoberta de serviços para redes veiculares $\quad 47$

5.1 Cenários e definições . . . . . . . . . . . . . . . . . . . . . . 49

5.1 .1 Exemplos de uso do OSDP . . . . . . . . . . . . . . . . 49

5.1 .2 Definições do sistema . . . . . . . . . . . . . . . . . 50

5.2 Protocolo de descoberta de serviço oportunista . . . . . . . . . . . . 51

5.2 .1 Tipos de mensagens . . . . . . . . . . . . . . . . 51

$5.2 .2 \quad$ Fases do OSDP $\ldots \ldots \ldots \ldots \ldots \ldots \ldots \ldots \ldots \ldots$

5.2 .3 Operações do protocolo . . . . . . . . . . . . . . . . 55

5.3 Implementação e testbed . . . . . . . . . . . . . . . . . . 55

5.3 .1 Implementação do OSDP . . . . . . . . . . . . . . . . . . . . 55

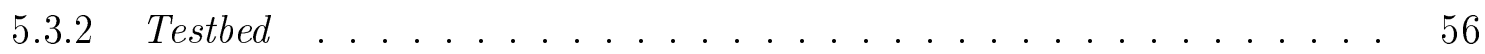

5.4 Experimentos e resultados $\ldots \ldots \ldots \ldots \ldots \ldots$ 
5.4 .1 Avaliação das fases I e II: Beaconing e Caching . . . . . . . . . . 57

5.4 .2 Avaliação da fase III: Querying . . . . . . . . . . . . . 59

5.4 .3 Medidas de tempo .................... 60

5.5 Considerações finais . . . . . . . . . . . . . . . . . 60

6 Disseminação anônima e inferência da posição de veículos $\quad 63$

6.1 Verificação e inferência de posições dos veículos . . . . . . . . . . . 63

6.1.1 Procedimento do protocolo . . . . . . . . . . . . . . . . . 64

6.1 .2 Inferência e verificação da posição . . . . . . . . . . . . . 67

6.2 Testbed, implementação e resultados . . . . . . . . . . . . . . 68

6.3 Considerações finais . . . . . . . . . . . . . . . . 70

7 Conclusões $\quad 71$

7.1 Dificuldades e limitações do projeto . . . . . . . . . . . . 73

7.2 Publicações . . . . . . . . . . . . . . . . . . . 74

7.3 Sugestões de trabalhos futuros . . . . . . . . . . . . . 75

$\begin{array}{ll}\text { Referências } & 77\end{array}$ 

2.1 Principais entidades do cenário de redes veiculares - adaptado de Papadimitratos et al. (2009) . . . . . . . . . . . . . . . . .

2.2 As comunicações das partes do padrão WAVE. WBSS 1: comunicação entre OBUs. WBSS 2: OBU comunicando com a RSU. Adaptado de (Uzcategui e

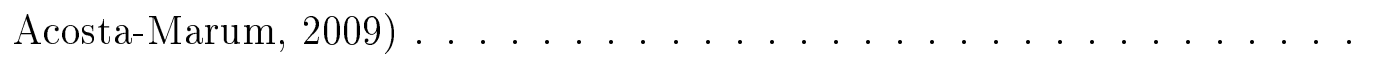

2.3 Padrão WAVE: As duas pilhas de protocolos IP e WSMP. As camadas Resource Manager e Security não se encaixam facilmente no modelo de referência

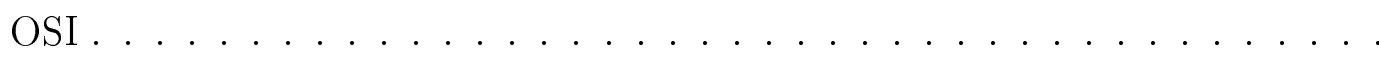

2.4 (a) Porcentagem de artigos em conferência e periódicos; (b) Porcentagem de artigos com método experimental; (c) Porcentagem de artigos por objetivo do estudo em beaconing . . . . . . . . . . . . . . . . . . .

3.1 Middleware Beaconing com duas partes principais. À esquerda estão as funções responsáveis pelo Envio do Beacon, e à direita as funções responsáveis pela Recepção do Beacon . . . . . . . . . . . . . . . . . . . . . .

3.2 Frame do beacon e os campos que são substituídos (spoofed) pelas informações do middleware beaconing (Yokoyama et al., 2013) . . . . . . . . . . . . .

3.3 Na figura está representado um fragmento do arquivo de $\log$ salvo no veículo receptor durante os testes. Cada linha é um beacon recebido . . . . . . . . .

3.4 (a) Foto da antena e do receptor GPS fixadas no teto do carro. (b) Foto da RSU instalado no testbed (Yokoyama et al., 2013) . . . . . . . . . . . . . . .

3.5 Foto de satélite destacando o circuito de $\approx 320 \mathrm{~m}$ utilizado para o experimento. Área interna do Campus II da USP-São Carlos . . . . . . . . . . . . . . . . 26 
3.6 Representação dos beacons transmitidos com sucesso. Os gráficos são os mapas dos beacons (representados pelos traços) trocados em diferentes instantes e distâncias: (a) beacons recebidos com distância inferior a $80 \mathrm{~m}$; (b) beacons recebidos com distância entre $80 \mathrm{~m}$ a $160 \mathrm{~m}$; (c) beacons recebidos com distância acima de $160 m$ (Yokoyama et al., 2013) . . . . . . . . . . . . . .

3.7 FDA para a distância e velocidade nos Testes I e II e o PDR é somente do Teste I: (a) FDA da distância inter-veículos; (b) FDA da velocidade do(s) veículo(s); (c) PDR inter-veículos (Yokoyama et al., 2013) . . . . . . . . . .

3.8 Na parte superior é ilustrado os locais onde as RSUs foram instaladas no circuito. Na parte inferior é ilustrado o perfil do terreno, representando o desnível do terreno (Yokoyama et al., 2013) . . . . . . . . . . . . . .

3.9 PDRs de cada RSU e do veículo com relação a cada RSU: (a) PDR da RSU-1 localizado a esquerda do testbed; (b) PDR da RSU-2 localizado a centro do testbed; (c) PDR da RSU-3 localizado a direita do testbed (Yokoyama et al.,

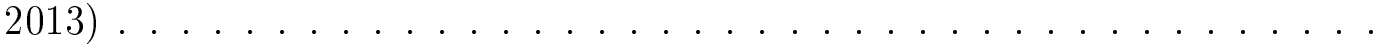

3.10 Distribuição do RSSI separado por RSU: (a) RSSI da RSU-1 localizado a esquerda do testbed; (b) RSSI da RSU-2 localizado a centro do testbed; (c)

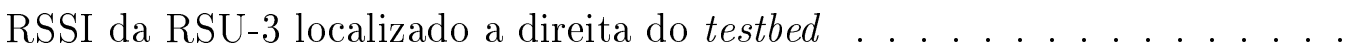

4.1 Foto de satélite do local e a configuração do testbed para coleta de dados . .

4.2 a) Valores diretos da coleta do RSSI em função da distância no veículo e na RSU e b) Mapa representativo do valor médio do RSSI por região do testbed.

4.3 Valores coletados no veículo do RSSI e distância em função do tempo para a primeira coleta . . . . . . . . . . . . . . . .

4.4 a) Frequência de beacons por valor de $\operatorname{RSSI}(\mathrm{bloco}=1 \mathrm{dBm}$ ) e b) Frequência de beacons por intervalo de distância $($ bloco $=10 \mathrm{~m}$ ) . . . . . . . . . .

4.5 Boxplots para análise da dispersão do RSSI a) aplicando um intervalo $\triangle=5 \mathrm{~m}$ e b) aplicando um intervalo $\Delta=10 \mathrm{~m} \ldots \ldots \ldots$

4.6 A figura representa os vinte histogramas da frequência do RSSI para intervalos de distâncias $\triangle=10 \mathrm{~m} \ldots \ldots \ldots \ldots$. . . . . . . . . . 38

4.7 Valores médios do RSSI e desvios padrões para a) $\triangle=5 m$ e b) $\triangle=10 m$. 39

4.8 Arquitetura da aplicação . . . . . . . . . . . . . . . . . . . . . 40

4.9 Ilustração das instâncias de duas dimensões definidas por $\hat{I}_{1 . .500}=\{\bar{X}, s, d\}$ para um $\triangle=50 m \ldots \ldots \ldots \ldots$

4.10 a) FDA do erro para $f p R$ e $f p s$ comparando com erro aleatório. Distribuição do erro $\delta$ em metros para cada intervalo de distância com $\triangle=10 \mathrm{~m}$, b) $\mathrm{fp} R$

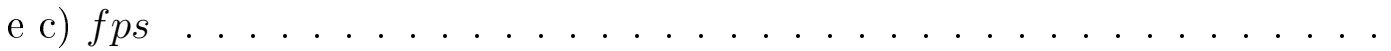


4.11 a) Erro médio $\varepsilon$ para diferentes valores de $k$ b) Erro médio $\delta$ até $95^{\underline{0}}$ percentil, por intervalo de distância com $\Delta=10 m \ldots \ldots \ldots$

4.12 a) Erro médio absoluto $\varepsilon$ para diferentes valores de $m$ e b) Taxa de acerto para diferentes valores de $\triangle$ e $m \ldots \ldots \ldots \ldots$

5.1 Exemplos do uso do OSDP na rede veicular. Os veículos $\left\{v_{1} \ldots v_{4}\right\}$ estão ouvindo e armazenamento beacons transmitidos pela $\left\{R S U_{1} \ldots R S U_{3}\right\}$. Os veículos por meio de contatos oportunos armazenam e encaminham as informações sobre os serviços descobertos (Yokoyama et al., 2014) . . . . . . . . .

5.2 Formato da mensagem para os três tipos, $M, Q$ e $R$, encapsulados no beacon ou probes response . . . . . . . . . . . . . . . . . .

5.3 Fases do OSDP. A $R S U$ transmite o serviço. Os veículos próximos da $R S U$ ouvem e armazenam na cache as informações. O usuário que deseja encontrar um serviço consulta a cache dos outros veículos próximos a ele (Yokoyama et al., 2014) . . . . . . . . . . . . . . . . . .

5.4 Máquina de estado OSDP no veículo (Yokoyama et al., 2014) . . . . . . . . . 55

5.5 A estrutura do beacon nativo IEEE 802.11a. O documento XML foi inserido nos dois campos consecutivos IE Vendor no final do frame. A divisão do documento XML é por causa da limitação de comprimento máximo de 255 bytes por campo (Yokoyama et al., 2014) . . . . . . . . . . . . . . .

5.6 O testbed utilizado para prova de conceito e avaliação do desempenho de OSDP. Nas avaliações das fases Beaconing e Caching o $A P_{3}$ representa o veículo $v_{j}$ e outros APs representam $R S U$ s. Na a avaliação da fase da Query o $A P_{3}$ representa $v_{i}$ e os outros APs representam veículos vizinhos $V \ldots$.

5.7 Exemplos dos cenários de avaliação: a) duas $R S U$ e um carro recebendo beacons e b) Um veículo consultando três veículos vizinhos . . . . . . . . . .

5.8 a) A taxa de sucesso $S_{b r}$ para as fases beaconing e cache do OSDP. Um cenário onde $v_{i}$ recebe beacons das $R S U_{\mathrm{s}}$ sob a densidade, $d_{r}$, que varia de 1 a 7 . A $R S U s$ transmitem beacons, $M$, cada $T=1 s$. b) A taxa de sucesso $S_{q r}$ para a fase de consulta do OSDP. Um cenário onde $v_{i}$ consulta os veículos $v_{j}$ sob a densidade, $d_{v}$, que varia de 1 a 7 (Yokoyama et al., 2014) . . . . . . . . .

6.1 Visão geral dos procedimentos A-VIP pelo Beaconer, Report e LA. Adaptado de Malandrino et al. (2013). . . . . . . . . . . . . . . . . .

6.2 a) Foto de satélite da Villa Gualino destacando o trajeto realizado durante o experimento; b) Mapa de propagação do sinal RF, adaptado de Malandrino et al. (2013) . . . . . . . . . . . . . . . . . . . .

6.3 Erro de localização em função do intervalo de beaconing $\tau_{b}$, adaptado de Malandrino et al. (2013) . . . . . . . . . . . . . . . . . . . 



\section{Lista de Tabelas}

2.1 Principais características dos testbeds . . . . . . . . . . . . . . 15

3.1 Configuração do Roteador sem fio (Yokoyama et al., 2013) . . . . . . . . . . 24

4.1 Configuração do roteador sem fio . . . . . . . . . . . . . . . 33

4.2 Total de beacons recebidos por coleta . . . . . . . . . . . . . . . . 34

4.3 Parâmetros e valores da avaliação geral . . . . . . . . . . . . . . . . . . 42

4.4 Ranking da avaliação geral ordenado pela taxa de acerto . . . . . . . . . 43

5.1 Arranjo de instâncias do OSPD para cada densidade . . . . . . . . . . 58

5.2 O tempo gasto na troca de mensagens OSPD . . . . . . . . . . . . 60 



\section{Lista de Abreviaturas}

$\begin{array}{lll}\text { A-VIP } & - \text { Anonymous Verification and Inference of Positions } \\ \text { AES } & - \text { Advanced Encryption Standard } \\ \text { AP } & - \text { Access Point } \\ \text { BS } & - \text { Base Station } \\ \text { BSS } & - \text { Basic Service Set } \\ \text { CCH } & - \text { Control Channel } \\ \text { CSMA CA } & - \text { Carrier Sense Multiple Access/Collision Avoidance } \\ \text { DSRC } & - \text { Dedicated Short Range Communication } \\ \text { FDA } & - \text { Função de Distribuição Acumulada } \\ \text { GPS } & - \text { Global Positioning System } \\ \text { ITS } & - \text { Intelligent Transportation System } \\ \text { k-NN } & - \text { k-Nearest Neighbors } \\ \text { MANET } & - \text { Mobile Ad Hoc Networks } \\ \text { OSDP } & - \text { Opportunistic Service Discovery Protocol } \\ \text { PIR } & - \text { Packet Inter-Reception } \\ \text { PDR } & - \text { Packet Delivery Rate } \\ \text { PoE } & - \text { Power Over Ethernet } \\ \text { POI } & - \text { Point Of Interest } \\ \text { RF } & - \text { Rádio Frequência } \\ \text { RSSI } & - \text { Received Signal Strength Indicator } \\ \text { RSU } & - \text { Road Side Units } \\ \text { SCH } & - \text { Service Channel } \\ \text { SSID } & - \text { Service Set Identifier } \\ \text { ToF } & - \text { Time-of-Fligth } \\ \text { V2I } & - \text { Vehicle to Infrastructure } \\ \text { V2R } & - \text { Vehicle to RSU } \\ \text { V2V } & - \text { Vehicle to Vehicle } \\ \text { VANET } & - \text { Vehicular Ad Hoc Network } \\ \text { WAVE } & - \text { Wireless Access in Vehicular Environments } \\ \text { WBSS } & - \text { WAVE Basic Service Set } \\ \text { WSMP } & - \text { WAVE Short-Message Protocol } \\ \text { XML } & - \text { eXtensible Markup Language } \\ & \end{array}$


Sistemas de Transporte Inteligentes (Intelligent Transportation Systems - ITS) são um conjunto de tecnologias integradas (sensoriamento, tecnologia da informação, eletrônica, sistemas de comunicação de dados, etc.) que visam oferecer serviços e gerenciamento de tráfego avançado para meios de transporte rodoviário, aéreo, ferroviários e outros (ETSITS, 2011). Exemplos de aplicações ITS são o fornecimento em tempo real de informações das condições do trânsito para os usuários, sistema de alerta de acidente para aumentar a segurança em rodovias, aplicações de gerenciamento do tráfego para reduzir engarrafamento etc. A maior parte dessas aplicações ITS serão providas por meio das redes veiculares que compreendem, essencialmente, a comunicação veículo para veículo (vehicle-to-vehicle - V2V) e veículo para infraestrutura (vehicle-to-infrastructure - V2I) com base em tecnologias de rede local sem fio (Cespedes et al., 2013).

As redes veiculares, ou rede veicular não infraestruturada (Veicular Ad Hoc Network VANET), são redes compostas por veículos capazes de comunicar dados entre si por meio de tecnologias de rede sem fio, tipicamente usando a família IEEE 802.11 (Hartenstein e Laberteaux, 2008). VANET foi vislumbrada, principalmente, para aproveitar a disseminação das redes 802.11 e prover acesso à Internet e entretenimento (por exemplo, jogos, multimídia streaming, etc) aos usuários (Zeadally et al., 2012). No entanto, com o início da padronização por meio do IEEE 802.11p (IEEE-802.11p, 2010) e do Wireless Access in Vehicular Environment (WAVE) (Uzcategui e Acosta-Marum, 2009), as redes veiculares passaram a considerar uma infraestrutura de rede às margens da rodovia, chamada de RoadSide Unit (RSU) e uma comunicação dedicada a curta distância, conhecida como Dedicated Short Range Communi- 
cation (DSRC) (Hong et al., 2009). Desta maneira, VANET deixou de ter somente ênfase em redes ad hoc e passou a ter uma infraestrutura para suportar as aplicações e serviços ITS (Karagiannis et al., 2011).

As aplicações em redes veiculares previstas no WAVE podem ser classificadas de duas maneiras fundamentais (Hartenstein e Laberteaux, 2008): i) aplicações de segurança (safety applications) - devem aumentar a segurança dos usuários (motoristas e passageiros) por meio da troca de informações pertinentes à segurança. Geralmente, essa troca de informações é direta, via comunicação V2V, devido ao requisito da troca das mensagens não tolerar longos atrasos. Exemplos de aplicações de segurança são o sistema de alerta de emergência, assistente de mudança de pista e coordenação do cruzamento; ii) aplicações de não-segurança (non-safety applications) - este tipo de aplicação, normalmente de infotainment (neologismo de informação e entretenimento), visa melhorar a experiência dos usuários durante a viagem. As aplicações de não-segurança podem utilizar de maneira conjunta ou independente a comunicação V2V e V2I. Exemplos de aplicações de não-segurança são o sistema de informações do tráfego local, aplicativos para download de arquivos, aviso de pontos de interesse (por exemplo, posto de gasolina, restaurantes etc), provimento de Internet etc.

A base da comunicação de muitas das aplicações de segurança e não-segurança é o DSRC (Jiang e Delgrossi, 2008), que faz uso de mensagens de status, de único salto (single-hop), tipo beacons, para troca de informações. Beacons contêm a posição geográfica e informações de cinemática do veículo e são transmitidos em broadcast, por cada veículo, de maneira periódica. Nas aplicações de segurança essas informações permitem que os veículos receptores fiquem cientes das condições do trânsito em sua volta e detectem qualquer situação anormal. Para tanto, os beacons são transmitidos em um canal prioritário, porém compartilhado entre os veículos e, como consequência, em situações de alta densidade de tráfego de veículos, o canal pode ficar sobrecarregado, degradando a rede veicular e o desempenho das aplicações de segurança (Ghafoor et al., 2013). Nas aplicações de não-segurança as informações são transmitidas em outros canais de serviços, de uso geral, que podem ser usados também para transmissão de beacons, porém não relacionados à segurança, por exemplo, informações de pontos de interesse para os motoristas.

O problema de otimização de desempenho do beaconing é abordado por diversos trabalhos na literatura e representam a maior parte dos trabalhos relacionados a beacons em redes veiculares (Ghafoor et al., 2013; Karagiannis et al., 2011; Daniel et al., 2012). Esses trabalhos têm por objetivo melhorar o desempenho de beaconing, com propostas de algoritmos para acesso ao meio ou métodos adaptativos da potência de transmissão (Torrent-Moreno et al., 2009). Entretanto, beacons são pouco explorados para outros propósitos, como aplicações de infotainment e aplicações que demandam cooperação entre os veículos. Além disso, existe uma carência da literatura de trabalhos com método de validação e avaliação experimental em ambientes reais (Martelli et al., 2012). Neste sentido, este estudo investigou estratégias de 
beaconing com método experimental, por meio de testbed, em ambientes reais. A motivação para a escolha de beacons é porque eles possibilitam a rápida troca de informações por não necessitar uma configuração prévia da rede. A rápida troca de informações é requisito importante devido à frequentes modificações da topologia da rede, decorrente, principalmente, da velocidade dos veículos.

Os principais trabalhos desenvolvidos foram: i) desenvolvimento de plataforma (software e hardware) de testes em ambientes reais (Yokoyama et al., 2013); ii) o estudo do comportamento do Received Signal Strength Indicator (RSSI) por meio de beaconing e o projeto, implementação e avaliação da aplicação para inferência de distância entre veículos com base no RSSI; iii) exploração de beacons para descoberta de serviços, realizando a concepção, implementação e avaliação do protocolo baseado nos paradigmas da comunicação oportunista e store-carry-and-forward em redes veiculares (Yokoyama et al., 2014) e por fim, iv) implementação e avaliação da proposta de verificação da localização cooperativa por meio de beacons anônimos que utilizam criptografia simétrica (Malandrino et al., 2013).

\subsection{Objetivos}

O objetivo geral desta tese é demonstrar que estratégias de beaconing podem ser utilizadas em aplicações cooperativas para resolver problemas ou melhorar soluções relacionadas à localização e posicionamento em redes veiculares. Para tanto, são objetivos específicos:

- Especificação e implantação de uma plataforma experimental compatível com o padrão de redes veiculares para a realização de testes com beaconing em ambientes reais;

- Projeto, implementação e avaliação de protocolos com base em beaconing para aplicações cooperativas relacionadas à localização e posicionamento.

\subsection{Organização do documento}

Este documento está organizado nos seguintes Capítulos:

- Capítulo 2: Detalha a revisão da literatura, principalmente os trabalhos relacionados e as características dos testbeds encontrados na revisão. Também discorre sobre os padrões de comunicação de redes veiculares e os fundamentos de beaconing;

- Capítulo 3: Descreve o hardware e software da plataforma experimental e os testes de desempenho das comunicações V2V e V2I realizados para validação da plataforma; 
- Capítulo 4: Discorre sobre o problema que pode ocorrer no posicionamento devido ao erro do Global Positioning System (GPS) e propõe uma aplicação para estimar a distância entre veículos com base no estudo realizado sobre o RSSI, no cenário de redes veiculares;

- Capítulo 5: Aborda o problema da descoberta de serviços em redes veiculares e demonstra que beaconing pode ser uma boa alternativa como solução do problema;

- Capítulo 6: Avalia experimentalmente o protocolo de inferência da posição e transmissão anônima de beacons;

- Capítulo 7: Pondera as conclusões e as principais contribuições deste trabalho. Também discorre sobre sugestões de trabalhos futuros. 


\section{expruse}

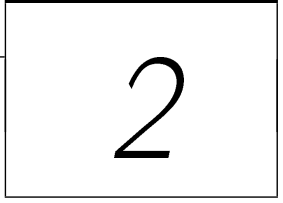

\section{Redes veiculares}

Os Sistemas de Transporte Inteligentes (ITS) abrangem diversos tipos de comunicações de dados e não estão restritos ao transporte rodoviário. Também incluem o transporte ferroviário, aquático e aéreo. ITS podem ser determinados como a aplicação de informações e tecnologias avançadas de comunicações nos meios de transportes, a fim de alcançar maior segurança e mobilidade e ao mesmo tempo reduzir o impacto ambiental do transporte. Para o transporte rodoviário, os principais objetivos são: agilizar e gerenciar tráfego de veículos, auxiliar os motoristas, garantir a segurança no trânsito e prover aplicações de interesse aos usuários (motoristas e passageiros) (ETSI-TS, 2011). Alguns exemplos desses serviços incluem sistemas automáticos de cobrança de pedágio, alerta de acidentes de trânsito, aviso de congestionamento etc. Portanto, neste contexto, as redes veiculares são uma instância para os ITS.

A pesquisa em redes veiculares se iniciou com o cenário da comunicação não infraestruturada (ad hoc) entre veículos. A característica da alta variação da velocidade dos nós móveis e a rápida mudança na topologia da rede, fez com que fosse classificada como um caso particular de Mobile Ad Hoc Network (MANET), sendo denominada Vehicular Ad Hoc Network (VANET). Entretanto, o termo VANET, originalmente adotado para refletir a natureza ad hoc de redes intensamente dinâmicas, tem sido debatido para a redefinição da sigla, de maneira que não enfatize unicamente as redes ad hoc, pela razão da comunicação entre o veículo e a infraestrutura às margens da rodovia (Hartenstein e Laberteaux, 2008). Neste trabalho, VANET é referenciada como redes veiculares que envolvem a comunicação veículo-com-veículo (V2V) e veículo-com-infraestrutura (V2I). 
Na Figura 2.1 são mostradas as principais entidades da rede veicular. O veículo que participa da rede veicular será equipado com um sistema com computador, interfaces de comunicação, sensores e interfaces para usuário. Este irá suportar uma gama de aplicações para melhorar a segurança do transporte e também proporcionar serviços aos usuários. Uma infraestrutura de rede às margens de rodovias e ruas, denominada de Road Side Unit (RSU), também será parte das redes veiculares e facilitará o acesso à Internet. Desta maneira, os dispositivos portáteis dos passageiros e o sistema do veículo também poderão conectar à Internet pela infraestrutura rodoviária. Um sistema de central pode ser adotado para gerenciar a entrada de veículos na rede, principalmente no aspecto da segurança computacional, como distribuição de chaves criptográficas, servidores de autenticação etc. O sistema também pode fornecer serviços e gerenciar a mobilidade do nó, durante as trocas de rede (Papadimitratos et al., 2009).

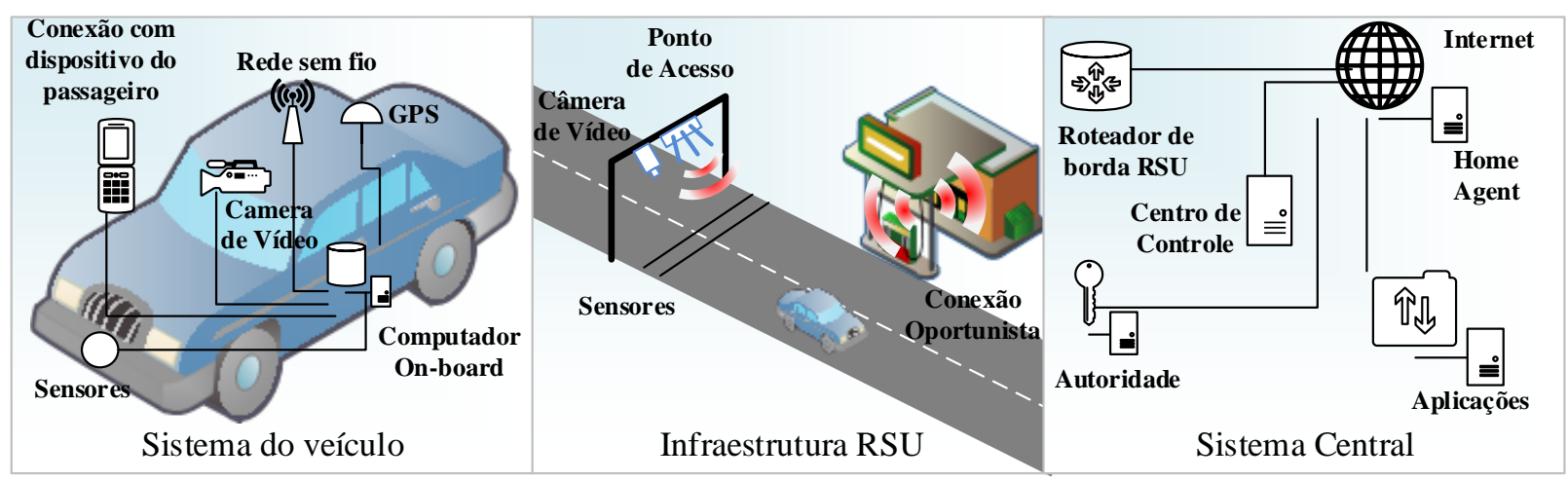

Figura 2.1: Principais entidades do cenário de redes veiculares - adaptado de Papadimitratos et al. (2009)

\subsection{Principais desafios}

Hartenstein e Laberteaux (2008) e Zeadally et al. (2012) discutem, em termos gerais, os principais desafios de redes veiculares que ainda demandam investigação e soluções inovadoras nos aspectos da comunicação, segurança, aplicação e serviços da rede.

Nas redes veiculares é difícil assumir uma única central de coordenação das comunicações e, por isso, diversas aplicações terão a necessidade de funcionar de maneira eficiente, usando coordenação descentralizada, ou seja, os veículos transmitem informações para muitos carros vizinhos no canal único e compartilhado. Este paradigma do canal compartilhado leva a alguns dos desafios das redes veiculares, como a otimização do broadcasting, um dos principais focos da pesquisa em redes veiculares. Um número significativo de mensagens transmitidas na rede são mensagens tipo broadcast e a tecnologia IEEE 802.11, proposta no padrão de rede veicular, não está totalmente adaptada para gerenciar transmissões tipo broadcast, devido às 
frequentes colisões de mensagens. Essas colisões, por sua vez, afetam a taxa de entrega de mensagens e aumentam também o tempo de entrega. Neste sentido, são necessárias soluções com esquemas de coordenação inteligentes para evitar a inundação do canal, por exemplo algoritmos distribuídos de acesso ao meio que sejam eficientes nas comunicações assimétricas entre os veículos para diferentes distâncias de transmissão.

Considerando a transferência de dados, outros problemas podem ocorrer, devido à topologia de rede ser muito dinâmica, decorrente da mobilidade dos veículos e o impacto do ambiente sobre a propagação do sinal de rádio frequência. A mobilidade e a elevada velocidade dos veículos fazem com que os protocolos de roteamento convencionais para MANET não sejam eficientes no ambiente veicular, porque nem sempre são encontrados nós intermediários entre a origem e o destino e, portanto, não pode ser estabelecida uma conexão fim-a-fim. O problema na propagação do sinal de rádio é causado pelas diferenças na altura da antena, interferências de outras fontes de rádio frequência no mesmo canal e a atenuação e reflexão das partes metálicas do veículo, que provocam condições adversas do sinal. Sendo assim, existe a necessidade de uma potência de transmissão e taxa de dados adaptativos para atingir uma comunicação confiável e de baixa latência.

No aspecto da segurança, existe o problema de equilibrar as necessidades de segurança e privacidade. Os veículos receptores querem ter a certeza de que podem confiar na fonte da informação, mas a disponibilidade de tal confiança pode contradizer os requisitos de privacidade de um veículo transmissor. Portanto, a segurança eficiente é um requisito importante de redes veiculares. Vários desafios de segurança ainda precisam ser abordados nas áreas de autenticidade, confidencialidade do usuário e disponibilidade. São necessárias soluções leves e estruturas de autenticação escaláveis, capazes de proteger o nó da rede veicular de ataques internos e ataques externos a rede. Nós maliciosos podem se infiltrar na rede utilizando uma identidade falsa e suprir, gerar, alterar ou reproduzir mensagens legítimas com diversos propósitos, como, por exemplo, falsificar a sua posição, provocar negação de serviço, roubar informações etc.

Na visão econômica existe a preocupação na introdução da tecnologia da comunicação em novos veículos. A tecnologia aumenta o preço do veículo para o cliente e, portanto, é necessário convencer os primeiros compradores a pagar por ela. Uma vez que, no início, uma pequena quantidade de veículos estará equipada com a tecnologia, pode não ser vantajosa para o usuário, pois o funcionamento das aplicações de segurança depende da comunicação com outros veículos. Entretanto, é provável que a instalação prévia da infraestrutura RSU para provimento de Internet e serviços atraentes consiga convencer os primeiros clientes a adquirir um veículo preparado para as redes veiculares.

Por fim, a qualidade de serviço (QoS) em redes veiculares está relacionada aos problemas do protocolo de roteamento e de segurança. É necessária a definição de um conjunto de métricas de QoS para redes veiculares, dadas as grandes variações de métricas de desempenho 
que podem ser utilizadas pela comunidade de redes veiculares. Por exemplo, atraso, jitter, taxa de entrega de pacotes e duração da conexão.

\subsection{Padrões de comunicação veicular}

Em 1999, a Federal Communications Commission (FCC) concedeu o espectro de $5.9 \mathrm{GHz}$ para a comunicação Dedicated Short Range Communication DSRC com foco em ITS. A FCC adotou como base para a camada física e a camada Media Access Control (MAC), o padrão IEEE 802.11, porque é um padrão estável. Em 2004, o IEEE task group p assumiu a responsabilidade do desenvolvimento do padrão IEEE 802.11p para ambientes veiculares. Outro grupo, IEEE working group 1609, assumiu a tarefa das especificações das camadas adicionais no conjunto de quatro protocolos: IEEE 1609.1 , 1609.2, 1609.3 e 1609.4. Coletivamente, IEEE 802.11p e IEEE 1609.x é chamado de Wireless Access in Vehicular Environments (WAVE), seu objetivo é facilitar o provimento do acesso a rede em ambientes veiculares (Jiang et al., 2008).

A frequência de operação do WAVE tem como base a comunicação DSRC; nos Estados Unidos é definida na frequência de $5.9 \mathrm{GHz}, 75 \mathrm{MHz}$ de banda e existe a separação dos canais de controle $(\mathrm{CCH})$, reservados para a transmissão de mensagens de aplicações de segurança (safety) e canais de serviço ( $\mathrm{SCH}$ ) para a troca de dados de mensagens para ambas aplicações de segurança e não-seguras (non-safety). A alteração fundamental introduzida pelo WAVE é permitir um veículo transmitir e receber dados sem a necessidade de pertencer a um Basic Service Set (BSS), a priori. Isso significa que os veículos podem se comunicar imediatamente um com o outro a partir de um tempo de contato, sem qualquer sobrecarga adicional, considerando que operam no mesmo canal (Jiang e Delgrossi, 2008).

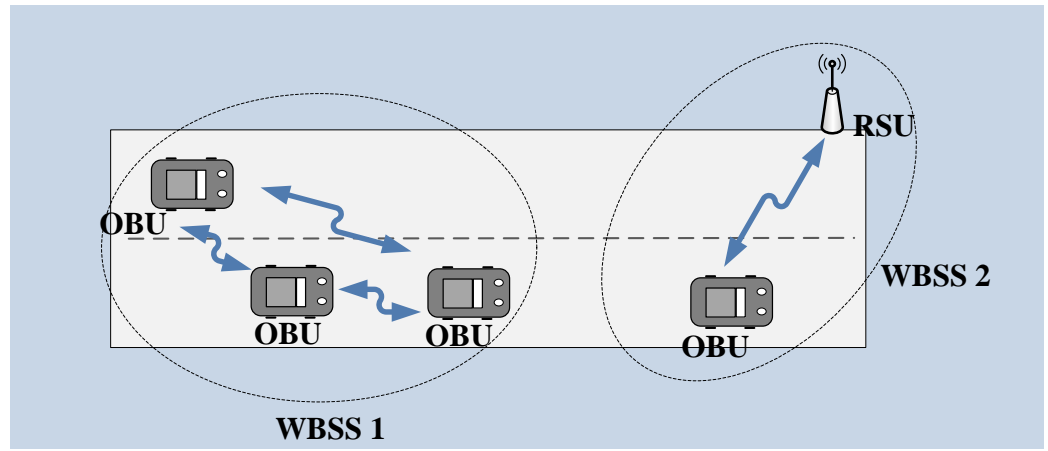

Figura 2.2: As comunicações das partes do padrão WAVE. WBSS 1: comunicação entre OBUs. WBSS 2: OBU comunicando com a RSU. Adaptado de (Uzcategui e Acosta-Marum, 2009)

O padrão WAVE é dividido em duas partes (Uzcategui e Acosta-Marum, 2009): i) RoadSide Unit (RSU) que podem ser instaladas em postes de iluminação, semáforos, sinais de trânsito e assim por diante; e ii) Onboard Unit (OBU) que são instaladas nos veículos 
(carro, moto, caminhão, ônibus). As partes do padrão operam de maneira independente e os veículos podem se organizar em pequenas redes chamadas WAVE Basic Service Set (WBSS). A WBSS pode consistir somente de OBUs ou uma mistura de OBUs e RSUs, como ilustrado na Figura 2.2. Os membros de um determinado WBSS trocam informações por meio de alguns canais de serviço $(\mathrm{SCH})$ e de controle $(\mathrm{CCH})$. Porém, pacotes de Internet Protocol (IP) são permitidos apenas no canal SCH e os veículos devem ser membros da mesma WBSS.

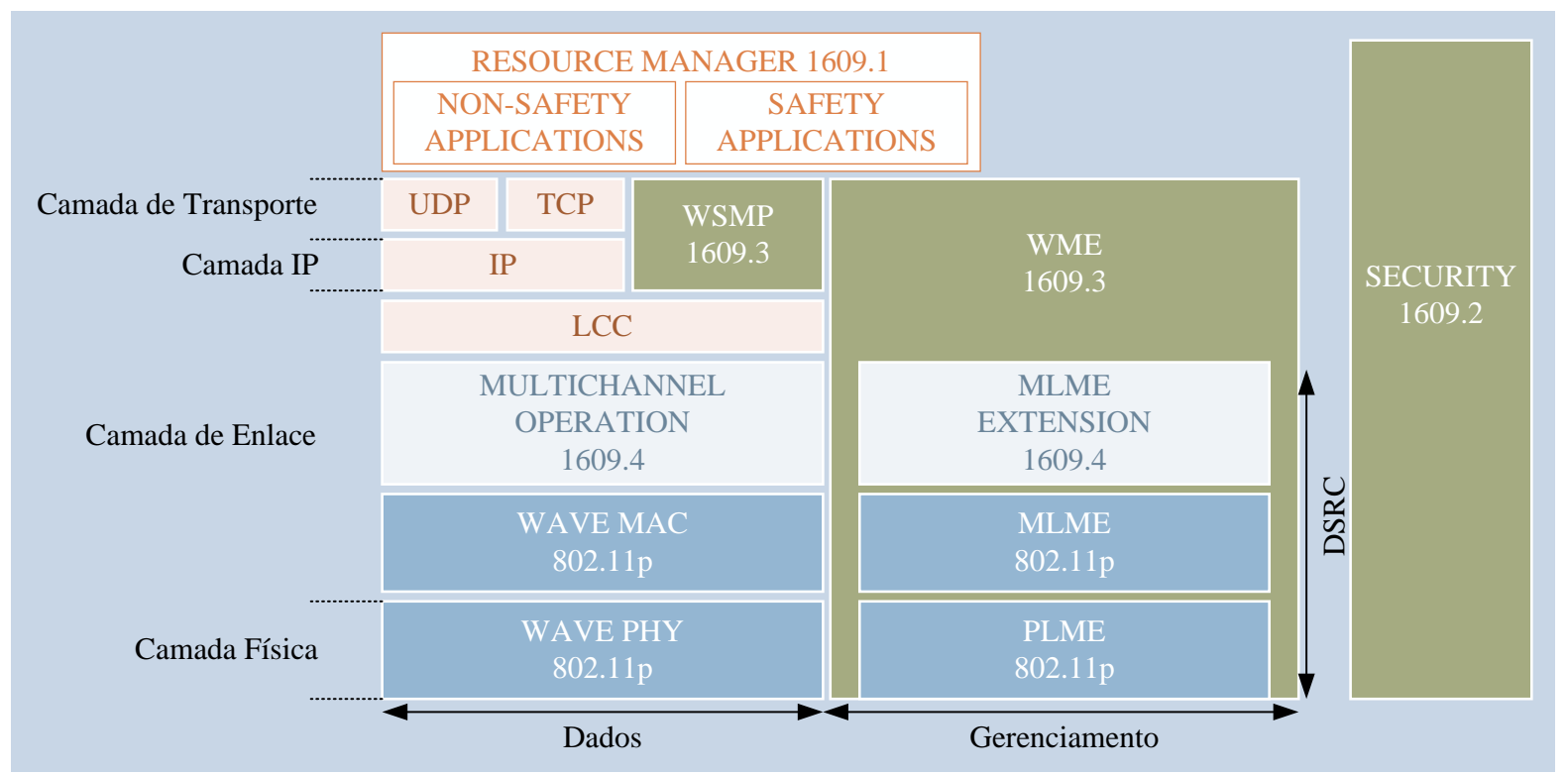

Figura 2.3: Padrão WAVE: As duas pilhas de protocolos IP e WSMP. As camadas Resource Manager e Security não se encaixam facilmente no modelo de referência OSI

As duas pilhas de protocolos do padrão WAVE referente aos dados, IP e WAVE ShortMessage Protocol (WSMP), podem ser observadas na Figura 2.3. Análogo à terminologia do modelo de referência Open Systems Interconnection (OSI), ambas as pilhas usam a mesma camada física e camada de enlace e as camadas de sessão, apresentação e aplicação não são especificadas. O motivo de ter duas pilhas de protocolos é para acomodar comunicações de alta prioridade e sensíveis ao tempo, bem como a tradicional comunicação por IP (Uzcategui e Acosta-Marum, 2009).

O IEEE 802.11p é limitado pelo âmbito do IEEE 802.11, ou seja, unicamente o nível físico (WAVE PHY) e de acesso ao meio (WAVE MAC). Na banda de $75 \mathrm{M} \mathrm{Hz}$, são alocados multicanais de $10 \mathrm{MHz}$ e taxas de dados de 3 a $27 \mathrm{Mb} / \mathrm{s}$ por canal. O problema relacionado ao gerenciamento dos multicanais da comunicação DSRC é resolvido pelas camadas superiores definidas pelos padrões IEEE 1609.x, representadas no WAVE Management Entity (WME). Em particular, o padrão IEEE 1609.4 permite às camadas superiores realizarem, de forma transparente, operações através de múltiplos canais, sem a necessidade de conhecimento dos parâmetros da camada física (Jiang et al., 2008).

A ideia é monitorar periodicamente o canal de controle $(\mathrm{CCH})$, para receber mensagens de controle e de advertência e, posteriormente, ajustar para um dos canais de serviço SCH 
disponíveis, para a troca de dados não relacionados à segurança. O regime de coordenação divide o tempo do canal em intervalos de sincronização de $100 \mathrm{~ms}$, que consiste em alternar a cada intervalo de $50 \mathrm{~ms}$ para $\mathrm{CCH}$ e para o $\mathrm{SCH}$, com um tempo de guarda de $4 \mathrm{~ms}$ (Hartenstein e Laberteaux, 2008).

As demais camadas do WAVE, em linhas gerais, são definidas como (Karagiannis et al., 2011):

- IEEE 1609.3 Network Services: Fornece serviços de roteamento e endereçamento necessários na camada de rede WAVE; o WAVE Short Message Protocol (WSMP) facilita o roteamento por meio do provimento de grupos de endereços para aplicações de segurança. Além disso, utiliza ambos os canais de controle $(\mathrm{CCH})$ e de serviço ( $\mathrm{SCH})$.

- IEEE 1609.2 Security Services: Especifica os conceitos de segurança do WAVE e define os formatos das mensagens e seu processamento para a comunicação segura. Adicionalmente, determina as circunstâncias para o uso da segurança na troca de mensagens.

- IEEE 1609.1 Resource Manager: Descreve a aplicação em uma OBU com recursos limitados que pode utilizar, remotamente, recursos de processamento de outras entidades de forma transparente.

\subsection{Conceitos de beacons}

Nesta seção são abordados os conceitos de beacons em redes WiFi (IEEE-802.11, 2012) e em redes veiculares. Em decorrência da dificuldade da aquisição das interfaces de rede IEEE 802.11p durante a realização deste trabalho, foi utilizado o beacon do padrão IEEE 802.11a. Portanto, para facilitar o entendimento da implementação do middleware da plataforma experimental, descrita no Capítulo 3, revisamos brevemente o formato do frame do beacon do WiFi na subseção 2.3.1. Por fim, na subseção 2.3.2 discorremos sobre a utilização de beacons em redes veiculares.

\subsubsection{Beacons em redes WiFi}

A mensagem de beacon é utilizada, no geral, em redes infraestruturadas WiFi, para as estações (por exemplo, notebook, tablet e smartphones) identificarem a presença do Access Point (AP), o padrão da rede e os parâmetros de configuração (por exemplo, canal e tipo de criptografia) para poder realizar a associação na rede. Após a associação, as estações continuam a receber beacons de outros APs. Se o sinal de rádio frequência (RF) do AP, no qual a estação está associada, se tornar muito fraco para conseguir manter a comunicação, a estação pode realizar a troca para outro AP que estiver com o sinal melhor. Em redes ad 
hoc WiFi não existe a função do AP gerenciando as conexões das estações e, como resultado, as estações se comunicam aos pares e assumem a responsabilidade pelo envio dos beacons (Kurose, 2010).

As estações, comumente, recebem beacons por meio da varredura ativa ou passiva dos canais de RF. Em linhas gerais, no modo passivo, a estação monitora o canal por tempo determinado e escuta os beacons transmitidos dentro do tempo de medição e, no modo ativo, a estação envia uma mensagem probe resquest no canal e, em seguida, monitora os beacons de resposta dentro do período de medição (IEEE-802.11, 2012).

Um beacon típico é formado pelo campos com MAC Header, Frame Body e Frame Check Sequence(FCS). O MAC Header possui os endereços MAC de origem e de destino do beacon e outras informações sobre o processo de comunicação (controle do frame, endereços do Basic Service Set, duração e controle de sequência). Neste caso, o endereço de destino é sempre o valor de broadcast (FF:FF:FF:FF:FF:FF) da camada MAC, isto obriga as estações a receberem e processarem os beacons. O FCS é um IEEE CRC (cyclic redundancy check) de 32-bits (IEEE-802.11, 2012).

O Frame Body possui o comprimento variável (Kurose, 2010), contém informações específicas relacionadas ao tipo (Management, Controle e Data) e ao subtipo (por exemplo, Beacon, Resquest-to-Send e Data) do frame. O tipo do beacon é o Management e com o subtipo Beacon podendo carregar 56 tipos de informações, com o formato Element Id, Length e Information, por exemplo:

- Service Set Identifier (SSID), Element $I d=0$, Length=2 até 34 bytes. SSID identifica uma rede sem fio específica. A estação deve ter o mesmo SSID do AP para associar-se. Os APs incluem o SSID no beacon para que a estação configure com o SSID correto. Alguns APs têm a opção de desabilitar o SSID para não serem transmitidos no beacon, com a intenção de reduzir os problemas de segurança;

- Vendor Specific, Element Id $=221$, Length $=3$ até 257 bytes. Vendor Specific é usado para transportar informações não definidas pelo padrão, mas usando um formato que facilite a interoperabilidade entre elas. Múltiplos elementos podem ser encadeados opcionalmente, limitado pelo tamanho máximo de frame.

O WiFi não reserva recursos no canal para o envio de beacons, para serem enviados usam o algoritmo carrier sense multiple access/collision avoidance (CSMA/CA). Se outra estação estiver utilizando o canal no momento que o beacon deve ser enviado, o AP ou a estação esperam o canal ficar livre. Assim, o tempo real entre o envio de beacons pode ser mais longo do que o intervalo de beaconing configurado (Tanenbaum e Wetherall, 2011). 


\subsubsection{Beacons em redes veiculares}

Um dos objetivos das redes veiculares é melhorar a segurança no trânsito por meio de aplicações de segurança. Para tanto, os veículos transmitem beacons periodicamente para informar a posição e outras informações relevantes aos veículos vizinhos. Os beacons podem ser usados para detectar uma situação anormal na rodovia, ruas urbanas etc. Por exemplo, no caso de acidentes de carro, a aplicação de segurança transmite beacons de alerta, decorrentes do evento e com maior prioridade, com a finalidade de avisar rapidamente os veículos mais próximos (Ghafoor et al., 2013).

Os beacons estão, normalmente, no contexto da comunicação DSRC e podem ser transmitidos pelos veículos ou pela RSU. Segundo Campolo et al. (2011) para garantir uma precisão e eficiência das aplicações de segurança é recomendado uma frequência de transmissão de beacons de 5 a $10 \mathrm{~Hz}$. O formato das mensagens é definido pela Society of Automotive Engineers (SAE) no padrão draft J2735 (SAE-International, 2009) por meio de quinze tipos de mensagens, classificadas nas categorias de transmissões broadcast V2V ou V2I e unicast V2I. Basicamente, a maioria das mensagens carrega a identificação do veículo, timestamp e informação de posição geográfica. Exemplos dos tipos de mensagens são: Safety Message aviso de acionamento do freio do veículo e Roadside Warnings - alerta de pista molhada.

As mudanças na situação do trânsito, para uma densidade elevada de veículos, na mesma região, pode fazer com que o canal $\mathrm{RF}$ fique saturado devido ao envio periódico de beacons, degradando o desempenho da rede veicular. Além disso, quanto maior for a frequência de transmissão dos beacons, maior será a sobrecarga em condições de tráfego denso (Nzouonta et al., 2009). Por essa razão diversos estudos focam na otimização do desempenho de beaconing (Ghafoor et al., 2013).

\subsection{Visão geral dos estudos da literatura}

O trabalho está no contexto de beaconing em redes veiculares, portanto a revisão dos trabalhos da literatura se limita a estudos de problemas de redes veiculares que envolvam beaconing. Neste sentido, foram realizadas buscas das palavras chave: VANET, vehicular network, beacon e testbed nas principais bases bibliográficas, IEEE, ACM, Elsevier e Springer. Um total de 114 artigos foram selecionados após a leitura dos resumos, 94 artigos sobre beaconing e 20 artigos sobre redes veiculares com avaliação em testbeds. Os estudos com testbed estão descritos na Seção 2.5 e os trabalhos relacionados estão descritos na Seção 2.6.

Na Figura 2.4 é mostrada uma visão geral dos artigos encontrados. A separação dos artigos foi com base nos objetivos descritos no resumo, categorizados de acordo com nosso melhor entendimento, nos seguintes tópicos: 
- Broadcasting: são trabalhos que abordam i) algoritmos de acesso ao meio para otimizar broadcasting, ii) avaliação de desempenho da taxa de perda de beacons para diferentes modelos de propagação, tamanhos da mensagem, potências de transmissão e cenários, e iii) modelos analíticos para avaliação de beaconing;

- Beaconing Adaptativo: são trabalhos que também buscam otimizar o desempenho de beaconing, porém exploram a densidade de nós para adaptar a potência de transmissão, a taxa de dados e a frequência de beaconing;

- Disseminação de Dados: são os trabalhos que utilizam as mensagens beacons para disseminar informações na rede. Essas mensagens são de aplicações que não envolvem segurança do tráfego;

- Localização e Posicionamento: são os trabalhos que investigam o problema de posicionamento seguro e inferência da localização do veículo. As técnicas que usam beacons para solução desses problemas, geralmente, são cooperativas, com base em informações de nós vizinhos;

- Privacidade e Segurança: são trabalhos sobre a preservação da privacidade do usuário, uma vez que a identidade pode ser enviada nos beacon, as técnicas de privacidade geralmente utilizam pseudônimos ou criptografia. Sobre segurança, são estudos para deteç̧ão de ataques, técnicas para redução de overhead na criptografia, distribuição de certificados e verificação de assinaturas;

- Roteamento e Encaminhamento: são trabalhos que propõem algoritmos de descoberta e atualização de rotas com base em beaconing e técnicas de encaminhamento de dados com múltiplos saltos;

- Survey: são trabalhos que apresentam uma análise da coletânea de estudos sobre algoritmos de acesso ao meio ou modelos analíticos para avaliação de desempenho de beaconing.

\subsection{Testbeds de redes veiculares}

Nesta seção descrevemos os principais testbeds, encontrados na revisão da literatura, utilizados para validar estudos em redes veiculares. Os primeiros trabalhos experimentais com testbeds tinham o foco na comunicação carro-a-carro por meio da tecnologia WiFi. Estas pesquisas iniciais não consideravam o ambiente de rede veicular, mas a comunicação não infraestruturada entre dispositivos com WiFi (notebook, smartphones) (Mahajan et al., 2007) ou entre redes de sensores e o veículo (Hull et al., 2006). Adicionalmente, alguns trabalhos 


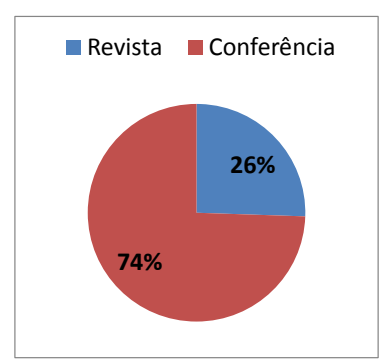

(a)

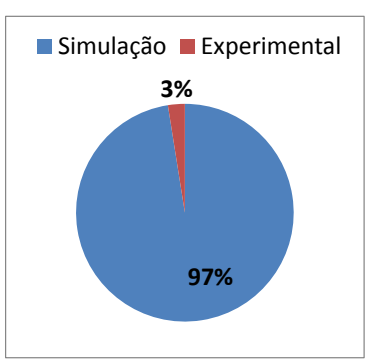

(b)

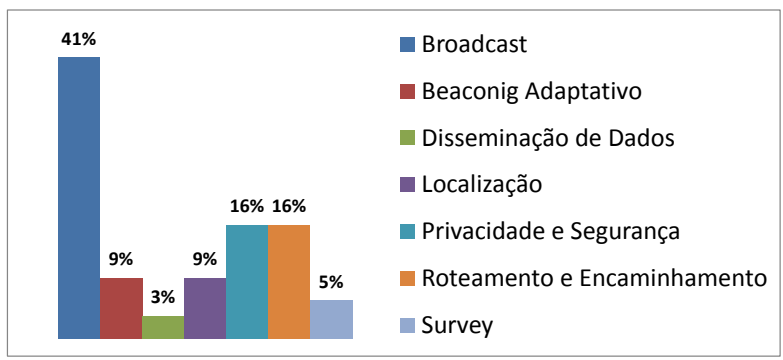

(c)

Figura 2.4: (a) Porcentagem de artigos em conferência e periódicos; (b) Porcentagem de artigos com método experimental; (c) Porcentagem de artigos por objetivo do estudo em beaconing

realizaram estudos com comunicação infraestruturada, analisando a conectividade de redes WiFi (Soroush et al., 2009) ou a transferência de arquivos via torrent (Lee et al., 2007).

Os avanços das tecnologias e dos padrões de comunicação para ambiente de rede veicular possibilitaram a configuração de veículos com equipamentos compatíveis com a comunicação entre carros (Santa et al., 2009; Toutouh e Alba, 2011; Dias et al., 2012; Marfia et al., 2013). Contudo, até o momento da finalização deste trabalho, poucas pesquisas utilizaram o draft do padrão IEEE 802.11p, devido à baixa oferta e aos altos custos do equipamento.

Segundo Gerla et al. (2012), os testbeds possuem dois propósitos: i) validar a precisão dos modelos utilizados em simulações (por exemplo, modelos de propagação do sinal RF) tornando-os mais confiáveis; ii) validar a corretude de protocolos e aplicações em ambiente reais. A maior parte dos estudos são realizados com pequenos testbeds, normalmente até cinco veículos. Ainda, Gerla et al. (2012) afirmam que estes testbeds são importantes casos de testes antes de uma avaliação em larga escala, fazendo parte de uma validação progressiva, com resultados aproximados, considerando as características (atraso, propagação do sinal, interferências etc) dos ambientes reais.

Por meio da revisão da literatura foi verificado que a maioria dos testbeds têm foco na validação de uma aplicação específica e, por isso, não proveem ambas as comunicações V2I e V2V, também não oferecem uma plataforma aberta para diferentes testes de comunicação entre veículos. A Tabela 2.1 resume os testbeds selecionados, encontrados durante a revisão da literatura. A Tabela 2.1 está organizada por meio de características de interesse para a especificação da plataforma experimental deste trabalho.

A maior parte dos testbeds são configurados com interfaces de rede sem fio IEEE 802.11g ou 802.11n e antenas externas fixadas no teto de veículo, mas não existe um consenso na posição (no centro, na traseira, na lateral do teto). As aplicações são executadas em laptops, localizados dentro dos veículos, com sistemas operacionais Linux ou Windows. 
Tabela 2.1: Principais características dos testbeds

\begin{tabular}{|c|c|c|c|}
\hline Aplicação & $\begin{array}{l}\text { Cenário, Comuni- } \\
\text { cação, Velocidade, } \\
\begin{array}{l}\text { Distância e Qtd } \\
\text { carros }\end{array}\end{array}$ & Softwares e Hardwares & Métricas \\
\hline $\begin{array}{l}\text { Avaliação de geren- } \\
\text { ciamento de mobili- } \\
\text { dade com múltiplos } \\
\text { saltos (Sanchez et } \\
\text { al., 2014). }\end{array}$ & $\begin{array}{l}\text { - Campus Universitá- } \\
\text { rio; } \\
\text { - } \mathrm{V} 2 \mathrm{~V} ; \\
\text { - } 50 \mathrm{~km} / \mathrm{h} \text {; } \\
\text { - Distância não infor- } \\
\text { mada; } \\
\text { - } 2 \text { a } 3 \text { carros. }\end{array}$ & $\begin{array}{l}\text { - Roteador Asus WL500g premium } \\
\text { com Linux OpenWRT, Laptop com } \\
\text { Linux Ubuntu, Interface de rede } \\
\text { sem fio IEEE 802.11a Atheros e } \\
\text { USB 3G modem. }\end{array}$ & $\begin{array}{l}\text { - Latência da sinalização do } \\
\text { handover; } \\
\text { - Porcentagem de otimização } \\
\text { da rota. }\end{array}$ \\
\hline $\begin{array}{l}\text { Sistema mensagens } \\
\text { de alerta de aciden- } \\
\text { tes (Marfia et al., } \\
\text { 2013). }\end{array}$ & $\begin{array}{l}\text { - Urbano, suburbano } \\
\text { e rural; } \\
\text { - V2V; } \\
\text { - } 54 \text { a } 126 \mathrm{~km} / \mathrm{h} ; \\
\text { - } 1000 \mathrm{~km} ; \\
\text { - } 1 \text { van e } 3 \text { sedans. }\end{array}$ & $\begin{array}{l}\text { - Laptop Dell com Ubuntu Linux } \\
\text { 11.04, gspd e Jpcap; } \\
\text { - GPS Sirf Start-III, antena omnidi- } \\
\text { recional com } 8 \mathrm{dBi} \text { de ganho, mon- } \\
\text { tada no teto do veículo, interface de } \\
\text { rede sem fio Ubiquity } 802.11 \mathrm{~g} \text { confi- } \\
\text { gurados com potência de transmis- } \\
\text { são a } 300 \mathrm{~mW} \text { e taxa de transmissão } \\
\text { a } 6 \mathrm{MB} / \mathrm{s} \text {. }\end{array}$ & $\begin{array}{l}\text { - Avaliação em função da dis- } \\
\text { tância: Número de mensa- } \\
\text { gens recebidas, quantidade } \\
\text { de saltos por mensagem, } \\
\text { tempo de atraso da mensa- } \\
\text { gem, máxima distância para } \\
\text { um salto; } \\
\text { - Avaliação em função da ve- } \\
\text { locidade: taxa de perda das } \\
\text { mensagens em função da ve- } \\
\text { locidade do carro transmis- } \\
\text { sor e receptor. Por fim, a } \\
\text { autocorrelação da perda da } \\
\text { mensagem com RSSI. }\end{array}$ \\
\hline $\begin{array}{l}\text { Gerenciamento de } \\
\text { Handover (Dias et } \\
\text { al., 2012). }\end{array}$ & $\begin{array}{l}\text { - Uma rua (ambiente } \\
\text { controlado); } \\
\text { - V2I; } \\
\text { - } 50 \text { e } 70 \mathrm{~km} / \mathrm{h} \\
\text { - } 400 \mathrm{~m} \\
\text { - } 1 \text { carro. }\end{array}$ & $\begin{array}{l}\text { - Computador com Debian Squeeze e } \\
\text { iperf; } \\
\text { - Interface } 3 G \text { e IEEE } 802.11 \mathrm{n} \text {. }\end{array}$ & $\begin{array}{l}\text { - Latência do handover verti- } \\
\text { cal, ou seja, entre diferentes } \\
\text { tecnologias de rede sem fio; } \\
\text { - Vazão média durante o han- } \\
\text { dover e em função da velo- } \\
\text { cidade. }\end{array}$ \\
\hline $\begin{array}{l}\text { Avaliação de algo- } \\
\text { ritmo adaptativo de } \\
\text { taxa de transmissão } \\
\text { (Deshpande e Das, } \\
\text { 2012). }\end{array}$ & $\begin{array}{l}\text { - Urbano; } \\
\text { - V2V, V2I; } \\
\text { - } 18 \text { a } 54 \mathrm{~km} / \mathrm{h} ; \\
\text { - } 9 \text { milhas; } \\
\text { - } 2 \text { carros. }\end{array}$ & $\begin{array}{l}\text { - Dois laptops Dell Latitude com li- } \\
\text { nux e iperf; } \\
\text { - Interface de rede sem fio Ubiquity } \\
\text { XR2, duas antenas omnidirecionais } \\
\text { com } 8 \mathrm{dBi} \text { de ganho. }\end{array}$ & $\begin{array}{l}\text { - Fração de pacotes entregues } \\
\text { em função RSSI para as ta- } \\
\text { xas de transmissão IEEE } \\
802.11 \text { b e } 802.11 \text {; } \\
\text { - Média, desvio padrão e fun- } \\
\text { ção de distribuição acumu- } \\
\text { lada do RSSI por amostra de } \\
\text { tempo. }\end{array}$ \\
\hline $\begin{array}{l}\text { Protocolo de trans- } \\
\text { ferência de arquivos } \\
\text { (Toutouh e Alba, } \\
\text { 2011). }\end{array}$ & $\begin{array}{l}\text { - Urbano; } \\
\text { - V2V; } \\
\text { - } 20 \text { a } 50 \mathrm{~km} / \mathrm{h} ; \\
\text { - Área } 1.440 .000 \mathrm{~m}^{2} \\
\text { - } 2 \text { carros. }\end{array}$ & $\begin{array}{l}\text { - Interface de rede sem fio ORiNOCO } \\
\text { IEEE } 802.11 \mathrm{~g} \text {, antena omnidirecio- } \\
\text { nal com } 7 \mathrm{dBi} \text { de ganho e receptor } \\
\text { GPS. }\end{array}$ & $\begin{array}{l}\text { - Goodput em função de dife- } \\
\text { rentes tamanhos de arquivo } \\
\text { e velocidades do veículo. }\end{array}$ \\
\hline $\begin{array}{l}\text { C-VeT um fra- } \\
\text { mework para redes } \\
\text { veiculares (Cesana } \\
\text { et al., 2010). }\end{array}$ & $\begin{array}{l}\text { - Campus Universitá- } \\
\text { rio (UCLA); } \\
\text { - V2V e V2I; } \\
\text { - Velocidade não in- } \\
\text { formada; } \\
\text { - } 700 \mathrm{~m} \text {; } \\
\text { - } 1 \text { carro. }\end{array}$ & $\begin{array}{l}\text { - Intel } 2.5 \mathrm{GHz}, 2 \mathrm{~GB} \text { RAM. Três in- } \\
\text { terfaces de rede sem fio: IEEE } \\
802.11 \mathrm{n} \text { Atheros AR9160, IEEE } \\
802.11 \mathrm{p} \text { Daimler-Benz e Bluetooh. } \\
\text { Sensores: CO2, CO, temperatura, } \\
\text { umidade, GPS e câmera de vídeo. } \\
\text { RSU: MobiMESH com Linux Open- } \\
\text { WRT. }\end{array}$ & $\begin{array}{l}\text { - Perda de pacotes UDP na } \\
\text { transmissão de streaming de } \\
\text { vídeo. }\end{array}$ \\
\hline $\begin{array}{l}\text { Avaliação do proto- } \\
\text { colo OLSR (Optimi- } \\
\text { zed Link State Rou- } \\
\text { ting) (Santa et al., } \\
\text { 2009). }\end{array}$ & $\begin{array}{l}\text { - Urbano, semi- } \\
\text { urbano e rodovia; } \\
\text { - V2V e V2I; } \\
\text { - } 10,15 \text { e } 30 \mathrm{~km} / \mathrm{h} \text {; } \\
\text { - Duração dos testes } \\
300 \text { a } 900 \mathrm{~s} ; \\
\text { - } 2 \text { a } 4 \text { carros. }\end{array}$ & $\begin{array}{l}\text { - Soekris net } 4521 \text {, interface de rede } \\
\text { sem fio IEEE } 802.11 \mathrm{~g} \text {; Texas Ins- } \\
\text { truments ACX } 111 \text { configurado a } \\
\text { 11Mps, GPS AgGPS } 323 \text {. Trans- } \\
\text { missor com Win XP e no roteador } \\
\text { Linux Debian, TCPDump, iPerf e } \\
\text { ping. }\end{array}$ & $\begin{array}{l}\text { - Perdas de pacotes com pro- } \\
\text { tocolo UDP; } \\
\text { - RTT (Round Trip Time); } \\
\text { - Vazão com protocolo TCP. }\end{array}$ \\
\hline
\end{tabular}


Os testbeds encontrados na literatura foram utilizados como base no projeto, implementação e implantação uma nova plataforma experimental para redes veiculares, chamada V-Beacon (Vehicular Beacon), que está descrita no Capítulo 3. Todavia, para concluir esta seção, é apresentada uma discussão dos testbeds da Tabela 2.1 com relação a plataforma V-Beacon. As principais diferenças do V-Beacon são: i) o V-Beacon pode ser utilizado em comunicações infraestruturadas e não-infraestruturadas tipo V2V, V2I e I2V; ii) os protocolos de comunicação podem ser implementados a partir da camada de enlace até a camada de aplicação; iii) o equipamento utilizado é flexível, podendo ser configurado para a função de OBU ou RSU; iv) o uso de baterias externas no V-Beacon permite a utilização do OBU e RSU sem a necessidade da ligação na rede elétrica ou fonte de alimentação do veículo e por fim; v) V-Beacon possui um middleware que provê facilidades para inserir informações em mensagens tipo beacon. Analisando as características da Tabela $2.1 \mathrm{com}$ relação ao VBeacon, a maior parte dos testbeds focam em uma aplicação ou protocolo específico, enquanto $\mathrm{V}$-Beacon pode ser considerada de propósito geral. Os cenários podem variar conforme a necessidade do experimento, uma vez que V-Beacon não requer uma rede elétrica e instalação em pontos fixos, não é limitado a um único cenário, diferente dos estudos da literatura que assumem, normalmente, um cenário urbano ou rodovia. O equipamento adotado no V-Beacon possui arquitetura i386, possibilitando fácil atualização do sistema operacional, a expansão da capacidade de memória e a troca da tecnologia de rede. Além da vantagem de poder usar a maioria de ferramentas de redes existentes para sistemas operacionais baseado em i386, como o Linux. Por fim, diferentes parâmetros da rede podem ser medidos por meio do V-Beacon, a principal diferença dos outros estudos é a medida do RSSI. Apesar das vantagens do V-Beacon com relação a outros testbeds, a plataforma exige um maior esforço de implementação e tempo para implantação, pelos motivos da adoção de uma arquitetura genérica i386 e a necessidade de instalar os equipamentos a cada realização do experimento, respectivamente. Além disso, V-Beacon também sofre com o problema de escalabilidade como os outros testbeds, sendo a quantidade de nós da rede limitada, principalmente, pelos custos do experimento em grande escala.

\subsection{Trabalhos relacionados}

Existem muitos trabalhos na literatura sobre redes veiculares, a maior parte utiliza o método de análise e simulação de protocolos que envolvem mensagens tipo beacon em aplicações de segurança. O foco dos estudos é a otimização de desempenho em função de parâmetros de comunicação (por exemplo, taxa de dados, potência de transmissão, etc). Entretanto, neste trabalho é adotado o método experimental com testbed para validação e avaliação de soluções com base em beaconing; portanto, nesta seção, são discorridos os trabalhos relacionados relevantes para estudos sobre beaconing com testbeds e não são considerados outros trabalhos 
experimentais destinados a avaliar características de aplicações não relacionadas a beaconing, como a maioria descritos na Tabela 2.1 da Seção 2.5.

Os estudos experimentais em ambiente de redes veiculares sobre beaconing iniciaram com medições que focam na métrica Packet Delivery Rate (PDR) na comunicação V2V. PDR se refere à fração de beacons recebidos corretamente sobre o número total de beacons transmitidos. A motivação para a avaliação está relacionada à mobilidade veicular e ambiente externo, que difere das avaliações de redes locais sem fio, além da diferença de frequência e da largura de banda (Bai et al., 2010). Hong et al. (2009) consideram uma aplicação de aviso de colisão no cruzamento e avaliam o PDR entre os dois veículos em função da distância e RSSI, aplicando diferentes valores de potência de transmissão. O estudo conclui que valores de potências de transmissão intermediários podem ter um bom desempenho e reduzir o congestionamento do canal sem fio. Bai et al. (2010) apresentam uma análise mais completa sobre o PDR em diferentes cenários (urbano, suburbano e rural) e para diferentes ambientes de propagação (via expressa, estrada, campo aberto). O estudo observou que o ambiente de propagação é o fator com maior impacto na comunicação e o efeito Doppler não teve impacto significativo. Considerando os parâmetros de comunicação, as baixas potências de transmissão geram menor degradação do canal e se constatou que a taxa de transmissão de $6 \mathrm{Mbps}$ é razoável. Além disso, os autores realizaram a análise da correlação temporal, espacial e simétrica. A principal conclusão é que a correlação temporal e espacial é fraca e a correlação simétrica é forte. Martelli et al. (2012) também fazem o estudo do PDR e introduzem a avaliação da métrica Packet Inter-Reception (PIR). A métrica PIR é definida como o intervalo de tempo decorrido entre duas recepções com sucesso de beacons. O trabalho estima o tempo do PIR e sua correlação com a distância, velocidade e também com PDR, por meio de uma extensa medição utilizando dois veículos equipados com IEEE 802.11p e percorrendo $2520 \mathrm{~km}$ transmitindo beacons a frequência de $1 \mathrm{~Hz}$. O resultado mais interessante do estudo é a modelagem do PIR como uma distribuição que segue a lei de potência (power law) e prova que é independente da distância e da velocidade dos veículos. Ainda, os resultados mostraram que os intervalos de tempos das falhas na recepção, chamados de (black-outs), ocorrem em rajadas e que existe uma fraca correlação entre PIR e PDR.

Finalmente, o C-Vet é considerado como trabalhado relacionado, apesar de não envolver diretamente beaconing, pelo motivo da proposta de uma plataforma experimental de propósito geral. Cesana et al. (2010) especificam o testbed C-Vet para redes veiculares. O estudo descreve hardwares e softwares para configurar um testbed com a comunicação V2I baseado em uma infraestrutura de Redes Mesh. A ideia do testbed é realizar testes em larga escala e diferentes aplicações. Para validar a proposta, os autores realizam um teste utilizando transmissão de vídeo. Contudo, durante o período de revisão da literatura, não foram encontrados outros artigos que descrevem a continuação ou experimentos ou aplicação que utilizem o C-Vet. 


\subsection{Considerações finais}

Neste Capítulo foi discorrido sobre redes veiculares, abordando os conceitos fundamentais, padrões e estudos relacionados a beacon. Por meio da revisão da literatura foi constatado que a maior parte dos trabalhos com beacons (41\%) têm como objetivo melhorar o desempenho de beaconing. Outras propostas exploram o beacon para resolver problemas de disseminação de dados, localização e verificação da posição, roteamento e survey. Entretanto, de todos os trabalhos selecionados, somente $3 \%$ são validados e avaliados com o método experimental em ambientes reais. Acredita-se que o motivo é a dificuldade de realização de experimentos em redes veiculares, devido ao alto custo para a montagem do testbed, a dificuldade e demanda de tempo para a implementação da aplicação, principalmente no nível da camada de enlace e a necessidade de longas medições. Por isso, os testbeds encontrados na literatura são para aplicações específicas e de pequena escala. No Capítulo seguinte é descrita a plataforma de testes desenvolvida neste trabalho. 


\section{V-Beacon: Uma plataforma experimental para redes veiculares}

Um dos focos das pesquisas em redes veiculares é o provimento de interoperabilidade de sistemas de comunicação entre os automóveis, sendo transparente aos usuários. Tais sistemas de comunicação permitem a implantação de serviços de segurança e de emergência a motoristas e passageiros, além de entidades de controle de trânsito e aplicações infotainment (informação e entretenimento) a passageiros (Cespedes et al., 2013). Para tanto, a comunicação requer ser provida em diferentes abordagens: entre veículos (V2V), entre veículos e a infraestrutura (V2I) e, eventualmente, entre os veículos e outros dispositivos.

Alguns exemplos de aplicações de segurança são a frenagem de emergência, o assistente de mudança de pista, o alerta para evitar colisão no cruzamento (VSC-Consortium, 2005). A Figura 2.1 ilustra algumas aplicações de segurança e entretenimento. O sistema do veículo requer a troca eficaz e confiável de informações entre as aplicações em um ambiente caracterizado pela rápida mobilidade dos veículos e de difícil previsão, sob a perspectiva da comunicação. Nesse sentido, a comunidade acadêmica tem direcionado a atenção para estudo de beaconing. Entretanto, os principais resultados sobre a estratégia de beaconing têm sido obtidos por meio de simulação (Joerer et al., 2012; Sommer et al., 2010; TorrentMoreno et al., 2009; Schmidt-Eisenlohr et al., 2007). Nesse contexto, V-Beacon (Veicular Beacon) é uma plataforma, composta por hardware e software, que possibilita experimentos de redes veiculares para obtenção de resultados em ambientes reais, diferindo das conhecidas limitações de resultados obtidos por simulações. O objetivo de V-Beacon é permitir testes 
de beaconing em ambientes reais com múltiplos veículos sob diversas condições de tráfego. Além disso, é possível configurar parâmetros de comunicação, como taxa de transmissão, potência de transmissão, intervalo de transmissão do beacon e, principalmente, permite inserir e transmitir informações arbitrárias no beacon, como posição geográfica, velocidade ou dados para verificação da posição.

Os componentes de hardware em V-Beacon são ordinários e possuem a vantagem de não necessitar de alterações na estrutura do veículo para instalação das antenas. O sistema é facilmente deslocado de local e permite que as RSUs possam ser configuradas e implantadas em locais sem rede de energia elétrica. V-Beacon foi validado e avaliado por meio de dois experimentos que testaram as duas formas de comunicação essenciais em redes veiculares: V2V e V2I. A ideia do primeiro experimento foi verificar a efetiva comunicação V2V com a variação da distância e velocidade inter-veículos. O segundo experimento teve como foco o beaconing em V2I com uma avaliação de desempenho da métrica PDR, utilizando três RSUs no testbed.

$\mathrm{O}$ experimento $\mathrm{V} 2 \mathrm{~V}$ resultou na validação do $\mathrm{V}$-Beacon pela confirmação da troca de beacons entre veículos. Essa troca foi representada por meio dos mapas da Figura 3.6. Os mapas são um conjunto de beacons recebidos em diferentes distâncias e posições durante o experimento no testbed. A validação da comunicação V2I é mostrada nos gráficos da Figura 3.9 por meio do PDR das RSUs.

\subsection{Implementação do middleware beaconing}

O objetivo do middleware beaconing é prover facilidades para a Aplicação manipular o beacon, especialmente, para a inserção de novas informações e o controle do intervalo de transmissão do beacon, assemelhando ao padrão WAVE. A implementação do middleware foi feita na linguagem $C$ e o código foi compilado para o Sistema Operacional Linux OpenWRT blackfire 10.0.3, o qual foi embarcado no roteador sem fio equipado com uma placa $P C$-Engine ALIX.3D2. Os detalhes do hardware do roteador sem fio estão descritos na Seção 3.2. O middleware é executado no espaço de usuário e não necessita de modificações no Kernel e tampouco no nível do driver MadWiFi.

As configurações dos parâmetros de comunicação, canal de RF, potência de transmissão e bitrate, são realizadas pelo middleware através de System Calls com valores dos parâmetros desejados, os quais são lidos a partir de um arquivo de configuração. O intervalo de beaconing é controlado por função implementada no middleware.

A Figura 3.1 ilustra a arquitetura do middleware beaconing. A arquitetura é dividida em duas partes, o Envio do Beacon e a Recepção do Beacon, descritas na Subseção 3.1.1 e 
Subseção 3.1.2, respectivamente. As duas partes são implementadas nos nós da rede, assim o veículo e o RSU são capazes de enviar e receber beacons simultaneamente.

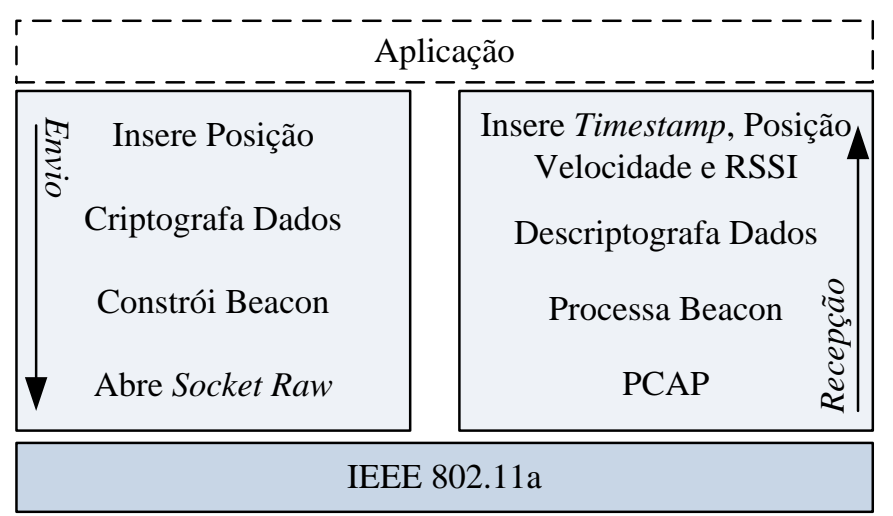

Figura 3.1: Middleware Beaconing com duas partes principais. À esquerda estão as funções responsáveis pelo Envio do Beacon, e à direita as funções responsáveis pela Recepção do Beacon

\subsubsection{Envio de beacon}

A Aplicação pode inserir no quadro do beacon até 255 bytes de informação. A função Insere Posição recebe o dado no formato de caractere sem sinal (unsigned char) e preenche a variável info da estrutura de dados $v \_$beacon, descrita no Código 3.1.

Essa função também está conectada ao GPSD 2.94 (GPS Daemon). O GPSD retorna a posição geográfica, obtida do receptor GPS, por meio da estrutura de dados gps_data_t. A estrutura gps_data_t possui a latitude e longitude que são atribuídas, respectivamente, a lat e lon da estrutura $v_{-}$beacon.

Código 3.1: Estrutura de dados do v_beacon

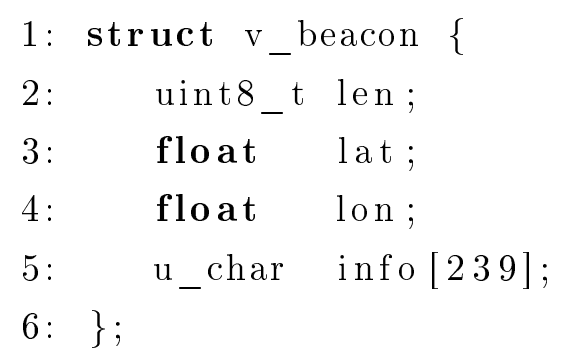

A criptografia da informação da Aplicação é opcional. A função Criptografa os Dados utiliza criptografia de chaves assimétricas com o algoritmo RSA, com implementação disponível na API OpenSSL 0.9.8 (Open Secure Sockets Layer). Se a Aplicação requer que os dados sejam cifrados, o certificado digital do nó de destino, contendo a chave pública, deve ser fornecido à Aplicação. Para propósito de validação, é assumido que o nó possui o 
certificado digital de qualquer outro nó de destino no testbed. A distribuição do certificado na rede veicular, contudo, está fora do escopo deste trabalho.

Na função Constrói Beacon é atribuído o valor da variável len da estrutura $v$ beacon e depois a estrutura é inserida no campo IE Vendor (Information Element Vendor) do beacon do padrão IEEE 802.11(IEEE-802.11, 2012). Para tanto, foi utilizado a técnica de spoofing do pacote de um beacon nativo. O procedimento de spoofing consiste em capturar um beacon e copiar o frame original, depois localizar o Element ID do campo IE Vendor Specific que é identificado pelo valor 221 e, por fim, os bytes na sequência são substituídos pelos bytes da estrutura $v \_b e a c o n$. Na Figura 3.2 é esquematizado o frame do beacon com a localização dos campos onde são inseridas as informações.

O middleware oferece a opção de configurar o SSID (Service Set IDentifier) transmitido no beacon, assim é possível ter controle dos beacons que pertencem à rede sem fio configurada. O nome do SSID deve ser inserido no arquivo de configuração, após isso é realizado o mesmo procedimento de spoofing com a diferença que agora Element ID tem valor 0.

Por fim, após a construção do beacon, ele é enviado usando a função send sobre um descritor de socket tipo Socket Raw, o qual é fornecido pela API de Berkeley.

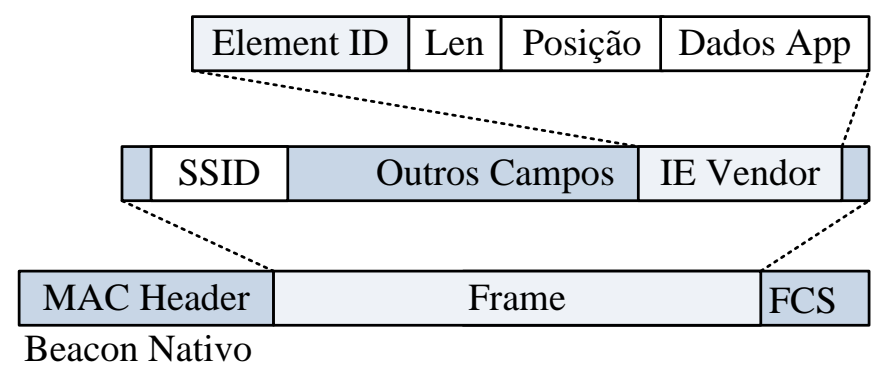

Figura 3.2: Frame do beacon e os campos que são substituídos (spoofed) pelas informações do middleware beaconing (Yokoyama et al., 2013)

\subsubsection{Recepção do beacon}

A recepção do beacon é realizada com o auxílio da API PCAP (Packet Capture). Quando o PCAP é usado, a interface sem fio trabalha em modo promíscuo e captura todos os tipos de pacotes que trafegam no canal de RF. Nesse caso, foi aplicado um filtro para a captura somente de beacons para diminuir a sobrecarga do processamento de pacotes. Outra questão é que beacons de outras redes podem estar sendo transmitidos no mesmo canal e, para evitar processar os beacons errados, os beacons foram identificados pelo SSID.

As funções Processa Beacon e Descriptografa os Dados, essencialmente, realizam o processo reverso das funções Constrói Beacon e Criptografa os Dados, respectivamente. A função Processa Beacon encontra o Element ID do campo IE Vendor Specific e extrai a lat,

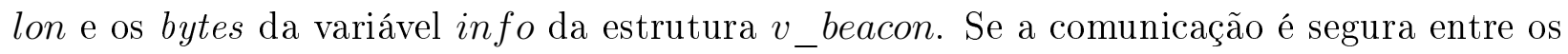


veículos, a função Descriptografa os Dados utiliza a chave privada do nó local para descriptografar os dados recebidos. A chave privada é armazenada em arquivo local, que é aberto pelo middleware a partir da indicação no arquivo de configuração do diretório onde está localizada a chave.

A função Insere Timestamp, Posição, Velocidade e RSSI também está conectada ao GPSD que recupera esses dados do receptor GPS. Assim, é possível ter o controle do tempo, da posição geográfica e da velocidade que o veículo estava quando o beacon foi recebido. O valor do Received Signal Strength Indicator (RSSI) em $d B m$ é lido no preâmbulo radio_tab do beacon.

Adicionalmente, foram inseridas variáveis de monitoramento nas funções do middleware. As variáveis são utilizadas para depuração e, principalmente, para efetuar o log dos pacotes, como ilustrado na Figura 3.3.

\begin{tabular}{|c|c|c|c|c|c|c|c|c|c|c|}
\hline & $q$ & reço MAC & & tude & dereço MAC & de & ngitude & & & \\
\hline 1373312859 & 774 & & & & & & -47.932835 & -71 & & \\
\hline 359 & 12 & 0.00 & -21.5 & & $00: 15: 6 \mathrm{D}: 6 \mathrm{Z}$ & -21.998 & -47.932835 & -55 & 00 & \\
\hline & 49 & & & & & & & -90 & & \\
\hline & 4775 & & -21 & & & & & -69 & & \\
\hline & 313 & $0: 15: 6 \mathrm{D}: 69: 77: 98$ & -21.999241 & -47.932884 & $00: 15: 6 \mathrm{D}: 6 \mathrm{~A}: \mathrm{F} 8$ & -21.998985 & -47.932835 & -48 & & \\
\hline 73312859 & 776 & 15. & -21.997845 & -47.931774 & $00: 15: 6 \mathrm{D}: 6 \mathrm{Z}$ & -21.998985 & -47.932835 & -68 & 8.736000 & 145.001511 \\
\hline
\end{tabular}

\section{Dados veículo transmissor Dados veículo receptor}

Figura 3.3: Na figura está representado um fragmento do arquivo de $\log$ salvo no veículo receptor durante os testes. Cada linha é um beacon recebido

\subsection{Hardware}

O principal equipamento do testbed é o roteador sem fio. A configuração do roteador está descrita na Tabela 3.1. O roteador possui uma interface de rede que é compatível com o padrão IEEE 802.11p (Vandenberghe et al., 2011). Se comparado com os roteadores que suportam Linux OpenWRT (por exemplo, WRT-54G Linksys), o roteador adotado no VBeacon tem as vantagens da fácil atualização das interfaces de rede sem fio e o suporte aos dispositivos USB, como GPS, interface Bluetooth e modem 3G. Além disso, há maior poder de processamento, mais memória RAM e também a opção de expandir a memória física por meio do uso do cartão Compact Flash. O mesmo roteador é utilizado na RSU e no veículo.

\subsubsection{Instalação do roteador no veículo}

A instalação do roteador no veículo é realizada de maneira simples. A antena e o GPS são fixados no teto do veículo usando de bases magnéticas e a fonte de energia do roteador é a bateria de $12 \mathrm{~V}$ conectada por meio de PoE (Power Over Ethernet). A Figura 3.4(a) é a foto da parte do carro com a antena e o GPS fixados no teto. Além disso, é possível observar 
Tabela 3.1: Configuração do Roteador sem fio (Yokoyama et al., 2013)

\begin{tabular}{l|l}
\hline Dispositivo & Descrição \\
\hline ALIX.3D2 & Placa PC-Engine, CPU 500 $M H z, 32 \mathrm{Mb}$ RAM e 2 USB. \\
XtremeRange-5 802.11a & Ubiquiti XR5 Wireless Card MiniPCI \\
Omni Antenna & Antena Omnidirecional - 2.4 GHz e $5 \mathrm{GHz}$. \\
Redundant PoE & Adaptador PoE (Power Over Ethernet) \\
Compact Flash & Memória física com 4 GB \\
Bateria & Bateria $12 V$ utilizada como fonte de energia \\
GPS BU-353 & Receptor GPS GlogalSat SiRF Star III \\
Base magnética & Base magnética para fixação da antena \\
\hline
\end{tabular}

os cabos passando pela abertura do vidro da porta traseira do veículo, porque o roteador é colocado dentro do carro. Ainda, com o auxílio de um notebook, o roteador é acessado via terminal e, desta maneira, a Aplicação é iniciada, monitorada e encerrada.

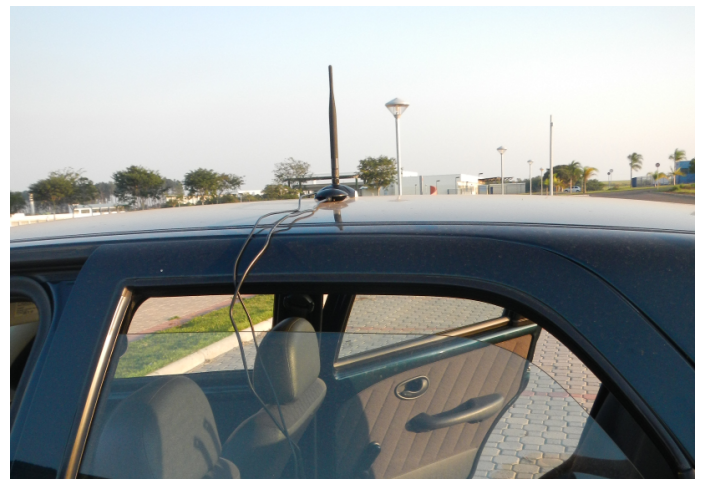

(a)

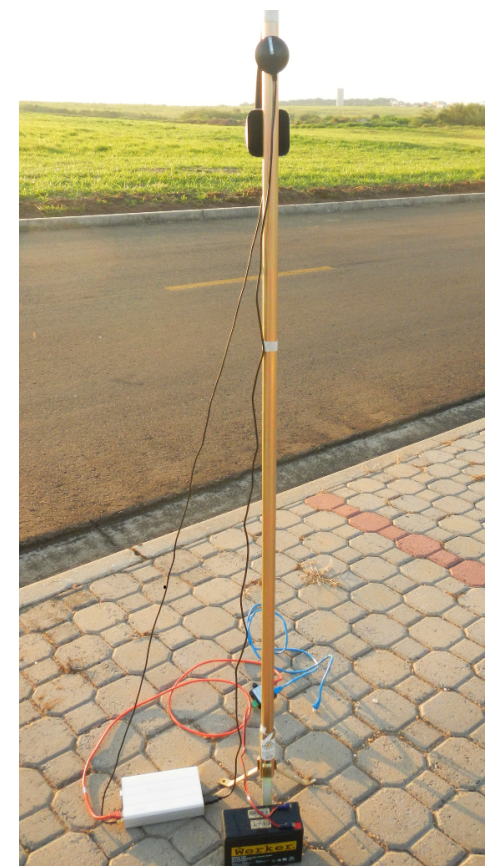

(b)

Figura 3.4: (a) Foto da antena e do receptor GPS fixadas no teto do carro. (b) Foto da RSU instalado no testbed (Yokoyama et al., 2013)

\subsubsection{Instalação do roteador na RSU}

O roteador é instalado na RSU com auxílio de uma haste metálica de 1,50 $m$ de altura. A haste é fixada no solo através da base. A antena e o receptor GPS são posicionados no topo da haste usando a base magnética, e a bateria é utilizada como fonte de energia do 
roteador. A Aplicação é iniciada por meio de acesso remoto com o notebook. A sessão do terminal é gerenciada com o uso do programa screen, que permite desconectar o cabo de rede do notebook sem fechar a sessão do terminal. A Figura 3.4(b) exibe a instalação da RSU, é possível observar a antena e o GPS no topo da haste e no solo o roteador e a bateria.

\subsection{Experimentos de validação da plataforma}

O objetivo principal do experimento foi validar a plataforma V-Beacon. Para tanto, o planejamento do experimento foi dividido em dois testes: 1) teste de comunicação veículo com veículo (V2V) por meio de beaconing; 2) teste de comunicação veículo com RSU (V2I) por meio de beaconing. Os valores dos parâmetros de comunicação utilizados para os dois testes foram a potência de transmissão de $23 \mathrm{dBm}$, a taxa de transmissão de $6 \mathrm{Mb} / \mathrm{s}$ e o intervalo de transmissão do beacon foi de $5 \mathrm{~Hz}$. Para calcular os PDRs dos testes foi utilizado um intervalo de distância de $25 \mathrm{~m}$ e o total dos 100 primeiros beacons recebidos para cada intervalo.

\subsubsection{Testbed e aplicação}

O testbed foi implantado no Campus II da USP (Universidade de São Paulo), na cidade de São Carlos-SP. A distância do circuito, ilustrado na Figura 3.5, é de $\approx 320 m$, o local é livre de interferências na frequência $5 G H z$ e os testes foram realizados durante um feriado, desta forma não teve a influência do tráfego de outros veículos. Neste trabalho, o termo testbed pode ser entendido como a utilização do V-Beacon com diferentes configurações, por exemplo, variando quantidade de nós da rede, a finalidade da aplicação, os parâmetros de comunicação etc.

A Aplicação implementada para os testes tinha duas funções: i) inserir um número de sequência no beacon e ii) enviar beacons de tamanho fixo. A ideia foi enviar um número de sequência incremental no beacon para que fosse possível calcular o PDR. Ainda, foi utilizado o tamanho fixo de 256 bytes e sem criptografia, uma vez que a variação do tamanho do pacote poderia influenciar no PDR. A avaliação de desempenho através de PDR não foi o foco do experimento. Contudo, o valor de PDR foi um importante indicador para determinar se a comunicação V2V e V2I foi efetiva, além de refletir a realidade da comunicação em redes veiculares.

\subsubsection{Teste I - Comunicação V2V}

O Teste I foi realizado com dois veículos, Fiat Palio e VW Gol, transmitindo e recebendo beacons. Os veículos percorreram o circuito durante aproximadamente 16 minutos, perfazendo 


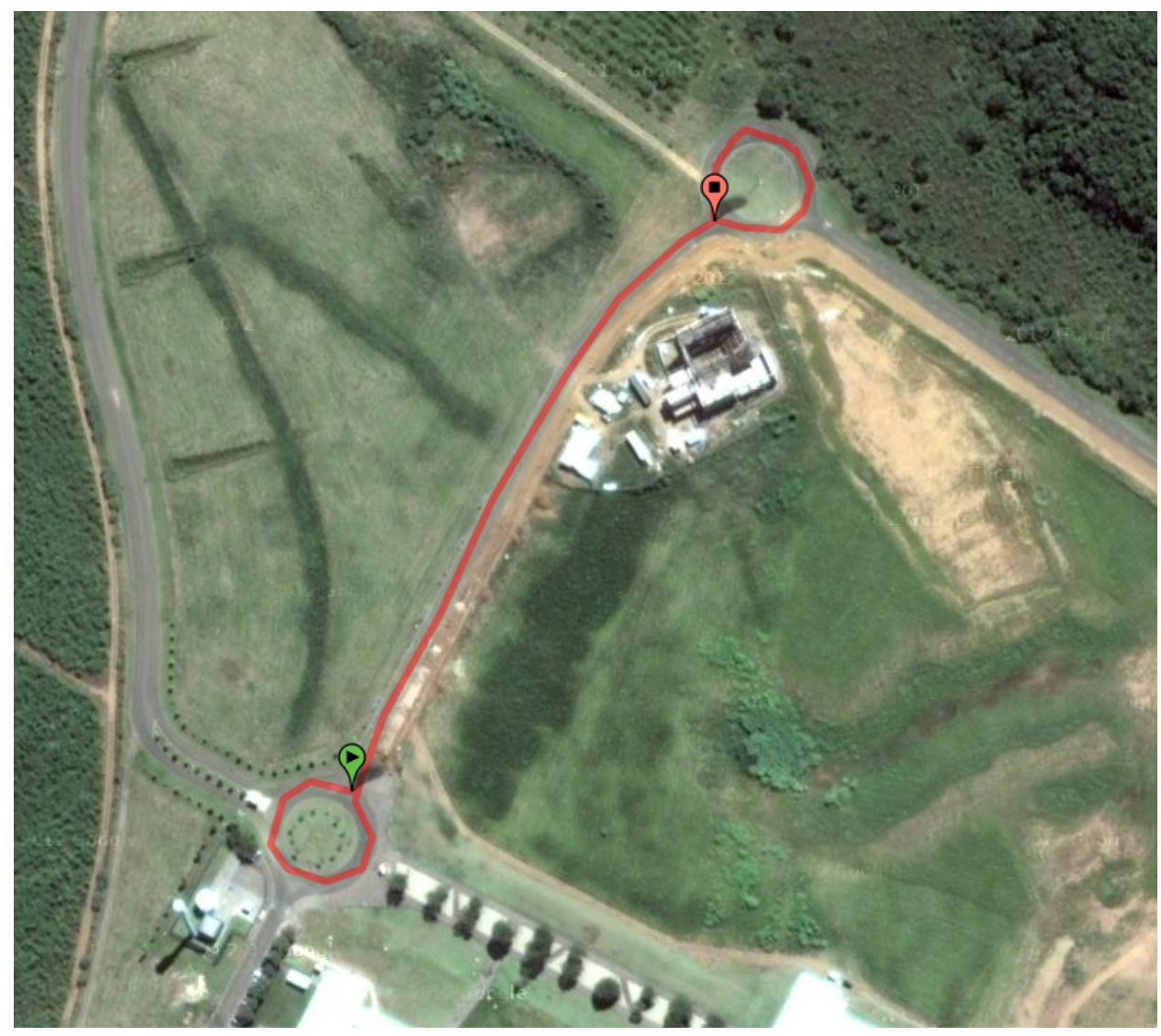

Figura 3.5: Foto de satélite destacando o circuito de $\approx 320 \mathrm{~m}$ utilizado para o experimento. Área interna do Campus II da USP-São Carlos

$\approx 9 \mathrm{~km}$. Cada veículo recebeu em média 3959 beacons. Durante o teste cada veículo variou a velocidade e a distância inter-veículos.

Inicialmente, para verificar a transmissão e recebimento de beacons na comunicação V2V, foram construídos três gráficos no formato de mapas que representam a troca dos beacons, os gráficos estão ilustrados na Figura 3.6. Para tanto, foi utilizado a posição geográfica do veículo que enviou e a posição geográfica do veículo que recebeu o beacon, para calcular a distância entre o transmissor e o receptor. As coordenadas foram normalizadas em metros, de modo que os mapas representam distância versus distância. Cada linha no mapa representa um beacon transmitido por um veículo e recebido por outro com sucesso e, por meio de uma sequência de snapshots em diferentes momentos (timestamp), foram construídos os mapas para três intervalos de distâncias inter-veículos. A Figura 3.6(a) são os beacons cuja distância inter-veículos é inferior a $80 \mathrm{~m}$, a Figura 3.6(b) são os beacons cuja distância inter-veículos é entre $80 \mathrm{~m}$ a $160 \mathrm{~m}$ e, por fim, a Figura 3.6(c) são os beacons cuja distância inter-veículos é superior a $160 m$.

Para completar a validação V2V, foi realizada uma análise dos dados por meio da métrica PDR. O comportamento PDR obtido (Figura 3.7(c)) foi consistente, ou seja, apresentou uma igual ou maior taxa de perda de pacotes em função do aumento da distância. Além 


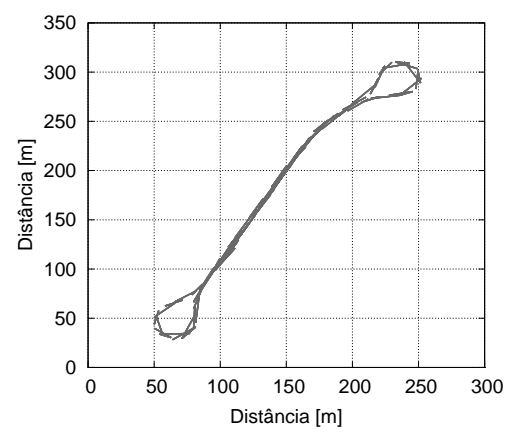

(a)

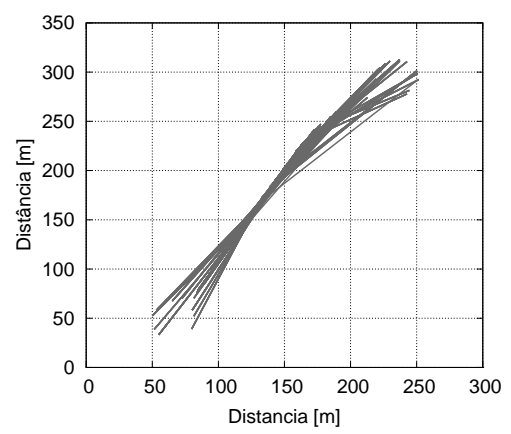

(b)

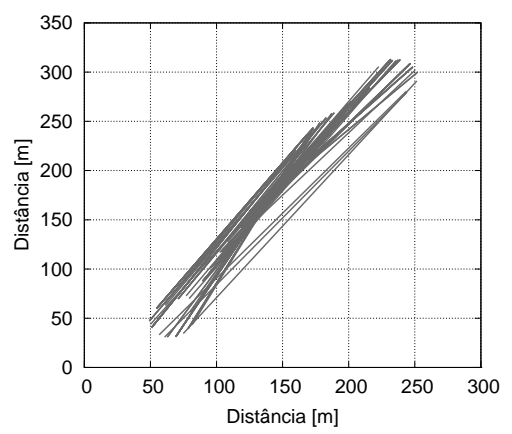

(c)

Figura 3.6: Representação dos beacons transmitidos com sucesso. Os gráficos são os mapas dos beacons (representados pelos traços) trocados em diferentes instantes e distâncias: (a) beacons recebidos com distância inferior a $80 \mathrm{~m}$; (b) beacons recebidos com distância entre $80 \mathrm{~m}$ a $160 \mathrm{~m}$; (c) beacons recebidos com distância acima de $160 \mathrm{~m}$ (Yokoyama et al., 2013)

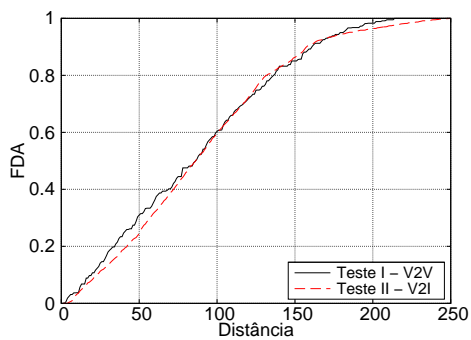

(a)

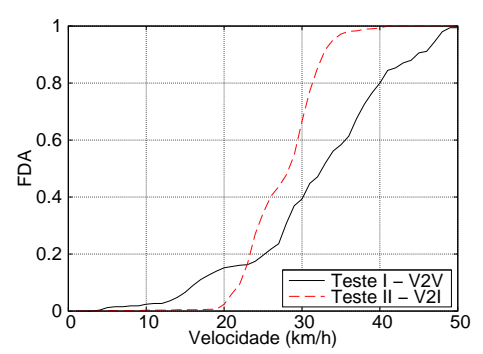

(b)

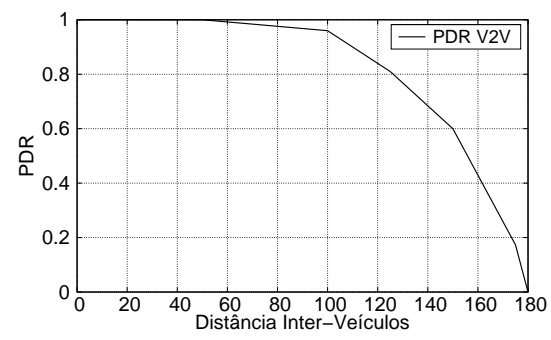

(c)

Figura 3.7: FDA para a distância e velocidade nos Testes I e II e o PDR é somente do Teste I: (a) FDA da distância inter-veículos; (b) FDA da velocidade do(s) veículo(s); (c) PDR inter-veículos (Yokoyama et al., 2013)

disso, calculamos a Função de Distribuição Acumulada (FDA) da distância e da velocidade, conforme os gráficos na Figura 3.7(a) e 3.7(b), respectivamente.

O resultado do desempenho através de análise em PDR foi satisfatório, atingindo o objetivo da comunicação V2V. Como pode ser observado no gráfico da Figura 3.7(c), para distâncias inferiores a $50 \mathrm{~m}$ o PDR foi de 1,0 e decresceu até 0,2 para a distância de $175 \mathrm{~m}$. Eventualmente, ocorreram poucas trocas de beacons acima de $175 \mathrm{~m}$, porém a quantidade obtida de pacotes não foi suficiente para calcular o PDR. A variação da distância foi de $1 \mathrm{~m}$ a $210 m$ como mostra o gráfico FDA da Figura 3.7(a). A variação da velocidade foi de $1 \mathrm{~km} / \mathrm{h}$ a $50 \mathrm{~km} / \mathrm{h}$, conforme o gráfico FDA da Figura 3.7(b). 


\subsubsection{Teste II - Comunicação V2I}

A finalidade deste teste foi validar a comunicação por meio de beaconing entre o veículo e a RSU. O teste foi realizado com 1 Fiat Palio e 3 RSUs, todos transmitindo e recebendo beacons. As RSU-1 e RSU-3 foram posicionadas próximas às rotatórias devido à limitação do espaço físico e, também, porque possibilita a coleta de dados a distâncias menores, no momento da aproximação do carro. A RSU-2 foi posicionada aproximadamente no centro do circuito para complementar a cobertura RF, como ilustra a Figura 3.8. O veículo percorreu o circuito durante aproximadamente 11 minutos, perfazendo $\approx 5.5 \mathrm{~km}$. O carro recebeu 2539 beacons e as RSUs receberam na média de 916 beacons. Os eventuais beacons trocados entre as RSUs não foram considerados. A variação da distância foi de $1 \mathrm{~m}$ a $250 \mathrm{~m}$ conforme FDA na Figura $3.7(\mathrm{a})$. A velocidade variou de $1 \mathrm{~km} / \mathrm{h}$ a $35 \mathrm{~km} / \mathrm{h}$, com a maior parte dos dados entre $20 \mathrm{~km} / \mathrm{h}$ a $35 \mathrm{~km} / \mathrm{h}$, como é possível observar no FDA do Teste II na Figura $3.7(\mathrm{~b})$.

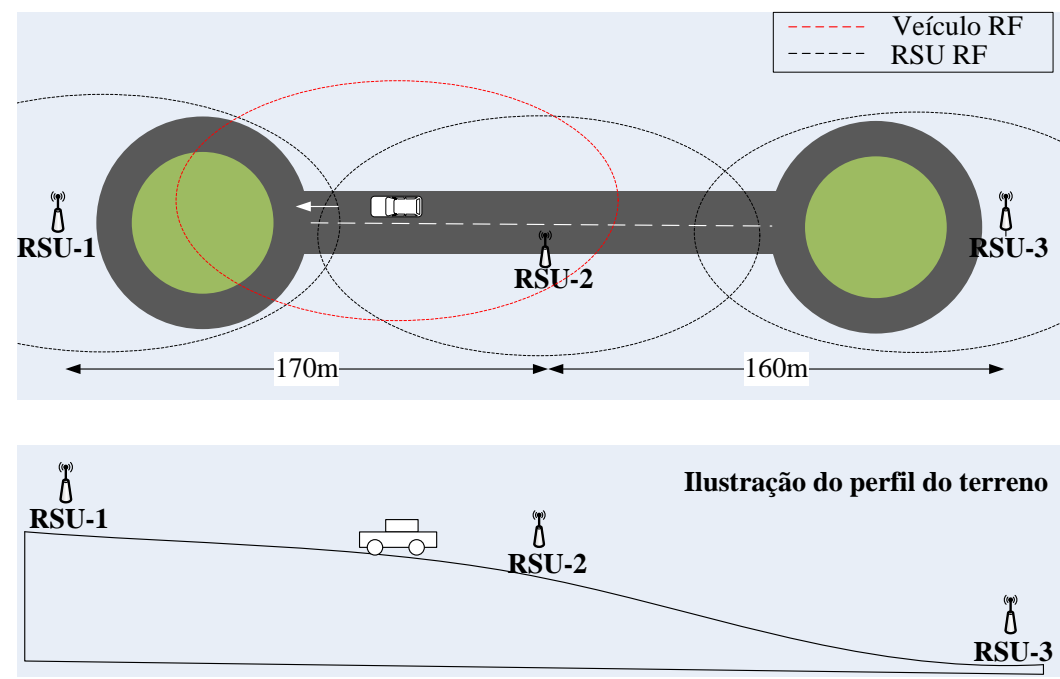

Figura 3.8: Na parte superior é ilustrado os locais onde as RSUs foram instaladas no circuito. Na parte inferior é ilustrado o perfil do terreno, representando o desnível do terreno (Yokoyama et al., 2013)

Os PDRs foram calculados individualmente para cada RSU nos dois sentidos da transmissão: Carro para a RSU (Carro $\rightarrow$ RSU) e RSU para o Carro (RSU $\rightarrow$ Carro). Os resultados estão representados nos gráficos da Figura 3.9. Para as distâncias inferiores a $50 \mathrm{~m}$ o PDR foi 1.0, o mesmo valor da comunicação V2V. Contudo, a partir de $50 \mathrm{~m}$ de distância os PDRs variam consideravelmente entre as RSUs, principalmente, entre a RSU-1, com o pior desempenho, e a RSU-3, de melhor desempenho. O principal fator que justifica a variação é o perfil do terreno que não permitiu a linha de visada entre a RSU-1 e a RSU-3, como ilustrado na Figura 3.8. Neste caso, a posição da RSU-3 no final do declive favoreceu o desempenho no PDR. Por outro lado, o desempenho da RSU-1, localizado antes do declive, foi sensivelmente prejudicado. Este resultado evidencia o problema do baixo desempenho do PDR em locais sem linha de visada. 


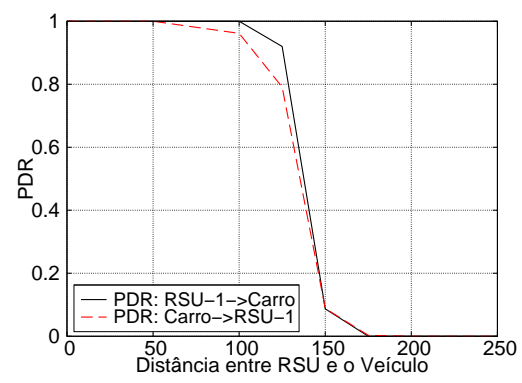

(a)

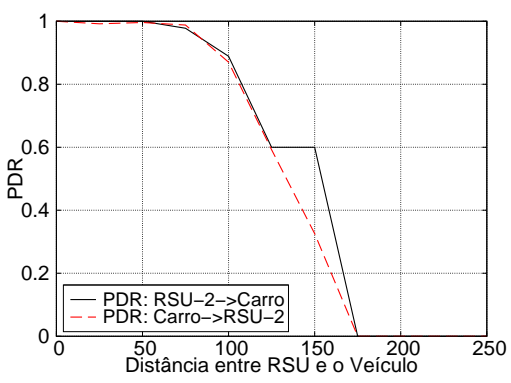

(b)

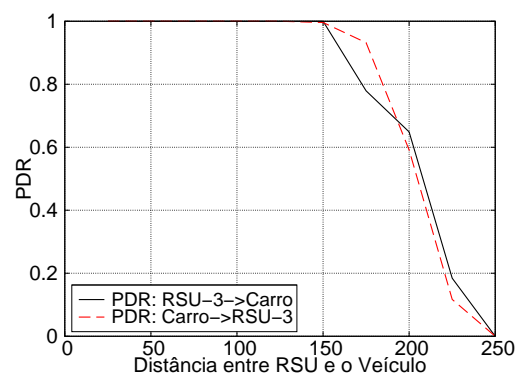

(c)

Figura 3.9: PDRs de cada RSU e do veículo com relação a cada RSU: (a) PDR da RSU-1 localizado a esquerda do testbed; (b) PDR da RSU-2 localizado a centro do testbed; (c) PDR da RSU-3 localizado a direita do testbed (Yokoyama et al., 2013)

Adicionalmente, o problema da estação oculta impactou no desempenho do PDR das três RSUs. O problema ocorre dinamicamente em algumas distâncias entre a RSU e o veículo, devido ao movimento do carro.

\subsection{Visualização do RSSI}

Para uma simples observação da distribuição do sinal de RF no testbed foram utilizados os gráficos com escala de cores, ilustrados na Figura 3.10. Os gráficos foram construídos a partir de dados do RSSI de todos os beacons recebidos no veículo e separados por RSU. A cada área de $2 \mathrm{~m}^{2}$ foi calculado a média dos RSSI observados, o resultado foi representado por um ponto sobre o mapa. As cores estão em uma escala que representa a qualidade do sinal RF: as tonalidades azul, amarela e vermelha, são o sinal de boa, média e baixa qualidade, respectivamente.

O declive do terreno, ilustrado na Figura 3.8, também influenciou na distribuição do RSSI. As RSU-1 e RSU-3 não conseguiram uma cobertura completa do tesbed, enquanto a RSU-2, conseguiu uma cobertura razoável, com uma baixa qualidade do RSSI no ponto mais afastado e baixo do terreno. Os gráficos 3.10(a) e 3.10(c) reforçam a afirmação de que ocorreu o problema da estação oculta nas extremidades (rotatórias) do testbed e essa impactou no PDR do Teste II.

\subsection{Considerações finais}

Este Capítulo descreveu o projeto, implementação, implantação e experimentos de validação da plataforma $\mathrm{V}$-Beacon para comunicação em redes veiculares. Os experimentos e resultados mostram a viabilidade da plataforma, sendo adequada para testes de protocolos que utilizam 


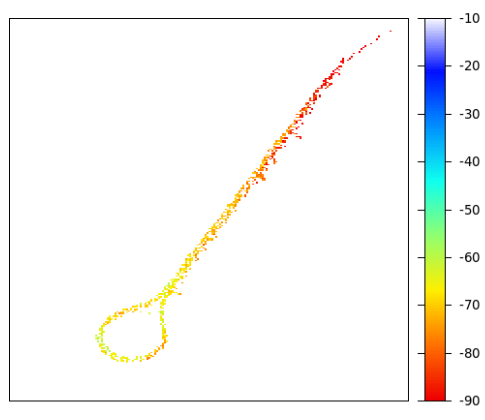

(a)

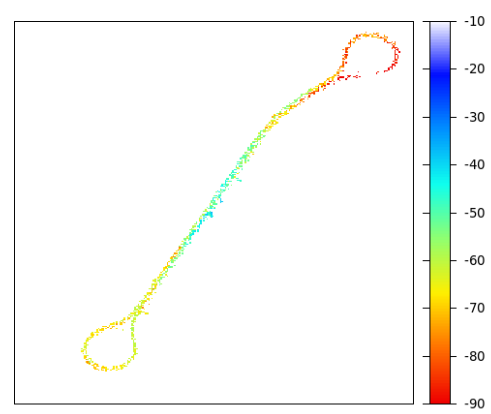

(b)

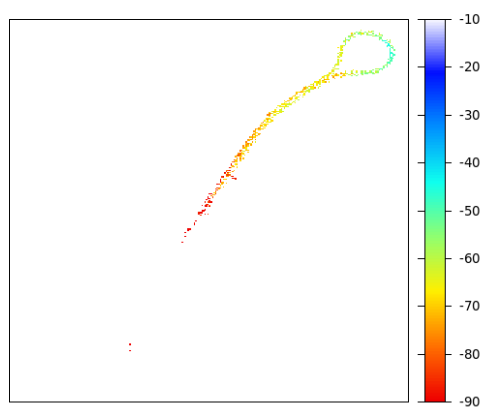

(c)

Figura 3.10: Distribuição do RSSI separado por RSU: (a) RSSI da RSU-1 localizado a esquerda do testbed; (b) RSSI da RSU-2 localizado a centro do testbed; (c) RSSI da RSU-3 localizado a direita do testbed

beaconing em comunicação V2V e V2I. V-Beacon tem a vantagem de ser um testbed de fácil implantação e mobilidade, sendo flexível ao permitir a inserção de novas informações no beacon e a configuração de diversos parâmetros de comunicação.

Os resultados dos experimentos indicam que aplicações de segurança devem levar em consideração os valores de PDRs. Uma vez que o cenário avaliado, com somente dois veículos, o PDR foi inferior a 1,0 para distância acima de $50 \mathrm{~m}$, não havendo garantias de que uma mensagem crítica via beacon possa atingir o destinatário. Adicionalmente, o perfil do terreno influenciou na distribuição da qualidade do RSSI e também gerou o problema da estação oculta, podendo afetar o desempenho do PDR.

Por fim, destaca-se que a contribuição da plataforma é permitir explorar o promissor cenário de redes veiculares por meio de experimentos em condições e ambientes reais, diferindo do método da simulação. V-Beacon pode ser aplicado na avaliação e validação de novos protocolos com base em beaconing. Entretanto, a utilização do V-Beacon demanda mais tempo de configuração que os testbeds fixos discutidos no Capítulo 2, devido à necessidade de montagem individual dos carros e RSU, dificultando os testes em grande escala. 


\section{4}

\section{Caracterização do RSSI de beaconing para estimar distâncias}

Diversas aplicações e serviços de segurança em redes veiculares confiam na informação de posição geográfica para calcular as distâncias entre veículos ou da infraestrutura ao redor. Atualmente, a tecnologia mais comum para posicionamento do veículo é o Global Positioning System (GPS). No entanto, o receptor GPS possui limitações, como a necessidade da linha de visada para os satélites, podendo falhar na acurácia da posição em situações em que o sinal do satélite esteja obstruído, tais como: túneis, locais com muitos prédios altos, ruas com alta densidade de árvores, locais com excesso de poluição atmosférica, ou ainda, simplesmente, o mau tempo, como dias chuvosos ou nevascas. Existe, também, o problema de segurança, uma vez que o canal civil do GPS não é criptografado, pode-se manipular o sinal para modificar a posição do veículo receptor (Chiang et al., 2009). Por fim, não é possível assumir que o dispositivo nunca apresentará um defeito.

Nestes casos, quando a posição é inconsciente ou inexistente, os aplicativos de segurança demandam uma maneira para estimar as distâncias dos veículos ao redor ou das infraestruturas para obter ciência do ambiente. Na literatura existem propostas para medir distância entre os veículos por meio de diferentes tecnologias, algumas delas são: Ying e Yuhui (2010) fazem uso do processamento de imagem digital para medir a distância do carro à frente, para a distância de $100 \mathrm{~m}$ consegue uma precisão de $7 \mathrm{~m}$ e leva $400 \mathrm{~ms}$ para calcular a distância. Porém, é limitado à visão da câmera e um veículo à frente. Atualmente, alguns veículos são equipados com sensores com tecnologia de laser para medir a distância até um 
obstáculo e auxiliar o motorista; essas soluções são limitadas à linha de visada e podem perder acurácia se sofrem interferências, por exemplo, da fumaça do motor do veículo, como é o caso do infravermelho (Tiedeke et al., 1990). As soluções propostas para redes veiculares utilizam sensores e se baseiam no Received Signal Strengt Indicator (RSSI) ou Time-of-Fligth (ToF) com o objetivo de obter medidas de distância dentro de túneis (Liénard et al., 2000; Widmann et al., 2013). Widmann et al. (2013) é o trabalho mais recente e utiliza sensores com tecnologia zigbee para comparar as técnicas RSSI e ToF para medir distâncias dentro do túnel do veículo mais próximo. Os resultados foram o erro médio absoluto de $175 \mathrm{~m}$ para RSSI e $67,7 \mathrm{~m}$ para ToF, considerando intervalo de distância entre 100 a $200 \mathrm{~m}$.

Neste estudo é proposta uma aplicação capaz de estimar a distância entre o veículo e outro veículo ou a RSU, com base no RSSI, sem a necessidade do conhecimento da posição geográfica de ambos, no momento da realização da inferência da distância. A ideia é aproveitar a comunicação por beaconing, definido no padrão de redes veiculares, para coletar informações sobre RSSI e estimar a distância em ocasiões que ocorrer falha do dispositivo GPS. Essa abordagem tem a vantagem de conseguir estimar distâncias acima de $100 \mathrm{~m}$ independente da direção do veículo ou da RSU. Por outro lado, tem a desvantagem de não possuir muita acurácia na medida, pelo motivo das flutuações do valor do sinal RF. O cenário deste trabalho tem três características fundamentais: i) é assumido somente um ponto de referência (veículo ou RSU), que é fonte do sinal RF da qual se deseja conhecer a distância; ii) o veículo está em constante movimento; e iii) o ambiente é externo e o receptor sofre com as interferências, como, por exemplo, as partes metálicas do veículo, ruído do motor, radiação solar, etc. e esses fatores afetam a acurácia da distância. Esta solução pode ser útil para outros pesquisadores e engenheiros com o objetivo de projetar aplicações para veículos que utilizam a medida da distância, porém não necessitam da distância exata, por exemplo, aplicações como de posicionamento seguro (Capkun e Hubaux, 2006) e privacidade (Ardagna et al., 2011) em redes veiculares.

Para desenvolver a aplicação veicular para estimar à distância, foram aproveitados alguns estudos da literatura sobre sistemas de posicionamento indoor em redes WiFi. Normalmente, as técnicas de posicionamento indoor que utilizam o RSSI se dividem em: i) triangulação (LaMarca et al., 2005), ii) predição por meio de fingerprint (Ladd et al., 2002) e iii) predição com base em modelos probabilísticos (Roos et al., 2002). As técnicas probabilísticas não foram exploradas neste trabalho para o cálculo da distância em redes veiculares. Portanto, com a finalidade de estimar a distância com a melhor acurácia possível, foram adaptadas duas técnicas de posicionamento indoor para redes veiculares. A primeira utiliza o algoritmo $k$-NN ( $k$-Nearest Neighbors), esse algoritmo foi aplicado originalmente no RADAR (Bahl e Padmanabhan, 2000), para localização de usuários em ambientes indoor com base no valor da média do RSSI da rede WiFi e na direção da antena no momento da coleta do RSSI. A segunda, FreeLoc (Yang et al., 2013), faz uso do valor de RSSI de maior frequência para 
calcular o fingerprint de cada Access Point (AP) da rede e, então, inferir a localização do usuário. As justificativas para a escolha dessas técnicas são discutidas na Seção 4.2.

A aplicação foi validada e avaliada por meio de dados empíricos coletados nos experimentos realizados no testbed de redes veiculares. Para tanto, foi analisado o comportamento do RSSI de beaconing por meio das principais técnicas estatísticas de posição e dispersão dos dados. Para implementar as técnicas de estimação de distância foi utilizada uma arquitetura com duas fases, a primeira é a coleta e armazenamento de instâncias exemplos e a segunda, de inferência com base nas instâncias coletadas. A avaliação foi como base em um ponto de referência RSU e um veículo, ambos transmitindo e recebendo os beacons. Os resultados mostram que a aplicação conseguiu uma acurácia média absoluta de $\approx 18 \mathrm{a} \approx 32 \mathrm{~m}$ para distâncias entre 10 a $200 m$ com base em 400 instâncias exemplos.

\subsection{Descrição do experimento}

Nesta Seção são descritas a configuração do experimento e as medições realizadas. A plataforma V-Beacon (Yokoyama et al., 2013) foi utilizada, com as configurações expostas na Subseção 4.1.1, para a realização das quatro coletas de dados usando um veículo e uma RSU, detalhadas na Subseção 4.1.2.

\subsubsection{Configuração do testbed}

O testbed foi instalado no campus 2 da USP-São Carlos, a Figura 4.1 é foto de satélite do local destacando a rua utilizada, que possui $\approx 500 \mathrm{~m}$ de distância. Os pontos finais $A$ e $C$ indicam o local onde o veículo fez o retorno para continuar o experimento e o ponto $B$ onde foi instalado a RSU. O experimento foi realizado utilizando um automóvel Celta e uma RSU instalada ao lado da via, equipados com um roteador sem fio. Os parâmetros de transmissão configurados no roteador sem fio estão descritos na Tabela 4.4. A aplicação beaconing é baseada no middleware descrito no Capítulo 3. Durante o experimento o veículo circulou entre pontos $A, B$ e $C$. Os beacons foram transmitidos e recebidos pela RSU e pelo veículo.

Tabela 4.1: Configuração do roteador sem fio

\begin{tabular}{l|l}
\hline Parâmetros & Valores \\
\hline Potência de transmissão & $23 \mathrm{dBm}$ \\
Largura da banda & $20 \mathrm{MHz}$ \\
Frequência & $5,8 \mathrm{GHz}$ \\
Taxa de transmissão & $6 \mathrm{Mbps}$ \\
Canal & 56 \\
\hline
\end{tabular}




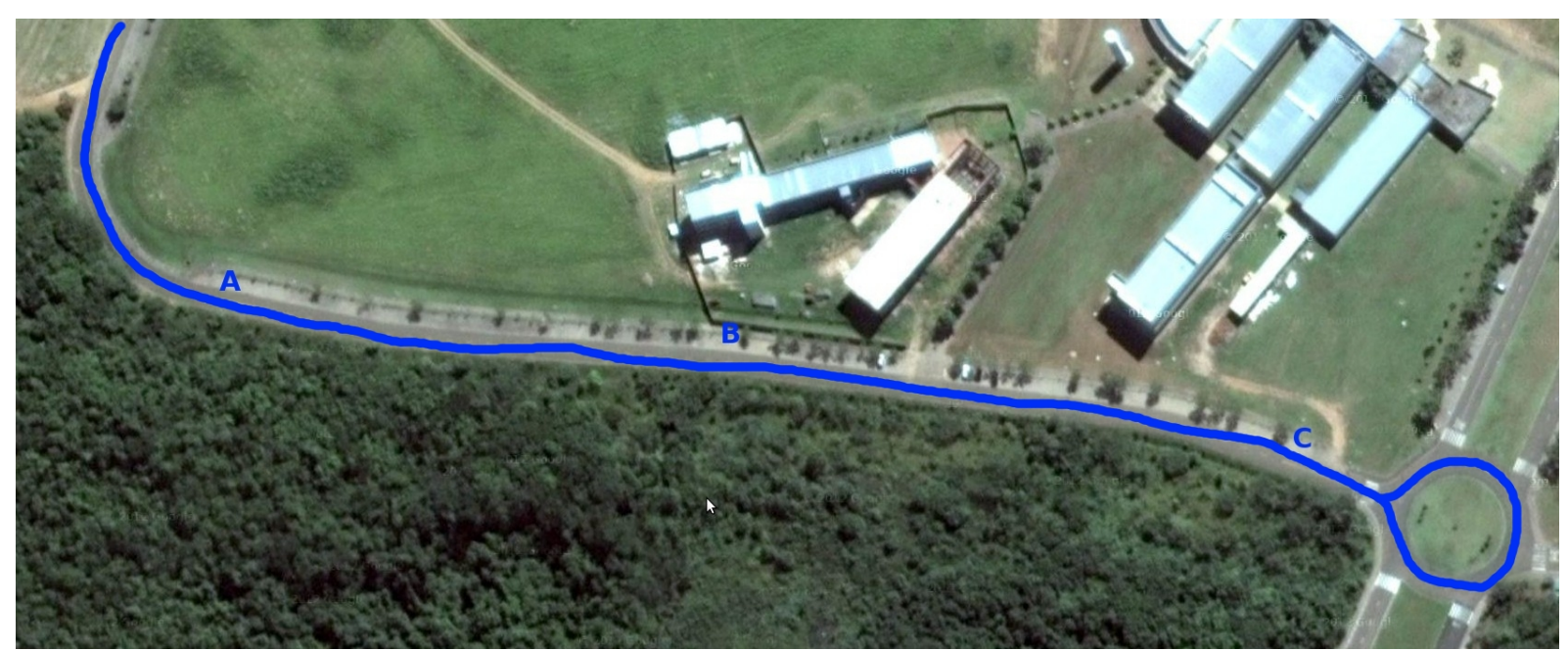

Figura 4.1: Foto de satélite do local e a configuração do testbed para coleta de dados

\subsubsection{Medições}

O experimento foi realizado por meio de quatro coletas de dados independentes. A cada coleta o veículo circulou nove voltas no testbed, transmitindo e recebendo beacons, a uma velocidade variável de até $50 \mathrm{~km} / \mathrm{h}$. Os arquivos de logs foram gravados no veículo e também na RSU. A aplicação beaconing enviou beacons a uma frequência de $5 \mathrm{~Hz}$.

A Tabela 4.2 sumariza o total de beacons coletados e tempo gasto em cada coleta. As quatro coletas foram realizadas no mesmo dia. A divisão em quatro coletas foi para facilitar o gerenciamento dos dados e também verificar, a cada coleta, a correta execução do experimento, assim reduzindo o risco de uma falha técnica prejudicar todo o experimento.

Tabela 4.2: Total de beacons recebidos por coleta

\begin{tabular}{c|c|c|c}
\hline Coleta & Recebidos no veículo & Recebidos na RSU & Tempo \\
\hline I & 5.555 & 7.959 & $29 \mathrm{~min}$ \\
II & 5.512 & 6.388 & $20 \mathrm{~min}$ \\
III & 6.162 & 7.276 & $22 \mathrm{~min}$ \\
IV & 5.281 & 5.640 & $19 \mathrm{~min}$ \\
\hline Total & 22.510 & 27.263 & $1: 30 \mathrm{~h}$ \\
\hline
\end{tabular}

Os dois gráficos da Figura 4.2 utilizam todos os dados coletados e representam uma visão geral do experimento. No primeiro, o gráfico 4.2(a), é apresentado o valor do RSSI em função da distância, onde cada ponto simboliza um beacon recebido pelo veículo ou RSU. O acúmulo de pontos existente na distância acima de $220 m$ é consequência da manobra do carro para o retorno, realizada em baixa velocidade. É possível observar uma sobreposição da maior parte dos beacons recebidos pelo veículo com os beacons recebidos pela RSU, mas existe uma pequena diferença do sinal RF recebido pelo veículo do beacon se comparado com o recebido na RSU. No segundo, o gráfico da Figura 4.2(b), é ilustrada a variação do sinal RF 
no estilo de mapa de site-survey. Os RSSI usados foram os recebidos pelo veículo durante o experimento. O gráfico retrata o percurso do testbed por meio de níveis de cores que representam as médias do RSSI, calculadas a cada $2 \mathrm{~m}^{2}$. Três níveis de RSSI se destacam, o primeiro é o verde, para uma boa qualidade do sinal, o segundo é o amarelo para uma qualidade média e terceiro é o vermelho para uma baixa qualidade do sinal.

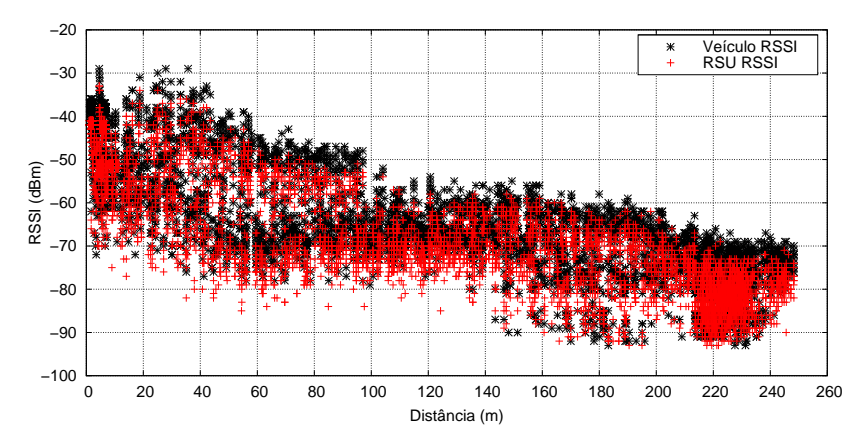

(a)

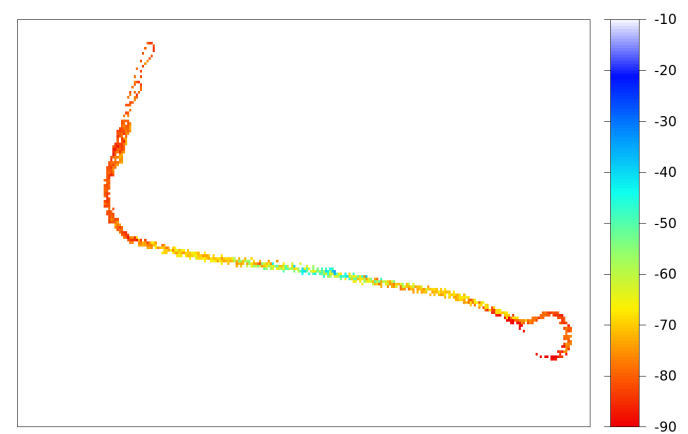

(b)

Figura 4.2: a) Valores diretos da coleta do RSSI em função da distância no veículo e na RSU e b) Mapa representativo do valor médio do RSSI por região do testbed.

O terceiro gráfico, ilustrado na Figura 4.3, é usado para representar a variação da distância e do RSSI em função do tempo, do início ao fim do teste referente à coleta I. Os pontos $A, B$ e $C$ do gráfico correspondem às posição $A, B$ e $C$ destacadas na Figura 4.1. É possível observar a variação da distância e do RSSI em função do tempo.

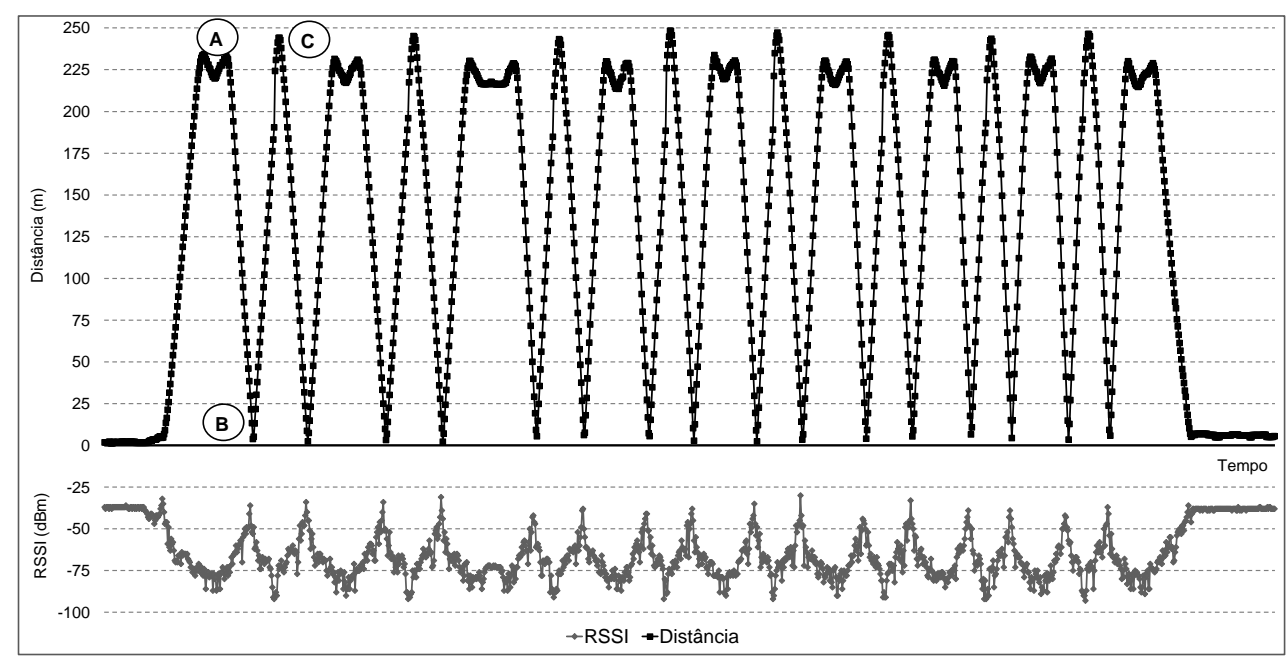

Figura 4.3: Valores coletados no veículo do RSSI e distância em função do tempo para a primeira coleta

Esta visão geral dos dados do experimento foi importante para verificar se foi obtido o comportamento esperado do sinal RF, ou seja, a atenuação do RSSI em função do aumento da distância entre o transmissor e receptor. Por meio da observação dos gráficos 4.2(a), é possível afirmar o RSSI obtido por meio de beaconing tem uma relação direta com distância e 
a RSSI. Portanto, na Seção 4.2 foram conduzidas algumas análises estatísticas para melhorar a caracterização do RSSI.

\subsection{Caracterização do RSSI}

Antes de iniciar a análise do comportamento RSSI, foi realizado um tratamento dos dados para filtrar outliers e também retirar os beacons coletados nas extremidades do testbed, para garantir: i) que veículo estava em movimento durante o envio do beacon, porque, eventualmente, durante a manobra para retorno, o veículo ficou temporariamente parado; e ii) uma quantidade de dados adequada para a análise, porque em posições muito afastadas da RSU ocorreu uma escassez de dados devido à perda de pacotes. Portanto, a distância máxima foi limitada a $200 \mathrm{~m}$ e foi assumido que essa distância é suficiente para validar e avaliar a aplicação.

As Figuras 4.4(a) e 4.4(b) são os histogramas, após o tratamento dos dados, para o RSSI e para intervalos de distância, respectivamente. O histograma da Figura 4.4(a) sugere que o RSSI segue uma distribuição normal e o histograma da Figura 4.4(b) mostra que, para este experimento, foi obtida uma quantidade razoavelmente uniforme de beacons por intervalo de distância, com exceção do intervalo de $50 \mathrm{~m}$. O ideal para uma boa estimativa da distância seria uma distribuição da frequência do RSSI uniforme, parecida com o a dos intervalos de distância.

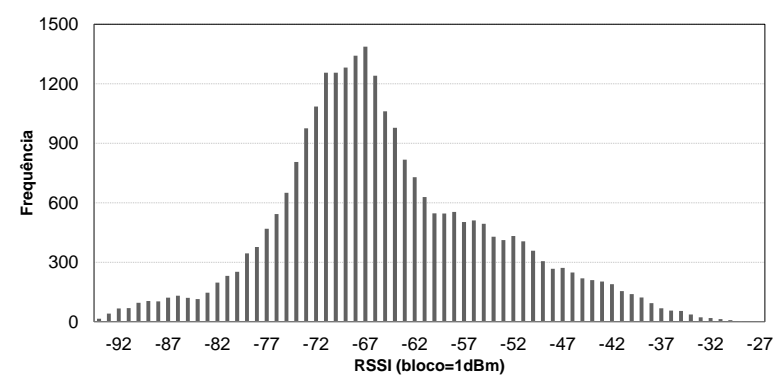

(a)

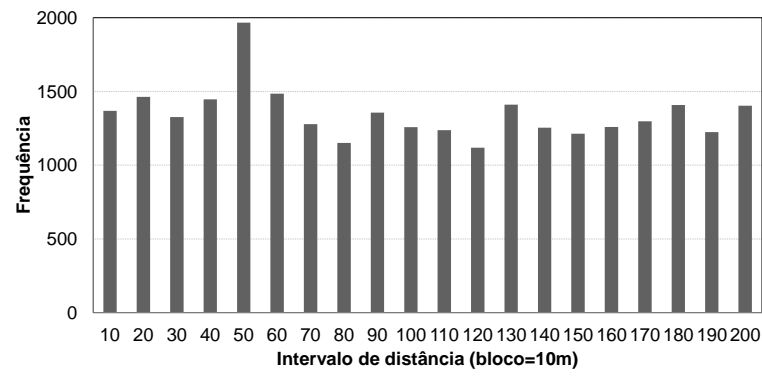

(b)

Figura 4.4: a) Frequência de beacons por valor de RSSI (bloco=1 $d B m$ ) e b) Frequência de beacons por intervalo de distância $($ bloco $=10 \mathrm{~m}$ )

O principal problema para determinar a distância usando o valor do sinal RF recebido é a flutuação deste valor. Portanto, para observar essa flutuação utilizou-se a representação da dispersão do RSSI por meio de boxplots da Figura 4.5. No gráfico 4.5(a) os RSSI são agrupados em amostras de intervalo de distância $\triangle=5 \mathrm{~m}$. É possível verificar que existem sequências de intervalos com a maior parte dos valores de RSSI sobrepostos, principalmente no primeiro e terceiro quartis. Por exemplo, de 50 a $80 \mathrm{~m}$ e de 100 a $130 \mathrm{~m}$, possuem variação de -80 a $-42 d B m$ e -71 a $-61 d B m$, respectivamente, na qual os valores do RSSI 
se justapõem. Assim, mesmo considerando intervalos $\triangle=5 \mathrm{~m}$, não é possível encontrar faixas de RSSI mais representativos para cada intervalo múltiplo do valor de $\triangle$.

Ampliando o intervalo para $\triangle=10 \mathrm{~m}$, representado no gráfico 4.5(b), é observada uma redução na variação dos valores do RSSI no primeiro e terceiro quartis, indicando uma melhora na caracterização do comportamento do sinal para intervalos maiores. Por meio da comparação entre os boxplots pode-se afirmar que o aumento do intervalo, $\triangle$, pode convergir a valores do RSSI que caracterizam os intervalos, porém se adotado um intervalo $\triangle \gg 10 \mathrm{~m}$, a precisão da estimativa da distância pode não atender requisitos das aplicações de segurança.

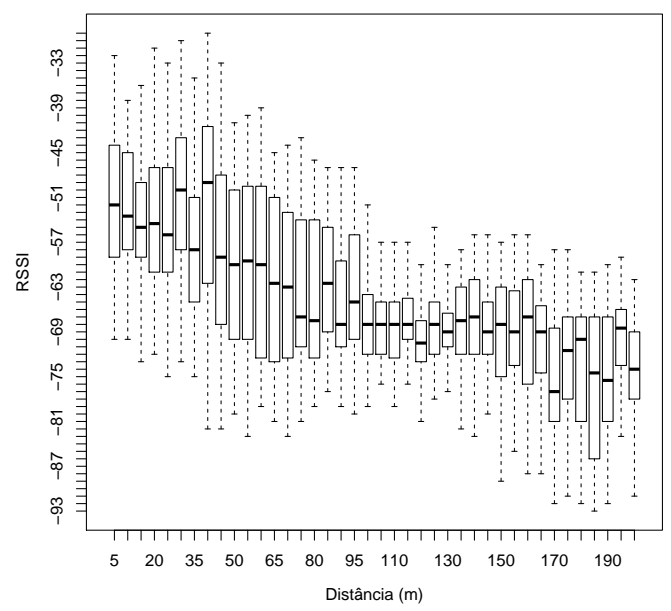

(a)

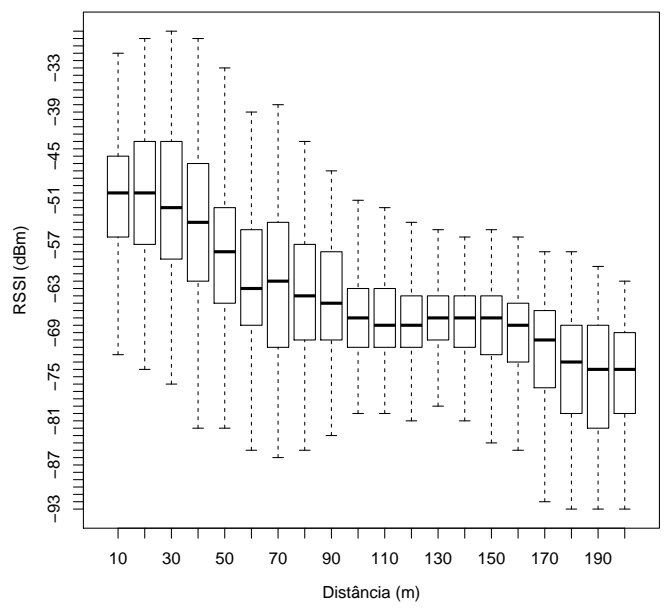

(b)

Figura 4.5: Boxplots para análise da dispersão do RSSI a) aplicando um intervalo $\triangle=5 \mathrm{~m}$ e b) aplicando um intervalo $\triangle=10 \mathrm{~m}$

Com base na técnica utilizada por FreeLoc (Yang et al., 2013) foi realizada a análise com relação à distribuição do RSSI por intervalo de distância $\triangle=10 \mathrm{~m}$. Em linhas gerais, a técnica consiste em utilizar a distribuição do sinal RF de cada AP para calcular o valor de fingerprint (fp Value). Segundo Yang et al. (2013), o RSSI mais representativo para o $f p$ Value é o com maior frequência, desta maneira o fp Value é calculado por meio da Equação 4.1, utilizando RSSI pico e também os valores de amplitude da amostra. Para análise da distribuição do RSSI foram construídos vinte histogramas, um histograma para cada intervalo múltiplo de $\triangle=10 \mathrm{~m}$. Os histogramas, ilustrados na Figura 4.6, não apresentam formas idênticas e nem sugerem uma distribuição semelhante para todos os intervalos. Entretanto, o importante para o FreeLoc é o valor do RSSI pico e fundamentado na observação dos dados; pode-se afirmar que na maioria dos intervalos existe um RSSI pico. Entretanto, nem sempre a maior distância é representada por um RSSI pico de menor valor, por exemplo, se comparados os intervalos $90 \vdash 100 m$ e $130 \vdash 140 m$ da Figura 4.6. Nos histogramas a partir de $140 m$ de distância, existe uma tendência do deslocamento dos dados para a esquerda essa tendência é discutida em Kaemarungsi (Kaemarungsi e Krishnamurthy, 2004). 


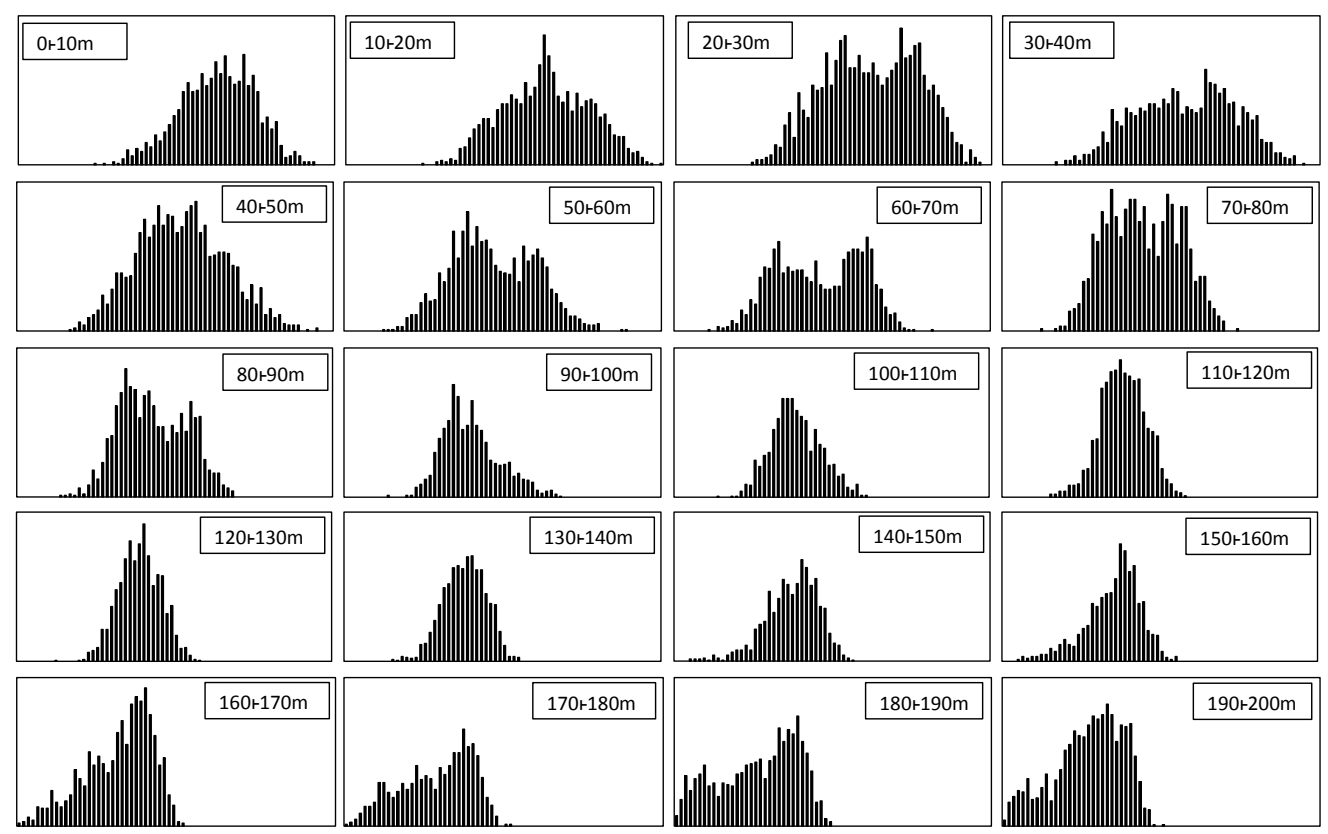

Figura 4.6: A figura representa os vinte histogramas da frequência do RSSI para intervalos de distâncias $\triangle=10 \mathrm{~m}$.

Outro parâmetro estudado e utilizado em trabalhos sobre sistemas de posicionamento indoor é o valor da média do RSSI (Bahl e Padmanabhan, 2000; Roos et al., 2002; LaMarca et al., 2005). RADAR (Bahl e Padmanabhan, 2000) foi um dos primeiros trabalhos a usar a média do RSSI em redes WiFi. A técnica do RADAR consiste na coleta do RSSI de cada AP em diferentes pontos do edifício e depois sumarizar em um banco de dados as informações: localização do usuário, média do RSSI, direção da coleta e a relação sinal-ruído. Para inferir a localização, RADAR faz o emparelhamento dos dados armazenados com os dados coletados on-line pelo usuário. Por isso, foram analisados os valores da média para cada intervalo. Para tanto, foi calculada a média do RSSI e o desvio padrão para os intervalos $\triangle=5$ e $10 m$, ilustrados na Figura 4.7. Em geral, a média é um parâmetro que consegue representar de maneira razoável o comportamento do RSSI, nas Figuras 4.7(a) e 4.7(b) foram observados a tendência do valor do RSSI diminuir em função da distância. Porém, se analisado localmente o comportamento, existe uma inversão dessa tendência do RSSI até $40 \mathrm{~m}$ e uma maior variação da média do RSSI a partir de $170 \mathrm{~m}$. Esse comportamento pode ser consequência de uma maior flutuação do sinal, como observado pelos desvios padrão que são maiores nesses intervalos.

Após esta análise estatística pode-se concluir que a técnica utilizada por Widmann et al. (2013), a aplicação da conhecida equação logarítmica de perda do caminho, free-space (Rappaport, 2009), sobre a média do RSSI, não terá uma acurácia muito boa. Portanto, foi escolhido o algoritmo $k$-NN que faz uma regressão do RSSI em função do valor $k$. Outra escolha foi calcular o valor fp Value para cada intervalo de distância, porque os histogramas 


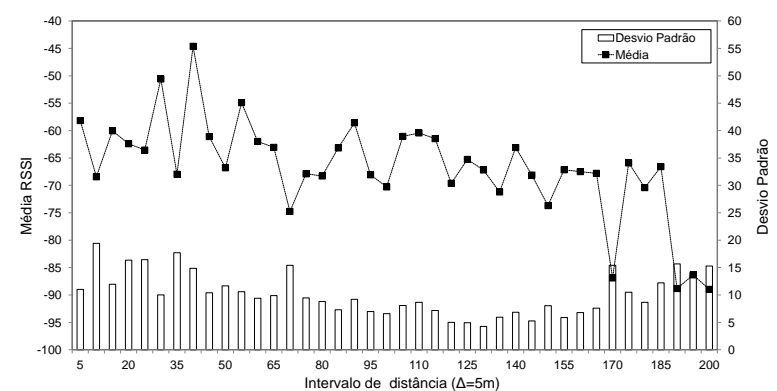

(a)

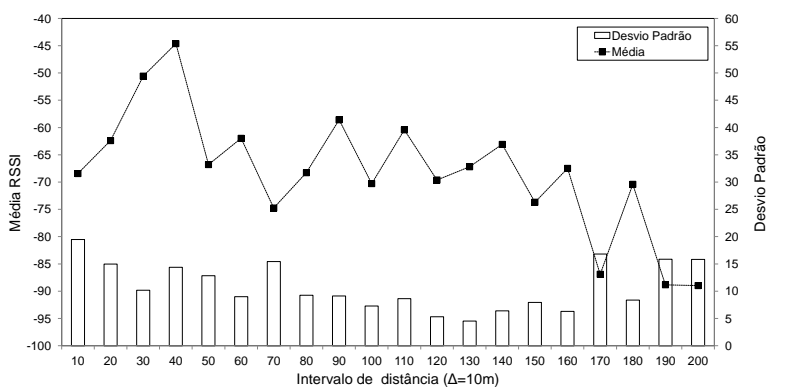

(b)

Figura 4.7: Valores médios do RSSI e desvios padrões para a) $\triangle=5 \mathrm{~m}$ e b) $\triangle=10 \mathrm{~m}$

da Figura 4.6 sugerem que é possível ter um fp Value que representa de maneira adequada o intervalo $\triangle$.

\subsection{Formalização do problema}

Seja $v$ o veículo que deseja estimar sua distância, $\bar{d}$, até o veículo ou a infraestrutura de referência $r_{j}$ encontrados durante o percurso de $v$, pertencentes à rede veicular. Cada $r_{j}$ envia beacons ordinários, a uma frequência $f$, acrescidos da posição geográfica dele. Assumindo que cada veículo $v$ possui a capacidade de armazenar $n$ instâncias $\hat{I}_{n}$, com informações do RSSI e da distância em relação de $r_{j}$, extraídos por meio dos beacons enviados por $r_{j}$ e recebidos por $v$. Se o GPS de $v$ falhar, $v$ computa $\bar{d}$ em relação a $r_{j}$, por meio de uma instância $\hat{I}^{j}$ gerada dos $m$ beacons recebidos de $r_{j}$. Para tanto, utiliza uma função de regressão $\mathbb{k}$ (definida na Eq. 4.2).

Hipótese: $\forall v$ que possui armazenadas $n$ instâncias $\hat{I}_{n}$ é capaz de estimar a distância $\bar{d}$ em relação a $r_{j}$ por meio da função $\mathbb{k}\left(\hat{I}_{n}, \hat{I}^{j}\right)=\bar{d}$.

\subsection{Arquitetura da aplicação}

A arquitetura proposta para a aplicação, ilustrada na Figura 4.8, é descentralizada, com a vantagem da distância $\bar{d}$ ser calculada pelo veículo $v$ e não necessita de uma autoridade central. Por outro lado, é necessário um tempo inicial para a coleta, chamado de Database procedure ou fase off-line, das $n$ instâncias $\hat{I}_{n}$, que são as instâncias de exemplos, portanto a aplicação possui duas fases distintas. A primeira é a geração das instâncias exemplos, é a fase de contínuo armazenamento das instâncias, $\hat{I}_{n}$, no buffer circular de tamanho $n$. A segunda é o procedimento de estimação que calcula a função $\mathbb{k}\left(\hat{I}_{n}, \hat{I}^{j}\right)$ quando $v$ deseja estimar sua distância com relação a $r_{j}$. As duas fases são detalhadas a seguir: 


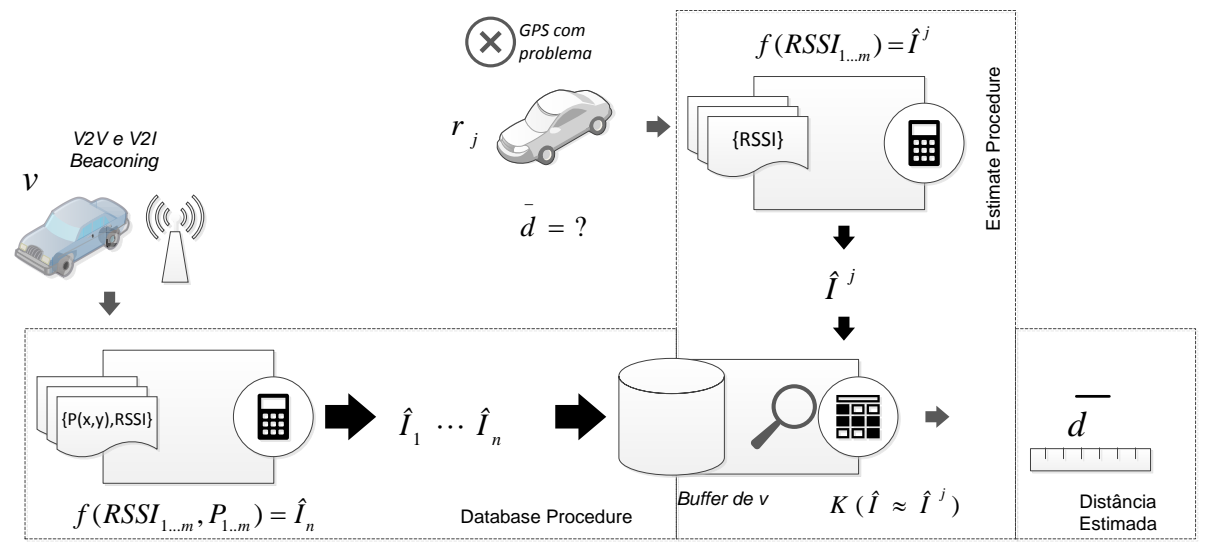

Figura 4.8: Arquitetura da aplicação

- Geração das instâncias exemplos: No cenário de redes veiculares é razoável assumir que os veículos enviam beacons a uma frequência $f \geqslant 5 \mathrm{~Hz}$, incluindo mensagens de segurança ou de serviços. Assim, as instâncias são definidas pelo conjunto de parâmetros $\hat{I}=\{\bar{X}, s, \tilde{X}, R$, fpValue, $\triangle, d\}$. Os parâmetros são calculados a cada amostra de tamanho $m$ dos beacons recebidos em sequência enviados por $r_{j}$. Sendo: $\bar{X}$ a média amostral, $s$ o desvio padrão amostral, $\tilde{X}$ a mediana amostral, $R$ a amplitude amostral e fpV alue o valor do fingerprint caculado conforme a Equação 4.1, extraída de Yang et al. (2013).

$$
f p \text { Value }=\frac{\sum_{p=1}^{w_{l t}}\left(R S S I_{\text {peak }}-p\right)+R S S I_{\text {peak }}+\sum_{q=1}^{w_{r t}}\left(R S S I_{\text {peak }}+q\right)}{w_{l t}+w_{r t}+1}
$$

Sendo a variável $w_{l t}$ o valor da amplitude à esquerda do $R S S I_{\text {peak }}$ e $w_{r t}$ o valor da amplitude à direita do $R S S I_{\text {peak. }}$. A distância $d$ é computada através das posições geográficas de $v$ e $r_{j}$. Se considerarmos a condição $\{m=f\}$, é gerado uma instância $\hat{I}$ por segundo, caso não ocorram perdas de pacotes.

Na Figura 4.9 são ilustradas instâncias geradas com amostras $m=5$ e intervalos grandes de $\triangle=50 \mathrm{~m}$. O intervalo grande é para facilitar a visualização, desta maneira as instâncias são mais distinguíveis e podem ser representadas por meio do gráfico de dispersão $\bar{X}$ versus $s$. Mesmo com intervalo de $\triangle=50 m$ existe uma sobreposição das instâncias, isso dificulta o procedimento de estimação da distância. Por exemplo, o intervalo $100 \vdash 150 \mathrm{~m}$, está misturado com parte das instâncias dos intervalos adjacentes.

- Procedimento de estimação: Algumas técnicas podem ser utilizadas para inferir a distância usando RSSI, considerando a arquitetura adotada e a representação por instâncias, por exemplo, as mais conhecidas que se adaptam à arquitetura são: $S u$ porte Vector Machine (SVM), Redes Neurais Artificiais (RNA) e $k$-NN (Denby et al., 2009). Por simplicidade e pelo motivo dos resultados do RADAR, utilizou-se o $k$-NN: 


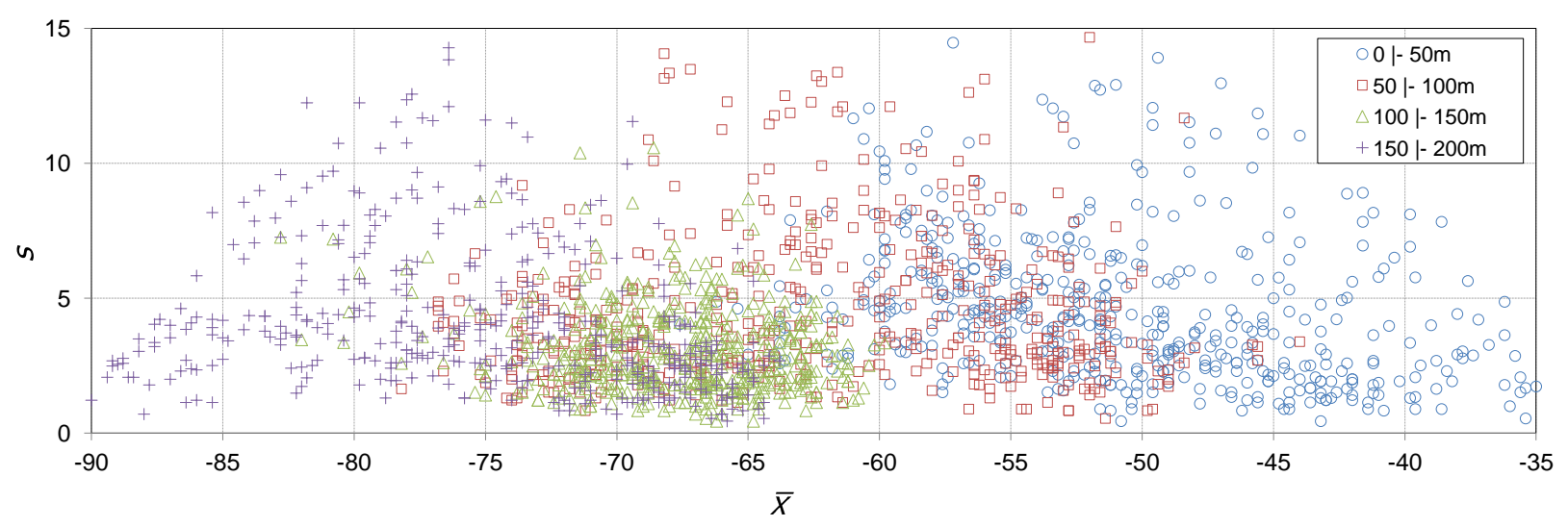

Figura 4.9: Ilustração das instâncias de duas dimensões definidas por $\hat{I}_{1 . .500}=\{\bar{X}, s, d\}$ para um $\triangle=50 \mathrm{~m}$

esta técnica primeiro classifica todas as instâncias de treinamento, $\hat{I}_{n}$, a partir da instância de teste, $\hat{I}^{j}$, de acordo com uma determinada métrica (por exemplo, distância euclidiana). A instância de teste definida como o conjunto de parâmetros $\hat{I}^{j}=\{\bar{X}$, $s, \tilde{X}, R, f p V a l u e\}$, sendo os parâmetros opcionais, sob a condição que $\left|\hat{I}^{j}\right|>0$, é obtida no procedimento de estimação por meio de uma amostra de tamanho $m$. A distância predita da instância de teste são as $k$ instâncias $\hat{I}_{k}$ mais próximas de $\hat{I}^{j}$ de acordo com a métrica definida. O valor de $k$ é escolhido empiricamente para otimizar o desempenho, normalmente é efetuada uma média entre os $k$ vizinhos mais próximos de $\hat{I}^{j}$.

\subsection{Resultados}

Nesta Seção são descritos os resultados da avaliação. Pela razão da quantidade de parâmetros, não foram avaliados todos os possíveis casos. Para realizar a avaliação utilizou-se os dados tratados conforme descrito na Seção 4.2. Os dados foram ordenados de maneira crescente por distância e lidos sequencialmente, para cada $m$ beacon lido foi gerada uma instância exemplo $\hat{I}$ até o total de $n$ por intervalo, os demais beacons foram utilizados como instâncias de teste $\hat{I}^{j}$.

Na Subseção 4.5.1 é realizada uma avaliação geral de desempenho. Com base na avaliação geral foram selecionados os casos para as avaliações subsequentes. Na Subseção 4.5.2 é avaliado o impacto do valor de $k$ e na Subseção 4.5.3 é avaliado o impacto dos valores de $m$ e $\triangle$. 


\subsubsection{Avaliação geral}

Para obter uma visão geral do desempenho, inicialmente foram utilizados os parâmetros e os respectivos valores descritos na Tabela 4.3. A métrica usada no $k$-NN foi a distância euclidiana $\mathbb{k}$, definida na Equação 4.2, sendo $x$ um parâmetro, tal que $\left\{x \in \hat{I}^{j}\right\}$, e o número de parâmetros é igual a $\rho=\left|\hat{I^{j}}\right|$.

$$
\mathbb{k}\left(x_{i}, x_{j}\right)=\sqrt{\sum_{z=1}^{\rho}\left(x_{i, z}-x_{j, z}\right)^{2}}
$$

Tabela 4.3: Parâmetros e valores da avaliação geral

\begin{tabular}{l|l|l}
\hline Parâmetro & Descrição & Valor \\
\hline$\triangle$ & Intervalo de distância & $10 \mathrm{~m}$ \\
$m$ & Tamanho da amostra de cada instância & 10 beacons \\
$k$ & Número de instâncias vizinhas selecionadas & 1 instância \\
$n$ & Número de instâncias exemplos $\hat{I}$ no buffer & 400 instâncias \\
$\aleph$ & Número de instâncias $\hat{I}^{j}$ avaliadas & 2026 instâncias \\
\hline
\end{tabular}

Na Tabela ?? estão algumas combinações dos parâmetros $[\bar{X}, s, \tilde{X}, R, f p V a l u e]$ e os respectivos resultados para uma visão geral do desempenho. A combinação dos parâmetros foi escolhida com a finalidade de avaliar medidas de posição como a média $\bar{X}$ e a mediana $\tilde{X}$, combinadas com parâmetros de medidas de dispersão como o desvio padrão $s$ e amplitude $R$. As colunas da Tabela 4.4 representam: a sigla das combinações dos parâmetros usadas para facilitar a descrição das avaliações; a taxa de acerto do intervalo estimado com relação ao intervalo correto $(\tau)$; o erro médio absoluto em metros, calculado por $\varepsilon=\frac{\sum_{e=1}^{\aleph}\left|\bar{d}_{e}-d_{e}^{j}\right|}{\aleph}$, sendo $\bar{d}$ a distância estimada e $d^{j}$ a distância real; e por fim, os parâmetros utilizados na função $\mathbb{k}$ da distância euclidiana.

Na Tabela 4.4 são apresentados os resultados ordenados pela taxa de acerto, $\tau$, do intervalo $\triangle$. Os melhores desempenhos da avaliação geral estão destacados, considerando a taxa de acerto do intervalo, $\tau$, a utilização da combinação $f p s R$ ( $f p$ Value, amplitude e desvio padrão) e $f p R$ ( $f p$ Value e amplitude) tiveram o mesmo desempenho, porém é mais vantajoso usar $f p R$ por possuir um menor número de parâmetros $\hat{I}^{j}$. Enquanto, considerado o erro médio absoluto, $\varepsilon$, o melhor desempenho foi para a combinação $f p s$ ( $f p$ Value e desvio padrão).

Os resultados da avaliação justificam o uso da combinação de parâmetros porque obtiveram as melhores taxas de acertos $\tau$ e os menores erros $\varepsilon$. Contudo, o aumento do número de parâmetros, para $\phi>2$, não mostrou uma melhora razoável no desempenho. Desta maneira, a continuação desta avaliação segue sobre a combinação de maior taxa de acerto e a de menor erro médio, $f p R$ e $f p s$, respectivamente. 
Tabela 4.4: Ranking da avaliação geral ordenado pela taxa de acerto

\begin{tabular}{l|c|c|l}
\hline Sigla & Taxa de acerto $\tau(\%)$ & Erro médio $\varepsilon(m)$ & Parâmetros de $\hat{I}^{j}$ \\
\hline$f p s R$ & 14 & $32,6 \pm 1,3$ & $f p$ Value, $s$ e $R$ \\
$f p R$ & 14 & $32,8 \pm 1,3$ & fpValue e $R$ \\
$f p M X$ & 13 & $34,3 \pm 1,4$ & fpValue, $\tilde{X}$ e $\bar{X}$ \\
$f p s$ & 12 & $31,6 \pm 1,2$ & fpValue e $s$ \\
$f p s X R$ & 12 & $32,6 \pm 1,3$ & fpValue, $\bar{X}, s$ e $R$ \\
$X R$ & 12 & $34,8 \pm 1,3$ & $\bar{X}$ e $R$ \\
$X s R$ & 11 & $34,5 \pm 1,3$ & $\bar{X}$, e $R$ \\
$f p M$ & 11 & $35,6 \pm 1,4$ & $f p$ alue e $\tilde{X}$ \\
$f p X$ & 11 & $35,4 \pm 1,4$ & $f p V$ alue e $\bar{X}$ \\
$M X$ & 11 & $34,3 \pm 1,3$ & $\tilde{X}$ e $\bar{X}$ \\
$M s R$ & 11 & $36,1 \pm 1,4$ & $\tilde{X}, s$ e $R$ \\
$M s$ & 11 & $37,9 \pm 1,5$ & $\tilde{X}$ e $R$ \\
$M R$ & 11 & $33,6 \pm 1,3$ & $\bar{X}$ e $s$ \\
$X s$ & 11 & $39,2 \pm 1,4$ & $\bar{X}$ \\
$X$ & 10 & $50,0 \pm 1,7$ & $f p$ alue \\
$f p$ & 8 & & \\
\hline
\end{tabular}

Os gráficos da Figura 4.10 são análises para $f p R$ e $f p s$. O primeiro gráfico, Figura 4.10(a), é a Função de Distribuição Acumulada (FDA) do erro médio absoluto para as estimativas realizadas por $f p R$ e $f p s$ comparadas com a estimava aleatória. Apesar de $f p R$ e $f p s$ possuírem um erro $\varepsilon$ de $\approx 30 \mathrm{~m}$, se comparado com a estimava aleatória, o uso da aplicação é justificável. O segundo e o terceiro gráficos, Figuras 4.10(b) e 4.10(c), respectivamente, representam a distribuição do erro $\delta$ para cada intervalo de distância com $\triangle=10 \mathrm{~m}$. Os resultados mostram que nos dois casos ocorrem, eventualmente, estimativas muito ruins, com erros entre $[100 \leqslant \delta \leqslant 150 \mathrm{~m}]$ para os intervalos de distância de 20 a $80 \mathrm{~m}$ e de 130 a $200 \mathrm{~m}$. Analisando os dois boxplots é verificado que existe uma maior dispersão do erro $\delta$ para $\triangle \geqslant 120 m$ considerando o caso $f p R$.

\subsubsection{Impacto do valor de $k$ vizinhos}

O algoritmo $k$-NN permite escolher o valor dos $k$ vizinhos, $\hat{I}_{n}$, mais próximos de $\hat{I}^{j}$ com base na função $\mathbb{k}$. Para $k>1$ foi utilizada a média das distâncias $\bar{d}$, calculada por $\frac{\sum_{n=1}^{k} \bar{d}_{n}}{k}$, obtidas das instâncias $\hat{I}_{n}$. O gráfico da Figura 4.11(a) apresenta os erros médios $\varepsilon$ para $f p R$ e $f p s$, o erro médio teve uma redução de $6 m$ para $k=3$, contudo para valores maiores que três, $k>3$, não ocorreram uma redução significativa no erro $\varepsilon$. No gráfico 4.11(b) é observado o comportamento da média do erro $\delta$, calculado por $\frac{\sum_{e=1}^{w}\left|\bar{d}_{e}-d_{e}^{j}\right|}{w}$, tal que $w$ é o número de instâncias $\hat{I}^{j}$ do intervalo, os casos $f p R$ e $f p s$ tiveram comportamento semelhante para $k=3$. Nos intervalos de 90 a $100 \mathrm{~m}$ ocorreram os maiores erros e no intervalo de $30 \mathrm{~m}$ 


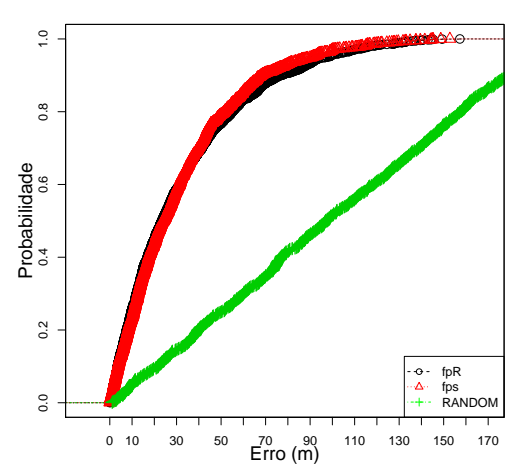

(a)

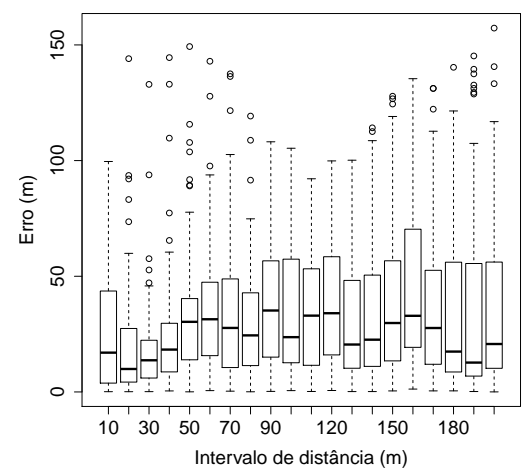

(b)

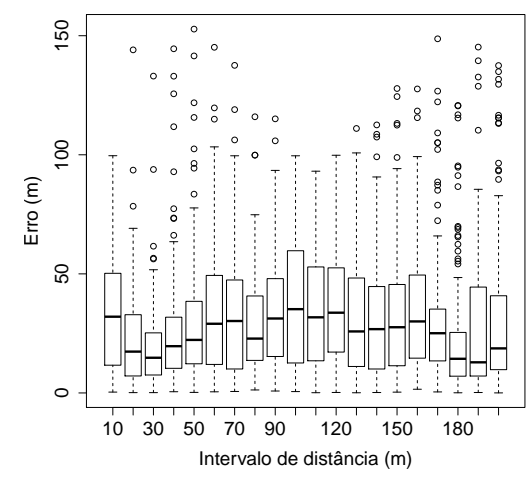

(c)

Figura 4.10: a) FDA do erro para $f p R$ e $f p s$ comparando com erro aleatório.

Distribuição do erro $\delta$ em metros para cada intervalo de distância com $\triangle=10 \mathrm{~m}$, b) fpR e c) $f p s$

o menor erro, esse comportamento pode ser explicado pelo gráfico da Figura 4.9, porque as instâncias $50 \vdash 100$ e $100 \vdash 150 \mathrm{~m}$ estão sobrepostas, provocando o aumento do erro, e as instâncias de $0 \vdash 50 \mathrm{~m}$ não estão muito sobrepostas com outras instâncias, reduzindo o erro. Entretanto, os pontos críticos são os intervalos de 10 e $20 \mathrm{~m}$ cujos erros médios por intervalo são maiores que o intervalo, $\delta>\triangle$, e também do erro médio, $\delta>\varepsilon$.

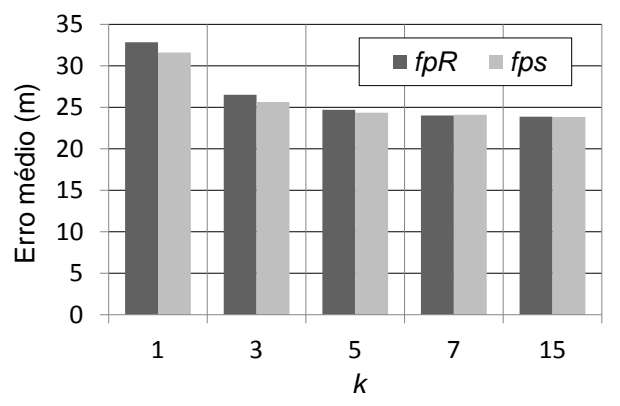

(a)

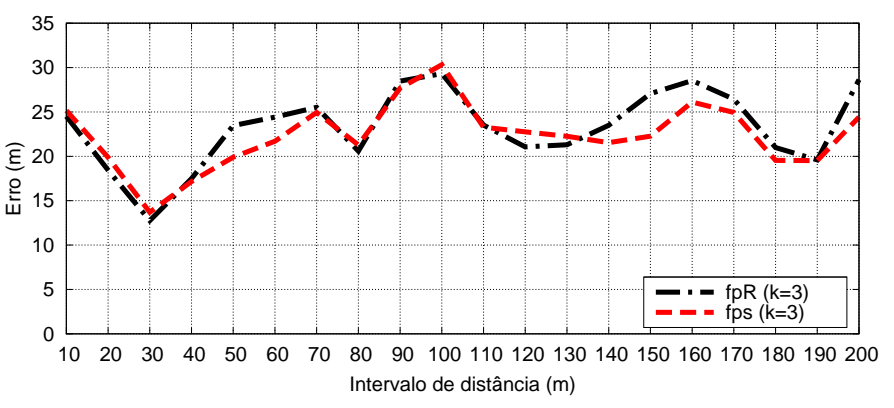

(b)

Figura 4.11: a) Erro médio $\varepsilon$ para diferentes valores de $k$ b) Erro médio $\delta$ até $95^{\mathrm{O}}$ percentil, por intervalo de distância com $\triangle=10 \mathrm{~m}$

\subsubsection{Impacto da quantidade de amostras $m$ e do intervalo}

Esta avaliação utilizou o valor de $k=3$ e o caso $f p s$ porque apresentaram os melhores resultados na avaliação da Subseção 4.5.2. O gráfico da Figura 4.12(a) mostra redução do erro médio absoluto $\varepsilon$ para aumento dos valores de $m$. Os resultados mostram que até $m=25$, ocorreram reduções significativas no erro $\varepsilon$. A melhora no desempenho foi a redução na média de 13, $1 m$ no erro $\varepsilon$, na comparação de $m=5$ com $m=30$. Por outro lado, como $m$ é o tamanho das amostras de beacons para a geração da instância $\hat{I}$, para $m=30$ implica que 
a referência $r_{j}$ necessita enviar 30 beacons em sequência para $v$ gerar uma instância. Os casos $m \gg 30$ não foram considerados porque ocorreu uma escassez do número de instâncias de testes $\aleph$, como pode ser observado no gráfico pela linha do número de instâncias $\hat{I}^{j}$ testadas para cada $m$.

O gráfico 4.12(b) é a taxa de acerto $\tau$ para diferentes valores de intervalo $\triangle$ e $m$. O comportamento da taxa de acerto foi linear com aumento do intervalo $\triangle$. O valor de $m$ teve um impacto maior para intervalos grandes, $\triangle=40 \mathrm{~m}$, com uma diferença de $\approx 10 \%$ na taxa de acerto na comparação de $m=5$ com $m=25$. A melhor taxa de acerto atingiu $60 \%$ para $\triangle=40 m$ e $m=25$, o resultado é útil para aplicações que demandam menor precisão da distância e maior taxa de acerto, por exemplo, uma aplicação de privacidade em que o motorista pode inibir a propagação da posição do GPS do veículo porque deseja ofuscar a localização exata, declarando uma região estimada do veículo (Ardagna et al., 2011).

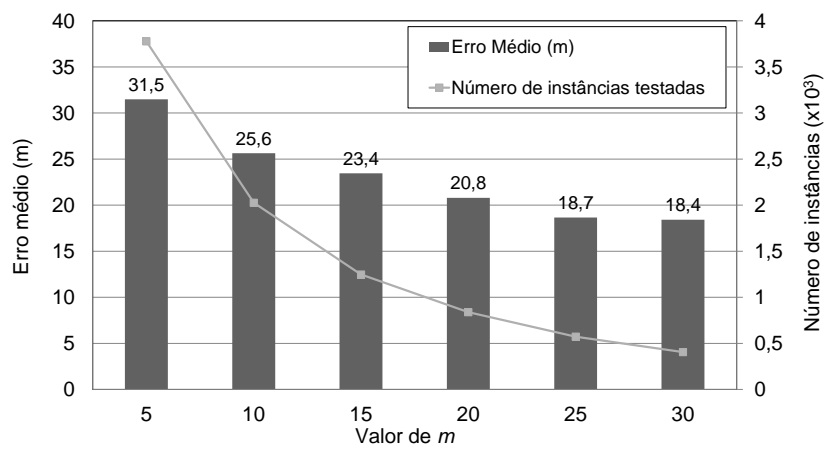

(a)

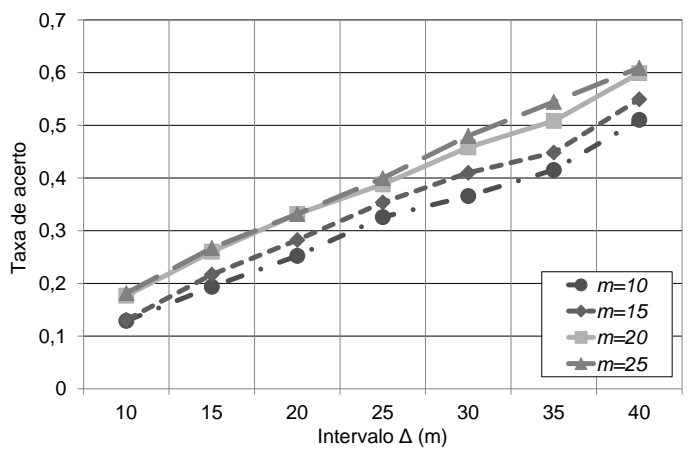

(b)

Figura 4.12: a) Erro médio absoluto $\varepsilon$ para diferentes valores de $m$ e b) Taxa de acerto para diferentes valores de $\triangle$ e $m$

\subsection{Considerações finais}

Neste estudo foi abordado o problema de estimar a distância entre o veículo e a RSU ou entre veículos. Uma aplicação para estimar distâncias pode dar suporte a falhas do dispositivo GPS e a outras aplicações como de posicionamento seguro (Capkun e Hubaux, 2006), privacidade (Ardagna et al., 2011) ou de segurança (safety) (Torrent-Moreno et al., 2009) em redes veiculares. A solução proposta utiliza o RSSI obtido da comunicação por beaconing e uma aplicação que representa os intervalos de distância em função do RSSI por meio de instâncias. A aplicação foi implementada e avaliada por meio de dados coletados em experimento em ambiente real. Para tanto, foram realizadas quatro coletas por meio de beaconing no tesbed com um veículo e uma RSU, análises do comportamento RSSI e avaliação de diversos parâmetros da aplicação. Os resultados mostraram que o erro médio absoluto $\varepsilon$ na estimativa da distância pode variar de 18,4 a 31,6 $\mathrm{m}$ e a taxa de acerto $\tau$ do intervalo de 
distância de 12 a $60 \%$, considerando o uso dos parâmetros $f p$ Value $(f p)$, amplitude $(R)$ ou desvio padrão $(s)$. Além disso, as variações do erro dependem do valor de $k$ e $m$, o menor erro médio absoluto foi obtido com $k=3$ e $m=30$ e o crescimento da taxa de acerto é linear com relação ao aumento do intervalo de distância $\triangle$, com o $\triangle=40 m$ foi obtida uma taxa de acerto de $60 \%$.

O Capítulo seguinte ainda explora beaconing no cenário de redes veiculares para um protocolo de descoberta de serviços de maneira oportunística. 


\section{5}

\section{OSDP: Um protocolo de descoberta de serviços para redes veiculares}

As redes veiculares estão sendo definidas pelo padrão WAVE, que estabelece canais de comunicação para aplicações de segurança e não-seguras (non-safety) para veículos e RSU (Jiang e Delgrossi, 2008; Uzcategui e Acosta-Marum, 2009). Os canais de serviços (SCH), destinados a aplicações não-seguras, criam oportunidades significativas para a implantação de uma grande diversidade de aplicações e serviços para ambientes veiculares, especialmente de serviços cientes de localização. Neste contexto, os protocolos para a descoberta de serviços tornam-se um requisito importante para redes veiculares. Os avanços em protocolos de descoberta de serviços, cooperando com aplicações cientes de localização, estão concentrados em pesquisas relacionadas ao conceito de MANET. No entanto, a maioria das MANETs não leva em conta as particularidades de redes veiculares, principalmente as mudanças altamente dinâmicas de topologia da rede e a conectividade de curto tempo, ambas decorrentes do rápido movimento dos veículos. Essas particularidades impossibilitam a exploração da difusão de serviços, devido à dificuldade de assumir que a posição geográfica declarada pelo veículo está atualizada. O padrão WAVE possui facilidades para o gerenciamento desses fatores na rede veicular. Portanto, é importante que o padrão WAVE seja considerado no projeto de protocolos de descoberta de serviços de rede veiculares.

Diferentes estudos relacionados a protocolos de descoberta de serviços para redes veiculares foram realizados. Alguns trabalhos recentes são de Dikaiakos et al. (2007) que fornecem informações sobre as condições de tráfego e também sobre os serviços disponíveis às mar- 
gens da rodovia por meio de comunicação carro para carro. No entanto, com o aumento da densidade de rede, o número de pedidos pode não ser escalável. Boukerche et al. (2009) propõem um protocolo de descoberta de serviços baseados em localização, que é capaz de descobrir serviços com base na localização do serviço solicitado pelos motoristas. Entretanto, as falhas na comunicação durante as consultas de serviços podem afetar significativamente o desempenho do protocolo. Abrougui et al. (2010) propõem uma solução que tolera falhas na comunicação; o sistema é baseado na infraestrutura de rede local, integrando informações do serviço na camada de rede por meio de dois canais de comunicação, dependendo de duas interfaces sem fios no veículo.

Para melhorar a descoberta de serviços em redes veiculares, foi proposto o Opportunistic service discovery protocol (OSDP). O protocolo é diferente de outras propostas da literatura em alguns aspectos. Primeiro, o protocolo foi concebido considerando o padrão WAVE. Segundo, OSDP é um protocolo de camada-2 que opera por meio da comunicação DSRC, enquanto que o protocolo de Dikaiakos et al. (2007) é uma aplicação executada na camada-7, e os outros protocolos (Boukerche et al., 2009; Abrougui et al., 2010) operam na camada-3. Por fim, esses outros estudos dependem do acesso à Internet ou uma interconexão com a RSU para troca de dados, enquanto que OSDP é baseado no contato oportunista e na técnica de store-and-forward ou store-carry-and-forward. Assim, OSDP pode lidar com interrupções de acesso a RSU ou à Internet.

Neste estudo é definido comunicações oportunistas como sendo comunicações ocasionais entre veículos. Nenhuma suposição é feita quanto à existência de uma pilha de protocolos completa para comunicações infraestruturadas entre veículos. Serviços oferecidos por um Point Of Interest (POI) e o veículo de destino podem não estar conectados à mesma rede, no mesmo momento. Além disso, store-and-forward denota o fato de que os anúncios dos serviços são armazenados no veículo para aguardar o contato de outros veículos à procura de serviços relacionados. Quando um serviço desejado corresponde ao armazenado, a informação sobre o serviço é encaminhada.

O OSDP é um protocolo lightweight de camada-2, o objetivo é localizar e fornecer informações de serviços cientes da localização para os veículos, no decorrer do caminho até destino final da viagem. Em vez de usuários (condutor ou passageiros) utilizarem smartphones com conexões $3 G / 4 G$ para encontrar os serviços desejados por meio da Web, OSDP pode ser integrado no sistema do veículo, interagindo com os usuários por meio de uma interface (por exemplo, a tela do sistema de navegação do carro) para procurar os serviços desejados. As informações retornadas (por exemplo, localizações e tabelas de preços de postos de gasolina, localizações e menus de restaurantes) ajudam os usuários que estão interessados no serviço local ou essas informações podem, eventualmente, despertar o interesse do usuário. Além disso, os anúncios dos serviços podem estender a funcionalidade a bordo dos sistemas de navegação e aplicações da Internet por meio da atualização das informações de POI. 
A validação do OSPD foi por meio de prova de conceito. A avaliação foi no testbed com cinco roteadores wireless, os mesmos utilizados na plataforma V-Beacon (Yokoyama et al., 2013), e realizada em dois experimentos independentes: i) comunicação veículo-a-RSU (V2R) e ii) comunicação veículo-a-veículo (V2V). Para o V2R, foi aumentado o número de serviços oferecidos aos veículos de 1 a 7 . Para o V2V, foi aumentado o número de veículos vizinhos de 1 a 7 . Os resultados mostraram a corretude e viabilidade do OSDP para diferentes tempos de contado e densidades de veículos ou RSUs.

\subsection{Cenários e definições}

Nesta Seção se descreve o cenário visionário com a infraestrutura WAVE implantada e exemplos de funcionamento do OSDP. Por simplicidade, o cenário não especifica o modelo de negócios entre POI e provedores, admitindo-se que as RSUs são capazes de propagar informações de serviços locais utilizando mensagens tipo broadcast. Por fim, com base no cenário, definiu-se as principais entidades envolvidas no OSDP.

\subsubsection{Exemplos de uso do OSDP}

É assumido um cenário urbano e de rodovia com a infraestrutura de redes veiculares de alguma forma já implantada, onde as RSUs e veículos estão equipados com built-in wireless interfaces, recursos mínimos de processamento e memória e dispositivos GPS. As questões de segurança e privacidade em redes veiculares estão além do escopo do OSDP e não são abordadas neste estudo. Mais detalhes sobre este assunto podem ser encontrados no estudos de (Antolino Rivas e Guerrero-Zapata, 2012; Lu et al., 2008; Malandrino et al., 2013).

Os serviços de segurança e não-seguros (por exemplo, de entretenimento) são distintos. Os serviços de segurança serão fornecidos no canal de alta prioridade para permitir a comunicação em todas as situações críticas, por exemplo, encontrar um hospital em uma situação de emergência. Os serviços não-seguros serão fornecidos no canal de baixa prioridade para melhorar a experiência dos usuários durante sua viagem. OSDP destina-se a serviços que não envolvam segurança, como uma alternativa para os usuários encontrarem, de maneira oportuna, serviços locais. Portanto, os usuários, às vezes, podem ter experiências negativas, como respostas não satisfatórias ou fracasso nas consultas.

O OSDP pode lidar com os tipos de serviços ilustrados na Figura 5.1. Serviços à margem da rodovia periodicamente transmitem mensagens usando beacons com informações do serviço local, por exemplo: a $R S U_{1}$ transmite a tabela de preços do posto de gasolina, a $R S U_{2}$ transmite os preços das diárias do hotel e a $R S U_{3}$ transmite a taxa de estacionamento. Os veículos, $\left\{v_{1}, v_{2}, v_{3}\right\}$, próximos das $R S U s$ podem ouvir esses beacons e armazenar 
as informações recebidas. Supondo que o usuário do veículo $v_{2}$ esteja interessado em receber informações sobre postos de gasolina ao longo do caminho, o usuário pode usar o OSDP para encontrar o posto de gasolina desejado ao longo da estrada. Para tanto, OSDP de $v_{2}$ verifica os dados armazenados nele e consulta o outro veículo próximo, $v_{1}$, para reunir mais informações. O veículo $v_{1}$ responde para $v_{2}$ com as informações recebidas da $R S U_{1}$, no momento que $v_{1}$ passou pelo posto de gasolina. Da mesma forma, o veículo $v_{1}$ recebeu e armazenou informações sobre o hotel e o estacionamento quando passou pela $R S U_{2}$ e $R S U_{3}$, respectivamente. O usuário do veículo $v_{3}$ está à procura de uma livraria, mas ele não encontra, porque $v_{4}$ não passou por nenhuma livraria. No entanto, o usuário do veículo $v_{3}$ pode continuar a consultar os veículos que encontra ao longo do caminho (por exemplo, quando encontrou $v_{2}$ ) até encontrar o serviço desejado.

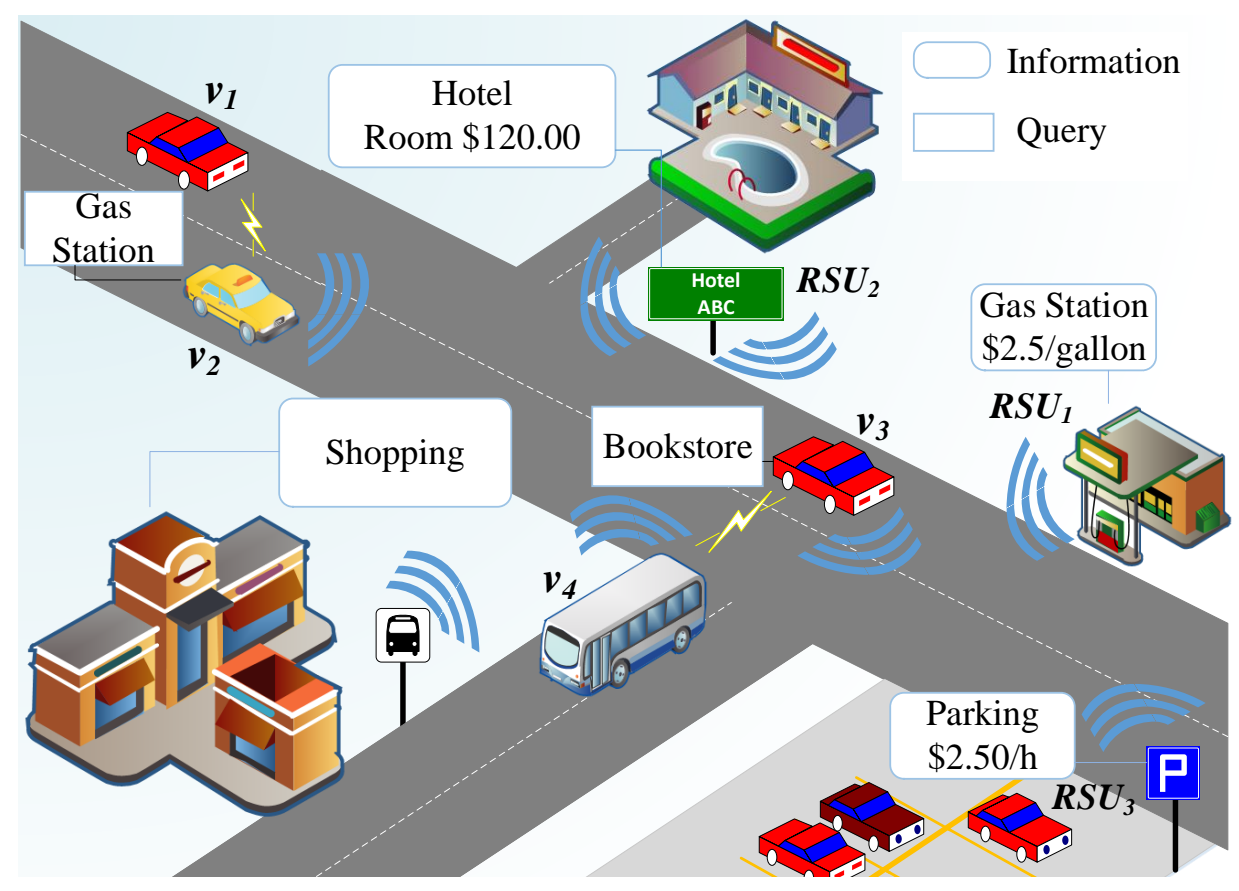

Figura 5.1: Exemplos do uso do OSDP na rede veicular. Os veículos $\left\{v_{1} \ldots v_{4}\right\}$ estão ouvindo e armazenamento beacons transmitidos pela $\left\{R S U_{1} \ldots R S U_{3}\right\}$. Os veículos por meio de contatos oportunos armazenam e encaminham as informações sobre os serviços descobertos (Yokoyama et al., 2014)

\subsubsection{Definições do sistema}

As entidades no cenário visionário de descoberta de serviços em redes veiculares são descritas a seguir:

- Veículo: Um veículo $v$ (carro, ônibus, moto ou caminhão) é equipado com dispositivos internos necessários para a rede veicular, pelo menos, a interface de rede sem fio, GPS e um computador de bordo. Assim, todos os veículos $v$ que implementam OSDP são 
capazes de receber informação do serviço transmitida pela $R S U$, e armazená-la em uma cache $c$. Além disso, $v$ pode consultar a cache $c$ de veículos vizinhos dentro da faixa de sua frequência e cobertura do rádio.

- RSU: RoadSide units são colocadas às margens das ruas, estradas, parques e outras localidades. Para cada tempo T, eles transmitem para os veículos, v, beacons que transportam informação do serviço local oferecido pelos POI da região geográfica.

- Serviço: Serviços são oferecidos por um POI para o usuário. Um serviço $s$ é definido por uma tupla $\langle N, P, E, D\rangle$, sendo $N$ o nome genérico do serviço (por exemplo, farmácia, livraria ou posto de gasolina), $P$ a posição geográfica com o par latitude-longitude, $E$ tempo de vida em segundos para o serviço expirar e $D$ uma descrição adicional sobre o serviço oferecido (por exemplo, endereço, nome da empresa e número de telefone).

Portanto, o problema é definido como:

Seja $R S U_{k}$ que propaga os serviços $s_{k}=\left\langle N_{k}, P_{k}, E_{k}, D_{k}\right\rangle$ e $V=\left\{v_{1} \ldots v_{j}\right\}$ o conjunto de veículos que ouvem e armazenam $s_{k}$ na sua cache $c_{j}$. Quando um veículo $v_{i}$ precisa encontrar $s_{k}$ e $s_{k} \notin c_{i}, v_{i}$ envia uma consulta $q_{i}=\langle N, D\rangle$ aos veículos vizinhos em $V$ sobre a cobertura RF de $v_{i}$, então $\left\{\forall v_{j} \mid s_{k} \in c_{j}\right\}, v_{j}$ responde $r_{j}=\left\{s_{1} \ldots s_{n}\right\}$ a $v_{i}$. Para cada $s_{k}$ diferente respondido, $v_{i}$ atualiza sua $c_{i}$.

Hipótese: $s_{k}$ é transmitido pela $R S U_{k}$ e ouvido por $V$. Se $v_{i}$ não passar pela cobertura $\mathrm{RF}$ da $R S U_{k}, v_{i}$ pode achar $s_{k}$ quando $v_{i}$ encontrar com um veículo de $V$.

\subsection{Protocolo de descoberta de serviço oportunista}

Nesta Seção, são detalhadas as mensagens, fases e procedimentos do OSDP. Primeiro, são definidos os três tipos de mensagens utilizadas por OSDP e é discutido o custo-benefício ao adotar a eXtensible Markup Language (XML) como um formato de dados do serviço. Segundo, são descritas as fases de OSDP. Por fim, são explicados os procedimentos do protocolo nas $R S U$ e veículos.

\subsubsection{Tipos de mensagens}

O OSDP é um protocolo de comunicação baseada em beaconing. As mensagens são tratadas na camada física (WAVE PHY) e na camada de controle de acesso ao meio (WAVE MAC) do WAVE. Portanto, as mensagens OSDP são encapsuladas na camada 2. Três tipos de mensagens são definidas: 
i) $\boldsymbol{M}$ é a mensagem que descreve o serviço $s$ que é transmitida pela $R S U$ a cada intervalo $T$ de tempo;

ii) $Q$ é uma mensagem de consulta que contém o nome do serviço $N$ e a descrição $D$. Para encontrar um serviço desejado, um usuário do veículo $v_{i}$ envia uma consulta $q_{i}$ aos veículos vizinhos em $V$;

iii) $\boldsymbol{R}$ consiste na mensagem $r_{j}$, em que os veículos vizinhos em $V$ enviam para $v_{i}$ uma resposta sobre os serviços $\left\{s_{1} \ldots s_{n}\right\}$ encontrados na cache $c_{j}$ deles. $R$ é uma mensagem de resposta tipo unicast para $v_{i}$.

As mensagens possuem os mesmos campos por frame, como ilustrado na Figura 5.2, sendo o campo TYPE um inteiro sem sinal para distinguir os tipos de mensagens, LENGHT é um inteiro sem sinal para definir o tamanho em bytes do campo XMLDATA e, por fim, o XMLDATA é um documento XML com tamanho variável. É importante notar que os três tipos de mensagens serão transportados por um beacon ou um probe response juntamente com outros campos ordinários do frame beacon/probe, de acordo com o formato do padrão WAVE.

\begin{tabular}{|l|l|l|}
\hline TYPE & LENGTH & XMLDATA \\
\hline
\end{tabular}

Figura 5.2: Formato da mensagem para os três tipos, $M, Q$ e $R$, encapsulados no beacon ou probes response

O campo XMLDATA carrega um documento XML com as hierarquias <service $>$ e $<$ description $>$. Por exemplo, em um anúncio do serviço $s$, a mensagem $M$ é mostrada no Código 5.1. A hierarquia <service $>$ define a informação obrigatória sobre $\langle N, P, E\rangle$ usando as tags de atributos $<$ name $>$, $<$ latitude $>$, <longitude $>$ e $<$ timelife $>$. A hierarquia $<$ description $>$ é opcional. Ela tem os atributos para detalhar o serviço, tais como $<$ url $>$, <phone $>$ e $<$ address $>$. Estes atributos são flexíveis e podem ser selecionados para representar melhor o serviço. A mensagem de resposta $R$ segue a mesma estrutura XML da mensagem $M$.

Para as mensagens $Q$, o documento XML também tem as hierarquias <service> e <description $>$. Contudo, os atributos são mais simples. Somente $<$ name $>$ da hierarquia $<$ service $>$ é obrigatória. Os atributos opcionais na hierarquia < description $>$ destinam-se a delimitar a pesquisa e reduzir o número de mensagens de resposta $R$. Por exemplo, um atributo $<$ max_distance> poderia especificar a distância máxima, tolerada pelo usuário, para chegar ao destino do serviço $s$.

Estamos cientes que a escolha do formato de dados em XML incorre em overhead na comunicação, pelo motivo das tags de marcação da linguagem. Por outro lado, os sistemas dos veículos e os bancos de dados locais, provavelmente conterão dados em formatos 
incompatíveis, uma vez que diversos tipos de serviços serão oferecidos e cada um pode ter informações e formatos de dados diferentes. Com a finalidade de minimizar o problema de semântica e compatibilidade dos dados, o OSDP usa XML (por exemplo, Código 5.1) nas mensagens para facilitar o compartilhamento de informações. Os documentos XML são estruturados em formato de texto simples, que permite o uso de métodos de armazenamento e processamento de dados independentes de plataformas de hardware ou software. Isso é possível porque a criação de dados é definida por tags capazes de descrever as principais características de qualquer serviço arbitrário, facilitando, assim, serem compartilhados por diferentes aplicações. Outra vantagem é a possibilidade de definir um XML scheme, sempre que o acesso à Internet estiver disponível, pode ser usada para melhorar a descrição da estrutura de um documento XML.

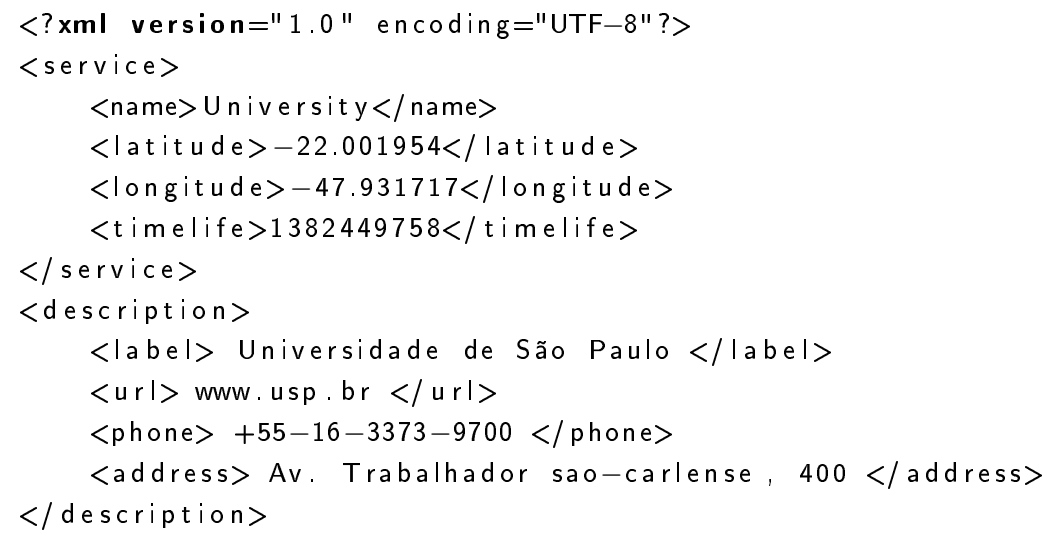

Código 5.1: Exemplo de um documento XML carregado por uma mensagem $M$.

\subsubsection{Fases do OSDP}

O OSDP trabalha em três fases, Beaconing, Caching e Query, conforme ilustrado na Figura 5.3 , as fases são independentes e possuem as seguintes funções:

i) Beaconing: As RSUs transmitem, periodicamente, a cada intervalo $T$, um beacon $M$, carregando informação sobre os serviços $\left\{s_{1}, \ldots, s_{n}\right\}$.

ii) Caching: Os veículos $v_{j}$ de $V$ que passam pela cobertura $R F$ da $R S U$ recebem o beacon $M$ e armazenam como um serviço $s$. Se o serviço $s$ já foi armazenado anteriormente na cache $c_{j}$ do veículo $v_{j}$, então $M$ é descartado. Caso contrário, $s$ é armazenado na cache $c_{j}$. Os veículos também verificam periodicamente a cache $c_{j}$ para remover os serviços expirados $\{\forall s \mid E<$ hora atual $\}$.

iii) Query: A consulta ocorre quando um usuário do veículo $v_{i}$ quer encontrar um serviço $s$. $v_{i}$ transmite um beacon de consulta com mensagem $Q$ para os veículos vizinhos $V$. 


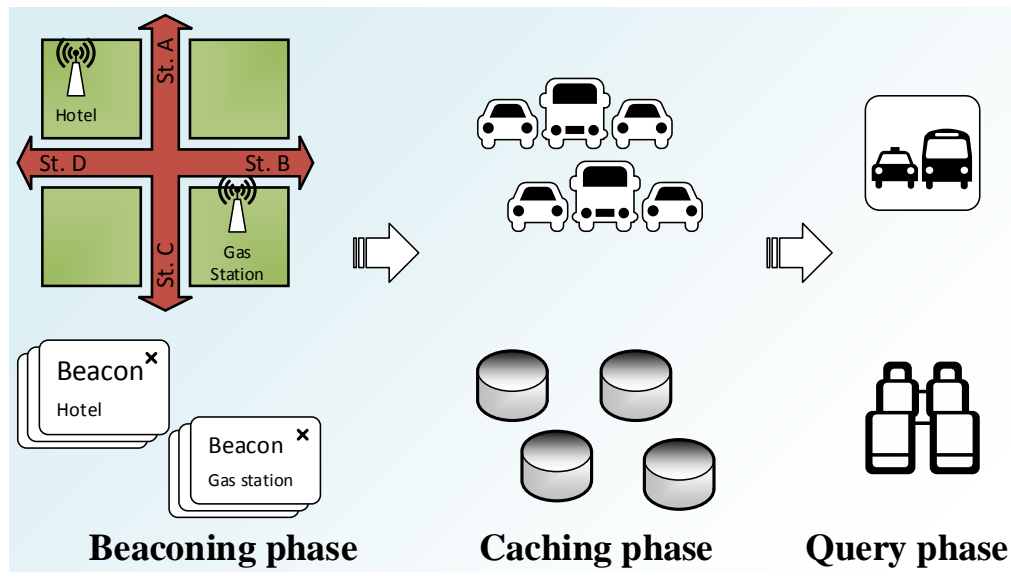

Figura 5.3: Fases do OSDP. A $R S U$ transmite o serviço. Os veículos próximos da $R S U$ ouvem e armazenam na cache as informações. O usuário que deseja encontrar um serviço consulta a cache dos outros veículos próximos a ele (Yokoyama et al., 2014)

Os veículos $v_{j}$ que receberam $Q$ verificam as caches $c_{j}$ deles para procurar serviços armazenados que sejam relacionados a $s$. Se um ou mais serviços forem encontrados, então cada $v_{j}$ envia uma resposta $R$ tipo unicast para $v_{i}$ com os serviços $\left\{s_{1} \ldots s_{n}\right\}$ encontrados. Quando $v_{i}$ recebe as mensagens $R$, a cache $c_{i}$ é atualizado com os serviços recebidos.

Estudos da literatura mostram que o uso de beacons com multi-hop podem degradar o desempenho da rede veicular (Slavik et al., 2012). Por isso, em todas as fases, as mensagens de $M, Q$ e $R$ são enviadas em single-hop. Apesar dos beacons serem single-hop, pela razão do paradigma store-and-forward, podemos considerar que os serviços são disseminados por meio de multi-hop. Além disso, OSDP adota a resposta $R$ como uma mensagem unicast, porque dois ou mais veículos $v_{i}$ podem enviar ao mesmo tempo consultas diferentes $Q$ e os veículos $v_{j}$ poderiam enviar as respostas $R$ também ao mesmo tempo. Portanto, a mensagem unicast permite a cada veículo $v_{i}$ distinguir as respostas $R$ que são destinadas a ele. Uma vez que as consultas e respostas não possuem identificadores de origem e destino além dos endereços de MAC.

Algumas decisões de implementação podem afetar o desempenho do OSDP. Primeiro, a tecnologia escolhida para implementar a cache $c$ pode afetar o desempenho do tempo de resposta, devido ao tempo dispendido para localizar os dados. A escolha adequada do banco de dados pode poupar recursos de memória e tempo de busca. Segundo, o mecanismo de busca do serviço na cache, um bom mecanismo de consulta, pode retornar os serviços corretos que correspondem à consulta $Q$, assim evitando o overhead na rede causada por respostas inúteis para o usuário. Por fim, parâmetros como o número de serviços e o tempo que os serviços devem permanecer na base de dados podem ser otimizados de acordo com a maneira de utilização do veículo, pelo usuário. Por essas razões, o projeto do OSDP não especifica essas tecnologias, deixando a decisão para o desenvolvedor. 


\subsubsection{Operações do protocolo}

A operação do OSDP na $R S U$ é simples: basicamente, possui dois estados, um para transmitir o beacon $M$ e outro para esperar $T$ segundos antes de enviar o próximo beacon. Para o veículo $v$, o OSDP opera em cinco estados, como ilustrado na Figura 5.4. O OSDP inicia no estado Listen ouvindo as mensagens, $M, Q$ e $R$, ou à espera de consulta do usuário. De acordo com o tipo da mensagem, OSDP vai para diferentes estados. Se o tipo é $R$ ou $M$, OSDP vai para o estado Update. No estado Update, ele processa a atualização mensagem na cache $c$ e, em seguida, retorna ao estado Listen. Se o tipo é $Q$, ele vai para o estado Find para processar a consulta $Q$ pesquisando na cache $c$ o serviço $s$. Caso um ou mais serviços forem encontrados, OSDP vai para o estado Reply, caso contrário, ele retorna para o estado Listen. No estado Reply, são transmitidas as respostas $R$ e, em seguida, ele retorna ao estado Listen. Finalmente, quando o usuário do veículo quer encontrar um serviço, o OSDP vai para o estado Query e envia a consulta $Q$ de acordo com o serviço desejado pelo usuário.

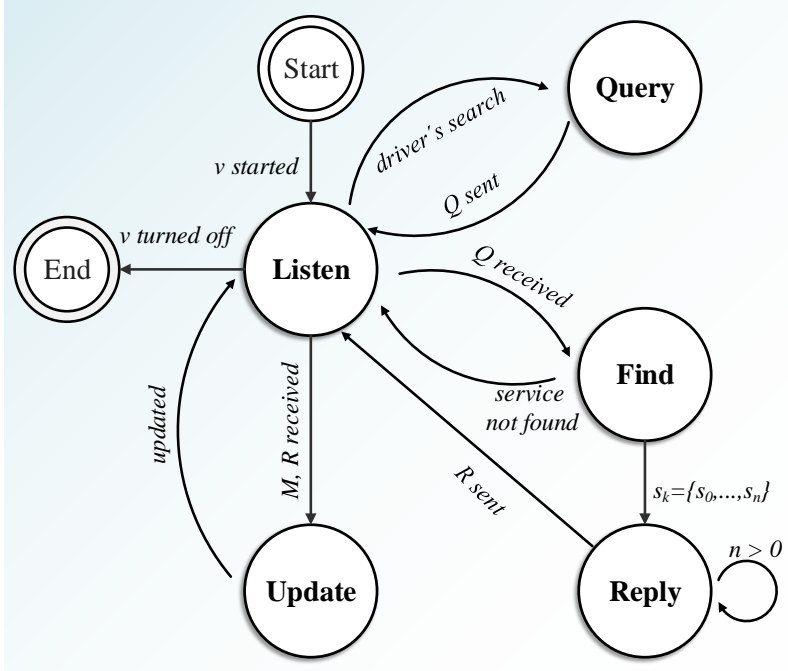

Figura 5.4: Máquina de estado OSDP no veículo (Yokoyama et al., 2014)

\subsection{Implementação e testbed}

O OSDP foi implementado e avaliado com base na plataforma V-Beacon (Yokoyama et al., 2013), como descrito no Capítulo 3.

\subsubsection{Implementação do OSDP}

A implementação do OSDP foi na linguagem $\mathrm{C}$. As mensagens, $M$ e $Q$, foram inseridas no beacon nativo do IEEE 802.11a. A base foi o framework beaconing, porém foram necessárias modificações para permitir inserir o documento XML do OSPD com mais de 255 bytes de 


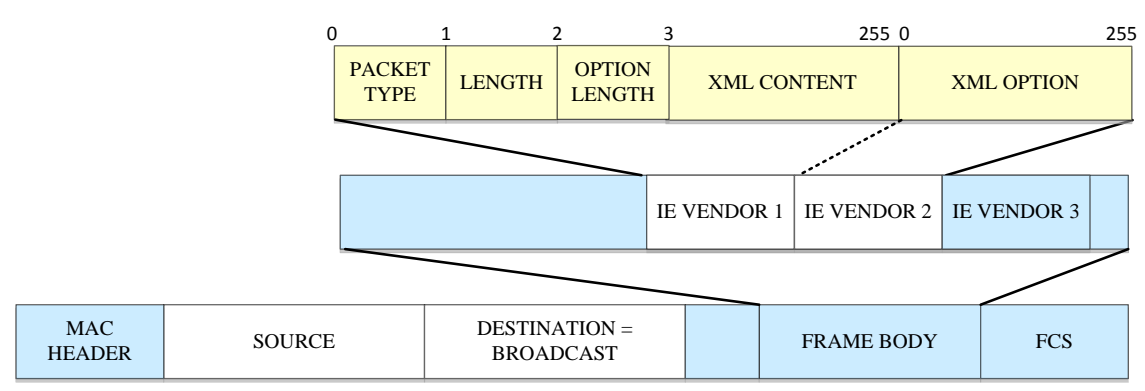

Beacon Frame

Figura 5.5: A estrutura do beacon nativo IEEE 802.11a. O documento XML foi inserido nos dois campos consecutivos IE Vendor no final do frame. A divisão do documento XML é por causa da limitação de comprimento máximo de 255 bytes por campo (Yokoyama et al., 2014)

comprimento. Para tanto, foram usados dois campos encadeados, o primeiro para <service> e o segundo para <description>, como ilustrado na Figura 5.5. A mensagem $R$ foi inserida utilizado o probe response, por ser uma mensagem unicast e o endereço MAC de destino do frame foi modificado de acordo com o $v_{i}$ que enviou a consulta.

A $R S U$ foi configurado para enviar uma mensagem $M$ por segundo. Este intervalo de envio é controlado pela chamada de sistema sleep(). A implementação do OSDP para o veículo foi com duas POSIX Threads, uma para enviar $Q$ ou $R$ e outra para receber $M$ ou $R$. Para extrair documento XML das mensagens $M$ ou $R$ foi utilizada a biblioteca libxml2. Para simplificar, a cache $c$ foi implementado como um buffer circular na memória e o mecanismo de busca procura sequencialmente no buffer e retorna os serviços cujo nome $N$ corresponde ao da consulta $Q$.

\subsubsection{Testbed}

Para prova de corretude e validação do OSDP foi implantado um testbed para prova de conceito. O testbed foi composto por cinco APs configurados na frequência de 5,8 $\mathrm{GHz}$, transmitindo a uma taxa de $6 \mathrm{Mbit} / \mathrm{s}$ e a uma potência de transmissão de $15 \mathrm{dBm}$. A disposição deles foi em uma fila, cada um separado por $\approx 50 \mathrm{~cm}$, como mostrado na Figura 5.6. As implementações do OSDP para a $R S U$ e para o veículo foram instaladas em todos os APs. Em alguns testes, o OSDP foi instanciado duas vezes no mesmo AP, em um esforço para aumentar o número de nós da rede.

\subsection{Experimentos e resultados}

O protocolo OSDP foi validado e avaliado por meio de dois testes que abrangem as três fases do OSDP. No primeiro, foram testadas as fases Beaconing e Caching, nas quais foram avaliados o envio de beacons $M$ por uma $R S U$ e de recebimento e armazenamento de $M$ por 


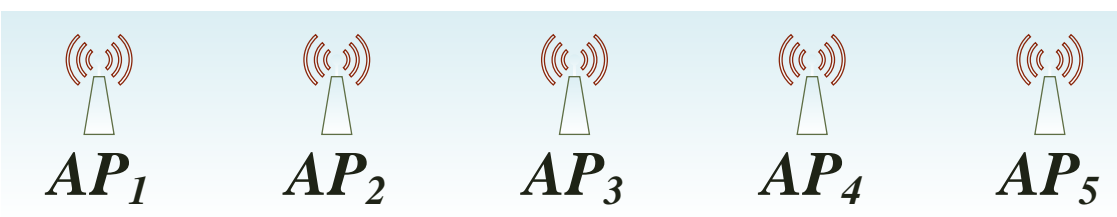

Figura 5.6: O testbed utilizado para prova de conceito e avaliação do desempenho de OSDP. Nas avaliações das fases Beaconing e Caching o $A P_{3}$ representa o veículo $v_{j}$ e outros APs representam $R S U$ s. Na a avaliação da fase da Query o $A P_{3}$ representa $v_{i}$ e os outros APs representam veículos vizinhos $V$

$v_{j}$. No segundo, foi testada a fase Query, com a finalidade de avaliar os procedimentos de consulta de descoberta de serviço. Por causa do custo, este estudo não realizou experimentos com veículos na estrada ou área urbana. Em vez disso, foi utilizada uma prova de conceito no testbed, os testes foram baseados na métrica de tempo inter-contato para a comunicação V2V e V2R, reproduzindo movimento do veículo artificialmente.

O tempo de inter-contato ocorre quando um veículo passa por uma área de cobertura RF da $R S U$ ou encontra um outro veículo na mesma direção ou na pista oposta na estrada. Rubinstein et al. (2009) demonstrou que o tempo inter-contato varia entre $10 s$ a $45 s$ para dois veículos em pistas opostas, com velocidades que variam entre $60 \mathrm{~km} / \mathrm{h}$ a $20 \mathrm{~km} / \mathrm{h}$, respectivamente. Em uma situação de tráfego urbano o tempo de inter-contato pode ser maior, por exemplo, um veículo parou em frente ao semáforo ou mesmo na rua com limite de baixa velocidade.

Nos testes, o tempo de inter-contato foi controlado por uma thread independente no $\mathrm{AP}_{3}$. Essencialmente, a thread acordava o OSDP por uma fração de tempo inter-contato e, depois colocava o OSDP para dormir por $3 \mathrm{~s}$. As densidades das $R S U, d_{r}$, e dos veículos vizinhos, $d_{v}$, variaram de 1 até 7 unidades. Definimos $d_{r}$ como o número das $R S U s$ que estão no alcance de RF de 1 (um) $v_{j}$ e $d_{v}$ como um número de veículos vizinhos $v_{j}$ que estão no alcance de RF de 1 (um) $v_{i}$.

O arranjo das instâncias do OSDP nos APs para cada densidade é mostrado na Tabela 5.1. Iniciamos os testes a partir de 1 e foi aumentado de 2 o número de $R S U$ e veículos. A densidade máxima foi de 7 unidades, devido à limitação do número de $A P$ s que possuímos. Para cada tempo de inter-contato, computamos a média e o intervalo de confiança a partir de uma amostra de 100 medições.

\subsubsection{Avaliação das fases I e II: Beaconing e Caching}

Esta avaliação considera um veículo $v_{j}$ recebendo beacons de uma ou mais $R S U$ s na comunicação V2R, como mostrado na Figura 5.7(a). A quantidade de $R S U$ s e o número de beacons $M$ que cada $R S U$ transmite por segundo variam conforme as densidades $d_{r}$, como mostra a Tabela 5.1, para $d_{r} \geqslant 5$ o OSDP foi instanciado duas vezes em alguns APs. O intervalo 
Tabela 5.1: Arranjo de instâncias do OSPD para cada densidade

\begin{tabular}{|c|c|c|c|c|c|c|}
\hline Fase $(\mathrm{s})$ & $d_{r} \mid d_{v}$ & $A P_{1}$ & $A P_{2}$ & $A P_{3}$ & $\boldsymbol{A P}_{4}$ & $A P_{5}$ \\
\hline \multirow{4}{*}{ I e II } & 1 & - & $R S U_{2}$ & $v_{j}$ & - & - \\
\hline & 3 & $R S U_{1}$ & $R S U_{2}$ & $v_{j}$ & $R S U_{4}$ & - \\
\hline & 5 & $R S U_{1}$ & $R S U_{2}{ }^{1}$ & $v_{j}$ & $R S U_{4}$ & $R S U_{5}$ \\
\hline & 7 & $R S U_{1}^{1}$ & $R S U_{2}{ }^{1}$ & $v_{j}$ & $R S U_{4}^{1}$ & $R S U_{5}$ \\
\hline \multirow{4}{*}{ III } & 1 & - & $v_{2}$ & $v_{i}$ & - & - \\
\hline & 3 & $v_{1}$ & $v_{2}$ & $v_{i}$ & $v_{4}$ & - \\
\hline & 5 & $v_{1}$ & $v_{2}^{1}$ & $v_{i}$ & $v_{4}$ & $v_{5}$ \\
\hline & 7 & $v_{1}^{1}$ & $v_{2}^{1}$ & $v_{i}$ & $v_{4}^{1}$ & $v_{5}$ \\
\hline
\end{tabular}

$T=1 s$ de beaconing foi escolhido para evitar inundações na rede (Sommer et al., 2010). O teste foi iniciado com instanciação do OSDP em todas $R S U$ s em sequência e, por fim, no veículo $v_{j}$.

As medições foram realizadas usando o tempo de inter-contato variando de $0,2 \mathrm{~s}$, com início em 0,2 s até $2 s$. Para cada tempo de inter-contato, foi observado 100 amostras em $v_{j}$. Uma amostra é referente ao beaconing success rate, $S_{b r}$, calculado por meio da razão do total de serviços oferecidos ao mesmo tempo pelo total dos serviços recebido por $v_{j}$ dentro do tempo de inter-contato. O gráfico da Figura 5.8(a) ilustra a média do $S_{b r}$. Para as densidades, $d_{r} \leqslant 5$, o beaconing success rate foi $S_{b r}<1,0$, para tempos inter-contato até $1 s$. Este resultado indica que somente o intervalo de beaconing $T=1 \mathrm{~s}$ afetou o desempenho, uma vez que temos um comportamento linear crescente até $1 \mathrm{~s}$. A partir de uma $d_{r}>5$ o número de $R S U$ também passou a influenciar no desempenho da beaconing success rate, como pode ser observado para a densidade $d_{r}=7$.

Os resultados também indicam que o aumento da densidade $d_{r}$ requer um tempo maior de inter-contato para garantir um beaconing success rate, $S_{b r} \approx 1,0$. Por exemplo, para $d_{r}=7$

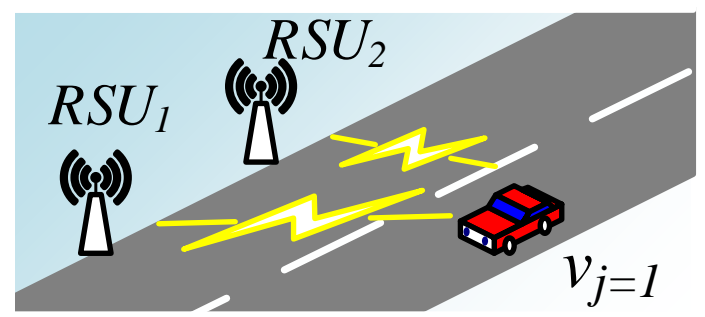

(a)

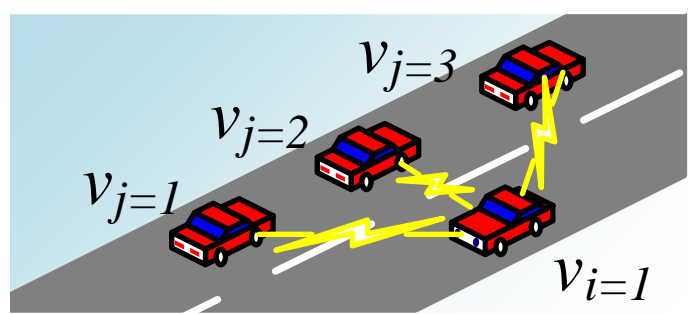

(b)

Figura 5.7: Exemplos dos cenários de avaliação: a) duas $R S U$ e um carro recebendo beacons e b) Um veículo consultando três veículos vizinhos 
foi necessário um tempo de inter-contato de $1,2 s$ para a taxa alcançar $S_{b r}=1,0$. Este aumento do tempo de inter-contato, provavelmente, é consequência de eventuais colisões de pacotes.

\subsubsection{Avaliação da fase III: Querying}

O teste avalia o desempenho da quantidade de serviços encontrados quando um veículo $v_{i}$ realiza uma consulta $Q$ aos veículos vizinhos $V$ na comunicação $\mathrm{V} 2 \mathrm{~V}$, como ilustrado na Figura 5.7(b). Os veículos vizinhos $v_{j}$ são $\left\{v_{1}, v_{2}, v_{4}, v_{5}\right\}$ e o veículo $v_{i}$ é $v_{3}$, eles correspondem aos APs do testbed, conforme o arranjo das instâncias e o valor das densidades $d_{v}$ da Tabela 5.1. Um esforço para evitar que o tempo em busca do serviço $s$ na cache $c_{j}$ dos veículos $v_{j}$ tivesse impacto no desempenho foi utilizar o artifício de inserir apenas o serviço $s$, procurado por $v_{i}$, armazenado na cache $c_{j}$ e, desta forma, foi otimizado o tempo de busca. Para início do teste, o OSDP foi instanciado sequencialmente em todos os veículos $v_{j}$ e então em $v_{i}$.

Análogo ao testes das fases I e II, as medições foram realizadas variando o tempo de inter-contato de $0,2 s$ a partir de $0,2 s$ até $2 s$. Para cada tempo de inter-contato, obteve-se 100 medições. Uma amostra é referente ao query success rate, $S_{q r}$, calculado por meio da razão entre o total de vizinhos $v_{j}$, no momento de transmissão da consulta $Q$ de $v_{i}$, pelo total de respostas $R$ recebidas por $v_{i}$. Na fase III existe uma dupla chance de colisões, a primeira é na consulta $Q$ e a segunda na resposta $R$. Essas mensagens podem colidir com os beacons $M$ ou, em menor frequência, com outra consulta $Q$ ou resposta $R$, nas situações mais comuns. Outro problema de desempenho são possíveis respostas sincronizadas, quando os veículos em $V$, tal que $|V| \gg 7$, transmitem $R$ ao mesmo tempo.

O gráfico da Figura 5.8(b) mostra a média da query success rate $S_{q r}$. Os resultados indicam que $S_{q r}$ depende apenas do valor de $d_{v}$, não sendo afetado pelo tempo de intercontato. É possível observar, na Figura 5.8(b), que o aumento do valor de $d_{v}$ resultou em queda do desempenho de $S_{q r}$, contudo para cada $d_{v}$ o $S_{q r}$ se manteve razoavelmente constante em função do tempo de inter-contato. Para entender os motivos porque o tempo de intercontato não afetou a fase III, foram realizadas medidas de tempo, detalhadas na Seção 5.4.3: o tempo médio para $v_{i}$ enviar $Q$ e receber a primeira resposta $R$, foi $t_{Q R}=1658,76 \mu \mathrm{s}$, como $t_{Q R} \ll 0,2 s$, o tempo é suficiente para $v_{i}$ enviar $Q$ e receber o respectivo $R$, por isso é independente do tempo de inter-contato. Desta forma, é possível assumir que $S_{q r}$ foi afetado por colisões.

Considerando os valores de $S_{q r}$, para uma densidade $d_{v}=1$, o veículo $v_{i}$ possui a chance de $95 \%$ de receber todas as respostas $R$; se a densidade aumenta para $d_{r}=7, v_{i}$ a chance cai para $48 \%$ de receber todas as respostas $R$, ambos independente de tempo de inter-contato. Apesar de $S_{q r}<0,5$ para $d_{r}=7$, o usuário encontra o serviço, contudo pode não descobrir todos os serviços que estão disponíveis na região. 


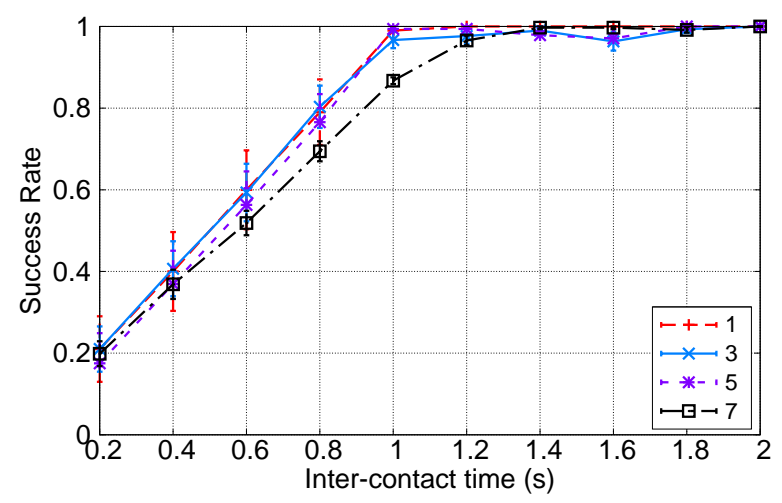

(a)

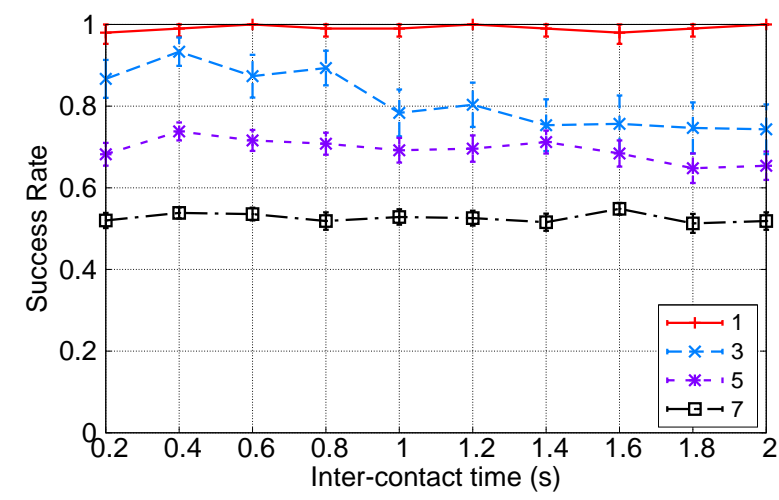

(b)

Figura 5.8: a) A taxa de sucesso $S_{b r}$ para as fases beaconing e cache do OSDP. Um cenário onde $v_{i}$ recebe beacons das $R S U$ s sob a densidade, $d_{r}$, que varia de 1 a 7 . A $R S U s$ transmitem beacons, $M$, cada $T=1 s$. b) A taxa de sucesso $S_{q r}$ para a fase de consulta do OSDP. Um cenário onde $v_{i}$ consulta os veículos $v_{j}$ sob a densidade, $d_{v}$, que varia de 1 a 7

(Yokoyama et al., 2014)

\subsubsection{Medidas de tempo}

Adicionalmente foram medidos os seguintes tempos: i) $t_{M}$ é o tempo gasto para a $R S U$ enviar um beacon $M$; ii) $t_{Q}$ é o tempo gasto para $v_{i}$ enviar uma consulta $Q$; iii) $t_{r}$ é o tempo gasto para $v_{j}$ enviar uma resposta $R$; iv) $t_{Q R}$ é o tempo total gasto para $v_{i}$ enviar uma consulta $Q$ e receber a primeira resposta $R$. Cada medida foi realizada de forma independente, usando variáveis de monitoramento na implementação de OSDP. Os tempos médios e os desvios padrão são apresentados na Tabela 5.2. É possível estimar o tempo gasto na busca para localizar o serviço na cache $c$ da seguinte forma: $t_{Q R}-\left(t_{Q}+t_{r}\right)=1461,57 \mu \mathrm{s}$.

Tabela 5.2: O tempo gasto na troca de mensagens OSPD

\begin{tabular}{l|r|r}
\hline Tempo & Média & Desvio Padrão \\
\hline$t_{M}$ & $113,31 \mu \mathrm{s}$ & $10,51 \mu \mathrm{s}$ \\
$t_{Q}$ & $102,86 \mu \mathrm{s}$ & $5,53 \mu \mathrm{s}$ \\
$t_{R}$ & $94,33 \mu \mathrm{s}$ & $13,25 \mu \mathrm{s}$ \\
$t_{Q R}$ & $1658,76 \mu \mathrm{s}$ & $194,52 \mu \mathrm{s}$ \\
\hline
\end{tabular}

\subsection{Considerações finais}

Neste Capítulo foi explorado o problema de prover aos usuários de redes veiculares informação de serviços locais às margens de rodovias ou em ruas de áreas urbanas. Essas informações podem ajudar motoristas e passageiros no sentido de melhorar sua experiência durante a 
viagem. Para resolver este problema foi proposto o OSDP, um protocolo de descoberta de serviços oportunista para redes veiculares, encapsulado na camada-2, baseado em beaconing, e que é capaz de encontrar e divulgar os serviços por meio do paradigma store-and-forward de mensagens, durante conexões oportunistas.

O OSDP foi implementado e validado por meio de dois testes em um testbed de prova de conceito. Primeiro, foram testadas as fases Beaconing e Caching. Segundo, foi testada a fase de Query. Os resultados comprovam a viabilidade do OSDP e por meio da avaliação é possível concluir que para o intervalo de beaconing, $T=1 \mathrm{~s}$, com densidades, $d_{r}>5$, o desempenho do beaconing success rate é afetado nas fases Beaconing e Caching. Adicionalmente, também é possível concluir que o desempenho da fase de Query independe do tempo de inter-contato.

No Capítulo seguinte, beaconing é explorado para aplicação cooperativa no problema de verificação da localização declarada pelo veículo. 



\section{Disseminação anônima e inferência da posição de veículos}

Este Capítulo discorre sobre o trabalho realizado durante o estágio sanduíche no ano de 2012. A visita foi ao Politecnico di Torino, Itália, sob a supervisão do Prof. Claudio Casetti. O objetivo da visita foi colaborar no projeto do protocolo "disseminação anônima e inferência da posição em redes veiculares". A implementação, realização dos experimentos e análise dos resultados experimentais foram as contribuições da visita. O protocolo implementado e avaliado foi o A-VIP (Anonymous Verification and Inference of Positions in Vehicular Networks). Os resultados expostos neste Capítulo são referentes à parte experimental. Os detalhes dos resultados de simulação e o modelo probabilístico de inferência podem ser encontrados em Malandrino et al. (2014).

\subsection{Verificação e inferência de posições dos veículos}

O beaconing geralmente utilizado em aplicações veiculares para fins de segurança, também pode ser explorado para aplicações cooperativas. A ideia de aplicações cooperativas é a troca de informações entre os nós para um objetivo em comum. A informação que eles carregam (por exemplo, identificação do veículo, data e hora e informações de localização) pode ser assegurada por meio do uso do Módulo de Segurança de Hardware inviolável (E-Security, 2014), criptografia e certificados. 
Beacons seguros são necessários para a identificação e rastreamento da posição do veículo. Em algumas situações a localização do veículo pode ser utilizada para responsabilizar os motoristas. Por exemplo, o motorista pode fundamentar provas, em caso de acidente, com base na localização do veículo, alegando que estava em outro local no momento do acidente. Contudo, as autoridades podem usar a localização segura para verificar a informação e fornecer uma localização não repudiável contra os envolvidos, a fim de prestar serviços à comunidade. Para tanto, esta solução possui três principais problemas, relativos i) à privacidade dos usuários, ii) aos custos computacionais de segurança e iii) à confiança no sistema de verificação. Primeiro problema é a divulgação pública da identidade do veículo para todos os veículos próximos que recebem o beacon. Os veículos podem ser monitorados pelos adversários, colocando em risco a privacidade dos motoristas (Wiedersheim et al., 2010). Existe, portanto, uma necessidade de separar identificação e posição segura pelas autoridades e veículos utilizadores. Segundo problema, os mecanismos de segurança com base em criptografia provocam sobrecarga no protocolo e complexidade computacional (Schoch e Kargl, 2010). Por fim, soluções tradicionais com criptografia não podem garantir a informação correta de localização fornecida por um usuário, devido a defeitos no receptor GPS ou um usuário mal intencionado capaz de mexer com os dados do GPS antes de entrar no Módulo de Segurança de Hardware.

Para superar os problemas descritos anteriormente é proposto o A-VIP, que utiliza um mecanismo de beacon anônimo transmitido pelos veículos e evitando que sejam identificados ou rastreados. Os principais diferenciais da proposta são: i) permite que uma autoridade verifique com segurança as posições declaradas pelos veículos, sem recorrer à criptografia assimétrica (tal como é feito na IEEE 1609.2); ii) garante a privacidade dos motoristas em relação a outros veículos que participam da rede; e iii) não requer uma infraestrutura de comunicação com cobertura total da rede. Além disso, o protocolo permite à autoridade inferir a real posição dos veículos com defeito ou mal intencionados Malandrino et al. (2013).

\subsubsection{Procedimento do protocolo}

É considerado um típico cenário de rede veicular composto por veículos comunicando-se uns com os outros e, eventualmente, com as unidades RSU à margem da estrada. Os veículos também possuem uma interface celular $3 G$, por meio da qual acessam a rede celular. Ambos RSU e a rede celular, permitem que os veículos se comuniquem com uma entidade chamada de Location Authority (LA).

Os veículos são equipados com dispositivos GPS, assim eles conhecem a posição geográfica deles e compartilham o mesmo horário de referência. Supõe-se que cada veículo possui o material criptográfico necessário para estabelecer um canal seguro de comunicação com LA a qualquer momento, através de uma RSU ou da rede celular. 
Os principais objetivos do protocolo são o baixo custo computacional, permitir a LA rastrear veículos, verificando as posições que eles anunciam com garantia da privacidade dos usuários com relação a outros veículos e, por fim, detectar e inferir as localizações reais de veículos adversários. Para tanto, o A-VIP classifica os veículos em: i) correto - são os veículos em conformidade com o A-VIP; ii) defeituoso - são os veículos que seguem o protocolo, mas fornecem informações incorretas devido, por exemplo, ao mau funcionamento do GPS; ou ii) adversário - são os veículos com objetivos de anunciar uma localização falsa e ter a localização deles verificada, ou interromper o funcionamento do protocolo.

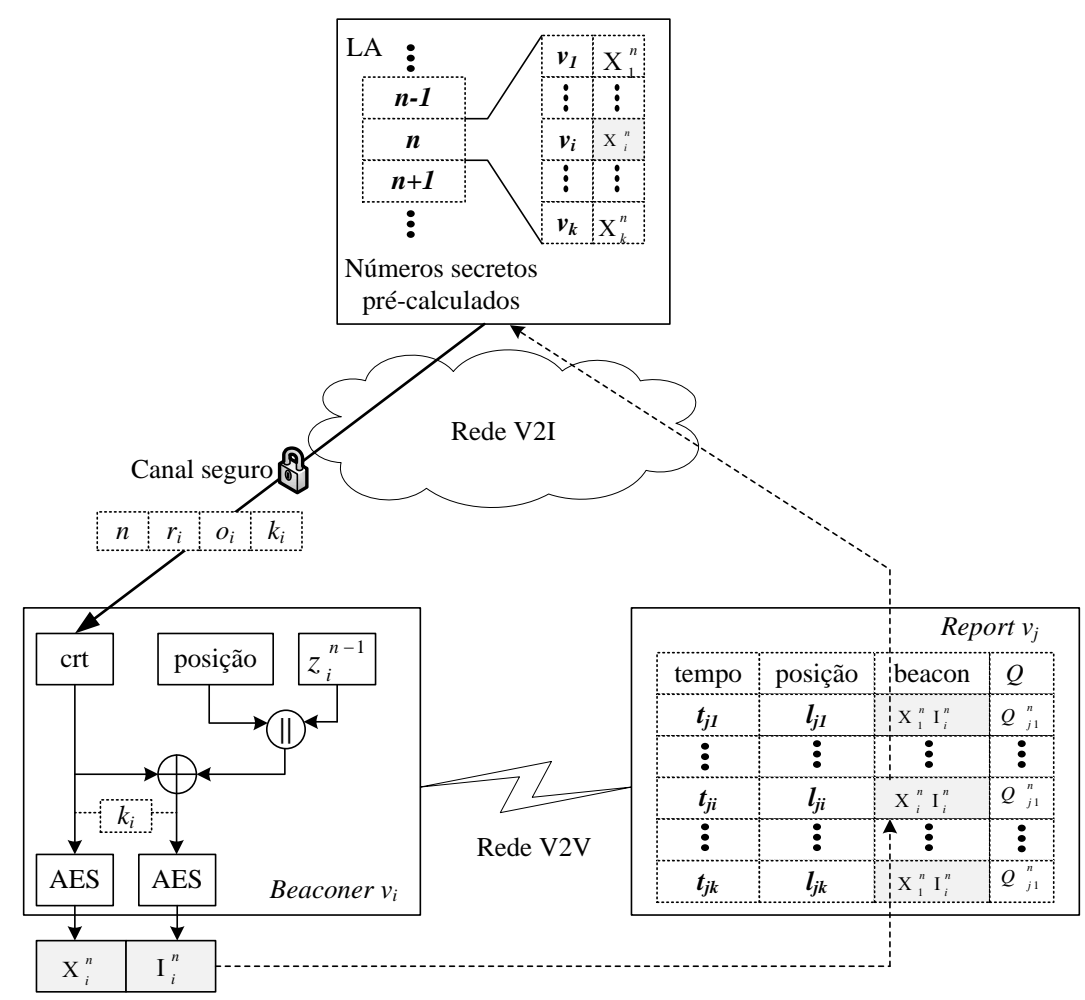

Figura 6.1: Visão geral dos procedimentos A-VIP pelo Beaconer, Report e LA. Adaptado de Malandrino et al. (2013).

Os procedimentos de comunicação do A-VIP, ilustrados na Figura 6.1, são definidos como (Malandrino et al., 2013):

- Registro. É realizado por meio de um canal seguro entre o veículo e a LA através das RSUs ou rede celular. O registro é realizado toda vez que o veículo é ligado ou quando o tempo do registro expira. Seja um veículo $v_{i}$ que envia um pedido de registro no momento $t_{i, 0}$. O LA então retorna ao veículo uma tripla $\left(K_{i}, r_{i}, o_{i}\right)$, sendo $K_{i}$ uma chave simétrica AES 128-bit e $r_{i}, o_{i}$ são números inteiros aleatórios. A tripla é usada para calcular o segredo $\mathbb{x}_{i}(t)$, partilhado entre o $v_{i}$ e o LA. Quando $v_{i}$ envia o $\mathbb{x}_{i}(t)$ para o LA, permite que o LA verifique a identidade do veículo. O segredo $\mathbb{x}_{i}(t)$ é calculado com base no tempo, para tanto, as duas entidades iniciam um contador $r_{i}$ e incrementam em $o_{i}$ a cada $\tau_{b}$ segundos em todas as transmissões de beacon. $\mathrm{O}$ 
contador atualizado é então criptografado com $K_{i}$ usando AES. Assim, em geral, se $t_{i, 0}+n \tau_{b} \leq t<t_{i, 0}+(n+1) \tau_{b}$, então $\mathbb{x}_{i}(t)=E_{K_{i}}\left\{r_{i}+n o_{i}\right\}=\mathbb{x}_{i}^{n}$. Ambos, $r_{i}$ e $o_{i}$, podem ser escolhidos ao acaso, uma vez que as chances de colisão entre valores de $\mathbb{x}^{n}$, relacionados com diferentes veículos, ao mesmo tempo, são desprezíveis.

- Beacon anônimo. Os veículos corretos, durante o percurso, transmitem um beacon a cada $\tau_{b}$ segundo. O beacon anônimo é dividido em duas partes: a primeira criptografada, para os fins previstos no A-VIP, e a segunda, com conteúdo não criptografado, para outros propósitos, tal como, evitar acidentes. Quando o veículo não está transmitindo, o veículo escuta o canal e coleta beacons transmitidos por outros veículos para ser reportado ao LA posteriormente. O beacon é construído usando a tripla atribuída ao veículo durante o registro. Especificamente, o n-ésimo beacon transmitido por um veículo $v_{i}$ transporta duas partes de informação, como mostra a entidade Beaconer da Figura 6.1:

$-\mathbb{x}_{i}^{n}$ : o segredo baseado no tempo, que pode ser calculado por $v_{i}$ e pela LA, de forma independente;

- $\mathbb{1}_{i}^{n}=E_{K_{i}}\left\{\left(l_{i}^{n} \| z_{i}^{n-1}\right) \oplus\left(r_{i}+n o_{i}\right)\right\}$ : é a localização atual do veículo, criptografada usando a chave $K_{i}$. A localização não cifrada $l_{i}^{n}$ é concatenada com um bit flag, $z_{i}^{n-1}$, então a operação de XOR com $\left(r_{i}+n o_{i}\right)$ é aplicada à sequência de texto para evitar ataques parciais de repetição.

- Relatório. Quando um beacon é transmitido por $v_{i}$ e corretamente recebido por $v_{j}$, este último necessariamente armazena os seguintes dados na tabela de relatório, como ilustrado pela entidade Reportador na Figura 6.1.

- $t_{j i}$ : a hora em que o beacon foi recebido;

- $l_{j i}$ : a própria posição geográfica de $v_{j}$ no momento em que o beacon foi recebido;

- $\mathbb{x}_{i}^{n}$ : o segredo criptografado transportado pelo beacon;

- $\mathbb{1}_{i}^{n}$ : a posição criptografada de $v_{i}$ transportada pelo beacon;

- $Q_{j i}^{n}$ : a qualidade do sinal recebido;

A cada $\tau_{R}$ segundos (intervalo de relatório), $v_{j}$ gera uma mensagem incluindo a tabela do relatório, preenchido com dados coletados de todos os beacons recém ouvidos. O relatório é transmitido para o LA , através da RSU ou da rede celular, garantindo a autenticação e integridade por meio de procedimentos padrão. 


\subsubsection{Inferência e verificação da posição}

LA discretiza a topologia de estradas/ruas em quadriláteros, denotado por $\mathcal{S}$ e $\mathcal{V}$ o conjunto de veículos que o LA deve verificar. Ao receber uma mensagem de relatório de veículo $v_{j} \in \mathcal{V}$, o LA processa um relatório por vez, do seguinte modo:

- LA extrai a hora $t_{j i}$ em que $v_{j}$ recebeu o beacon;

- para cada $v_{k} \in \mathcal{V}$, LA calcula $N$, tal que $t_{k, 0}+n \tau_{b} \leq t_{j i}<t_{k, 0}+(n+1) \tau_{b}$, ou seja, $n=\left\lfloor\left(t_{j i}-t_{k, 0}\right) / \tau_{b}\right\rfloor$, e procura o segredo pré-computado $\mathbb{x}_{k}^{n}$ que corresponde ao $\mathbb{x}_{i}^{n}$ na entrada da tabela relatório (entidade LA na Figura 6.1).

Quando for encontrada uma correspondência, o LA identifica $v_{i}$ como o veículo que enviou o beacon e recupera a tripla que foi associada a ele. Em seguida, o LA pode realizar as seguintes ações:

i) Decifrar a localização $\mathbb{1}_{i}^{n}$ anunciada por $v_{i}$ no beacon relatado por $v_{j}$;

ii) Verificar $z_{i}^{n-1}$, se o bit é um, ele descarta a entrada. Caso contrário, se $z_{i}^{n-1}$ é zero, ele armazena $n$, a posição $l_{i}^{n}$, incluída no beacon por $v_{i}$ e a posição $l_{j}^{n}$ anunciada por $v_{j}$ no registro da tabela de relatório. O LA também armazena a qualidade do sinal RF, $Q_{j i}^{n}$, que $v_{j}$ obteve por meio do beacon recebido de $v_{i}$.

O LA aproveita da informação extraída a partir do registro reportado para identificar o possível quadrilátero correspondente à posição do veículo. A ideia é adotar quadriláteros que correspondem à posição do beaconer $v_{i}$ e também a qualidade do sinal $Q_{j i}$ da recepção do beacon, para a inferência da posição aplicando um modelo de propagação RF da área onde ocorreu a transmissão do beacon. Isto é realizado pelas Equações 6.1 e 6.2 propostas por Malandrino et al. (2013).

Assumindo que todas as medidas se referem ao mesmo intervalo da transmissão do beacon $n$. Seja o modelo de propagação a função $h\left(s, t, Q_{j i}\right): \mathcal{S}^{2} \times \mathbb{R} \rightarrow[0,1]$ que, para qualquer par de quadrilátero $(s, t)$ e qualquer valor de $Q_{j i}$, fornece a probabilidade $\mathbb{P}\left(R_{t}^{(j)} \mid B_{s}^{(i)}, Q_{j i}\right)$ de um beacon enviado por $v_{i}$ de um quadrilátero $s$ poder ser recebido por $v_{j}$ localizado no quadrilátero $t$, com o nível da qualidade do sinal $Q_{j i}$ reportado por $v_{j}$.

Pela aplicação do teorema de Bayes, o LA pode usar tais valores para computar a probabilidade $\mathbb{P}\left(B_{s}^{(i)} \mid R_{t}^{(j)}, Q_{j i}\right)$ de que o beaconer estava no quadrilátero $s$, dado que o beacon foi ouvido por $v_{j}$ no quadrilátero $t$, com o nível de qualidade $Q_{j i}$. Mais especificamente,

$$
\begin{aligned}
p_{i, s}^{(j)} & =\mathbb{P}\left(B_{s}^{(i)} \mid R_{t}^{(j)}, Q_{j i}\right) \\
& =\frac{\mathbb{P}\left(R_{t}^{(j)} \mid B_{s}^{(i)}, Q_{j i}\right) \cdot \mathbb{P}\left(B_{s}^{(i)}\right)}{\sum_{u \in \mathcal{S}} \mathbb{P}\left(R_{t}^{(j)} \mid B_{u}^{(i)}, Q_{j i}\right) \cdot \mathbb{P}\left(B_{u}^{(i)}\right)}
\end{aligned}
$$


sendo $\mathbb{P}\left(B_{x}^{(i)}\right)$ a probabilidade de o veículo $v_{i}$ transmissor estar no quadrilátero $x$ no momento da transmissão. Isto depende da densidade de veículos e do tamanho da área considerada. Para simplificar, é assumido $\mathbb{P}\left(B_{s}^{(i)}\right)=1 /|\mathcal{S}|$ para qualquer $v_{i}$ em qualquer quadrilátero em $s \in \mathcal{S}$. Ao receber vários relatórios, o LA pode combinar as probabilidades acima e calcular a

probabilidade $P_{i, s}^{(n)}$ de que $v_{i}$ estava em $s$ ao enviar o $n$-ésimo beacon, com base nos relatórios:

$$
P_{i, s}^{(n)}=\frac{\prod_{j: v_{j} \in \mathcal{R}_{i}} p_{i, s}^{(j)}}{\sum_{u \in \mathcal{S}} \prod_{j: v_{j} \in \mathcal{R}_{i}} p_{i, u}^{(j)}} \quad \forall s \in \mathcal{S},
$$

sendo que $\mathcal{R}_{i}$ é o conjunto de veículos que relata os beacons transmitidos por $v_{i}$.

\subsection{Testbed, implementação e resultados}

O tesbed foi implantado na via pública, no bairro Villa Gualino, zona suburbana da cidade de Turim, Itália. A Figura 6.2(a) é a imagem de satélite do local e destaca o trajeto utilizado para testes. O experimento foi conduzido com cinco veículos perfilados circulando continuamente no testbed, perfazendo aproximadamente $2 \mathrm{~km}$ por volta. Os veículos permaneceram próximos um do outro, a maior parte do teste, para evitar escassez de dados.

O protocolo A-VIP tem como base a implementação do V-Beacon (Yokoyama et al., 2013). O framework beaconing (descrito na Seção ??) foi modificado com a inserção do módulo para reportar os beacons recebidos. O módulo Report quando detecta a presença da RSU envia os relatórios com os beacons recebidos que foram armazenados em memória por meio de um buffer circular. A transmissão dos relatórios é feita por meio de mensagens unicast encapsuladas na camada 2, a transmissão encerra quando o buffer está vazio ou quando o veículo pára de ouvir os beacon de anúncio da RSU. Para a criptografia de $\mathbb{x}_{i}^{n}$ e $\mathbb{1}_{i}^{n}$ foi utilizada a biblioteca OpenSSL com a função AES. Adicionalmente, foi alterado o $\log$ para salvar os dados transmitidos no formato do registro do relatório.

Os veículos foram equipados com uma antena omnidirecional de $5 d B i$ de ganho e fixadas no teto do veículo. A potência de transmissão foi configurada em $18 \mathrm{dBm}$. A posição geográfica e o horário foram obtidos por meio do receptor GPS. O modelo de propagação utilizado para o cálculo da probabilidade $p_{i, s}^{(j)}$, é obtido a partir de medições experimentais recolhidas pelos veículos utilizados no testbed. O mapa de propagação correspondente é retratado na Figura 6.2(b), onde, para maior clareza de apresentação, os valores da potência do sinal recebido foram discretizados em alta, média e baixa qualidade do sinal.

Para avaliar a qualidade da estimativa da localização do veículo no testbed, foi usada a métrica erro de localização, definida para um veículo $v_{i}$ no momento $n$ como: 


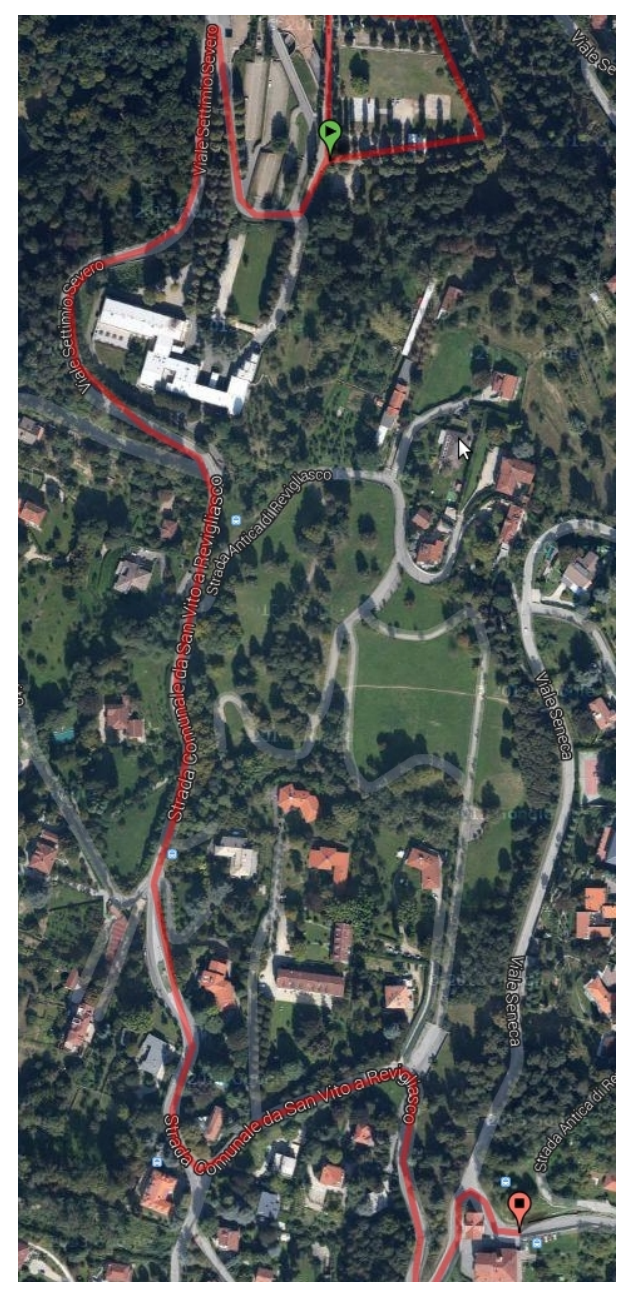

(a)

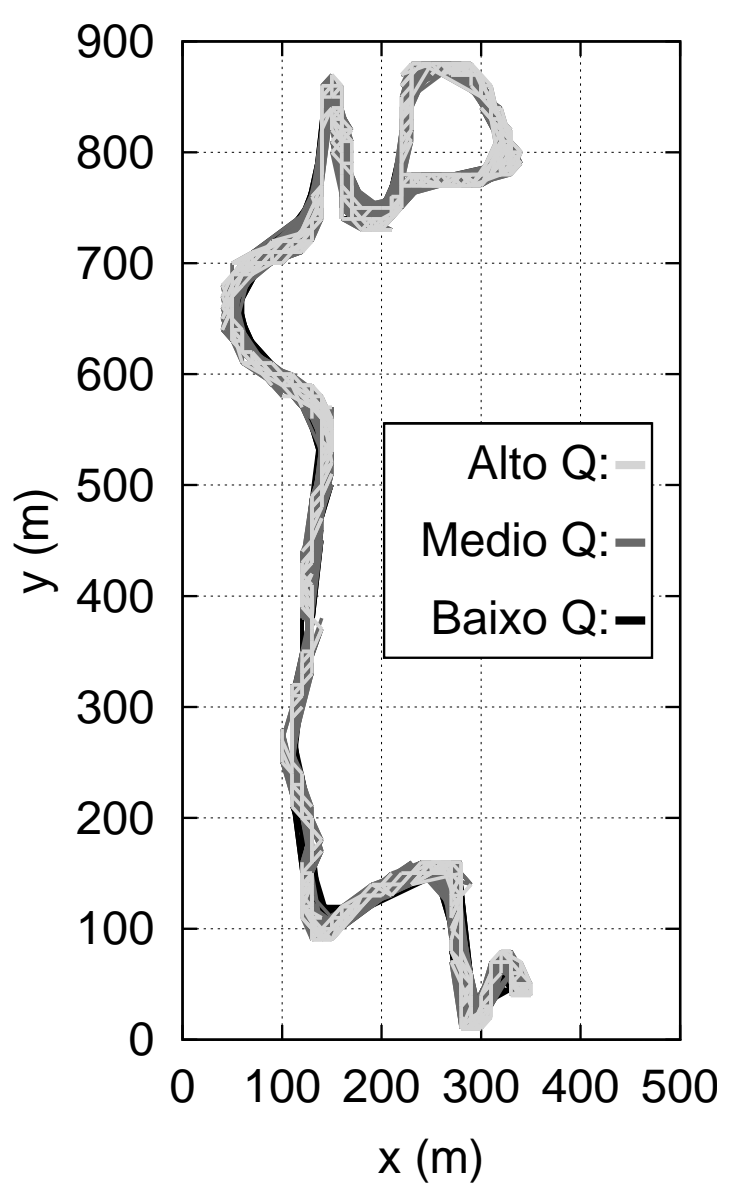

(b)

Figura 6.2: a) Foto de satélite da Villa Gualino destacando o trajeto realizado durante o experimento; b) Mapa de propagação do sinal RF, adaptado de Malandrino et al. (2013)

$$
e_{i}^{n}=\sum_{s \in \mathcal{S}} P_{i, s}^{(n)} d\left(\ell_{i}^{n}, s\right)
$$

O erro de localização é calculado a partir da distância $d\left(\ell_{i}^{n}, s\right)$ entre a localização real de $v_{i}$ no momento $n$, ou seja, $\ell_{i}^{n}$, e os centros de todos os quadriláteros $s$. Mais precisamente, essas distâncias são calculadas utilizando-se como probabilidade ponderada $P_{i, s}^{(n)}$ que $v_{i}$ está dentro do quadrilátero $s$ no tempo $n$, inferida a partir de relatos vindos de veículos próximos como na Equação (6.2). A interpolação é usada caso algumas posições não estejam disponíveis.

Os veículos possuem o comportamento correto no experimento, por isso, a incerteza da localização pode ser devida: i) a propagação de sinal de RF, a qual é variável com o tempo e pode induzir a erros no processo de estimação; ii) perdas de beacons e mensagens de relatórios, prejudicando o processo de verificação no LA; iii) a frequência de transmissão do 
beacon, que pode ser insuficiente para capturar o movimento de veículos dentro do intervalo de $\tau_{b}$.

Os resultados mostraram que as duas primeiras fontes de erros, ou seja, a variação da propagação do sinal RF e as perdas de pacotes, não têm impacto significativo nos resultados experimentais. Entretanto, o último aspecto, ou seja, o intervalo de beaconing, afeta operações de A-VIP. Isso é comprovado na Figura 6.3 que ilustra o erro de localização, calculado pela Equação 6.3, em função do intervalo $\tau_{b}$, com número variável de veículos participantes.

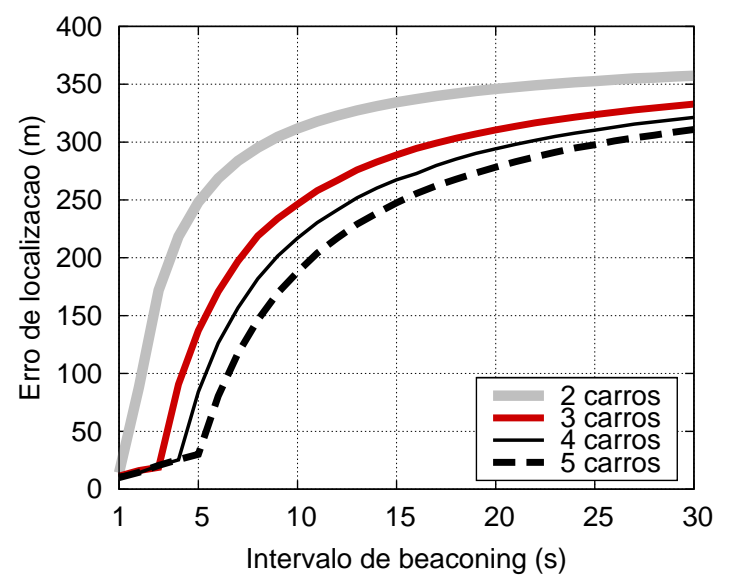

Figura 6.3: Erro de localização em função do intervalo de beaconing $\tau_{b}$, adaptado de Malandrino et al. (2013)

O erro de $\tau_{b}=1 s$ é da ordem do tamanho do quadrilátero (definido como $10 \mathrm{~m}$ nos testes) que é a precisão espacial máxima que o A-VIP pode atingir. Com o aumento do intervalo de beaconing, o erro de localização cresce, isto é, permite os carros percorrerem distâncias maiores entre as operações da transmissão de beacon, forçando o LA estimar a localização com menos dados. No entanto, o problema pode ser contornado com um conjunto maior de veículos participantes do A-VIP. Desta forma, o LA recebe informações de posicionamento em uma frequência maior, uma vez que os veículos transmitem beacons de uma forma não sincronizada durante $\tau_{b}$ e cada beacon gera um relatório dos carros vizinhos.

\subsection{Considerações finais}

Neste Capítulo discorremos sobre o A-VIP, um protocolo de preservação da privacidade para verificação e inferência de posições do veículo por uma autoridade de localização. O A-VIP tem baixo custo computacional por usar criptografia simétrica e também é eficaz na comunicação anônima com veículos nas proximidades por meio de beacons. Os experimentos em ambiente real mostraram que o A-VIP atingiu os seus objetivos, mesmo em redes veiculares esparsas, com erro de localização limitado. 


\section{Conclusões}

As redes veiculares são fundamentais para os Sistemas de Transporte Inteligentes. Os dois principais objetivos de redes veiculares são: i) melhorar a segurança no transporte rodoviário e ii) prover acesso à Internet e serviços de entretenimento a motoristas e passageiros. A aplicação de segurança é baseada na mensagem tipo beacon, para enviar e receber alertas e dados da cinemática dos veículos vizinhos. Este trabalho, estende a aplicação do beacon, explorando o beacon para resolver problemas de posicionamento, localização e serviços. A metodologia usada foi a implementação e avaliação em ambientes reais das soluções propostas, diferindo do uso de simulações, realizadas na maior parte dos trabalhos que envolvem beaconing. Desta maneira, esta tese versou sobre as redes veiculares utilizando estratégias da comunicação por beaconing em várias facetas. Os principais resultados deste estudo foram os seguintes:

- A implantação da plataforma V-Beacon (hardware e software) para testes de redes veiculares em ambientes reais. Para tanto, foram especificados os hardwares e implementado um middleware para manipular a mensagem tipo beacon, nativo do IEEE 802.11a, possibilitando a inserção de dados como, por exemplo, a posição geográfica, números sequências, informações no formato XML, entre outros. O V-Beacon foi validado por meio de dois experimentos, utilizando a comunicação V2V e V2I: i) avaliação de desempenho da taxa de perda de beacons em função da distância (PDR) e ii) análise do comportamento do sinal RF (RSSI) em função da distância. Ambos considerando o(s) veículo(s) em movimento. A realização dos experimentos em ambientes reais utilizando o V-Beacon é um dos diferenciais deste trabalho. A validação de protocolos 
e avaliações de desempenho com beaconing, até o momento da finalização deste trabalho, têm sido realizadas na maior parte por meio de simulações. Desta maneira, a plataforma permite suprir a necessidade de trabalhos científicos com implementação e avaliação em ambientes reais.

- Um estudo de redes veiculares sobre comportamento do RSSI obtido por meio de beaconing foi utilizada para a validação do V-Beacon. Adicionalmente, o modelo do comportamento do RSSI foi aplicado na arquitetura para a inferência da distância do veiculo até os veículos vizinhos ou até a infraestrutura ao redor. A arquitetura usa o algoritmo $k$-NN para estimar a distância com base no RSSI. A análise dos dados experimentais do RSSI mostrou que o sinal teve o comportamento já conhecido, ou seja, um esvaecimento do sinal RF em função do aumento da distância, validando a plataforma. Porém, como o experimento foi realizado com o veículo em movimento, se notou uma maior variação dos valores sinal RF por intervalo de distância. Por fim, o estudo mostrou a viabilidade da aplicação do algoritmo $k$-NN na estimação da distância e uma avaliação de desempenho determinou os erros médios por intervalo. A arquitetura pode auxiliar técnicas de posicionamento, por exemplo, dentro de tuneis em que a posição geográfica do GPS pode não estar disponível pela razão da obstrução do sinal do satélite.

- Aproveitando do procedimento de beaconing do padrão WAVE, foi proposto o OSDP - um novo protocolo de camada-2 para descoberta de serviços em redes veiculares. O protocolo tem como base a mensagem tipo beacon para propagar informações na rede, sobre serviços locais, que podem ser de interesse para motoristas e passageiros. O OSDP foi implementado sobre o middleware da plataforma V-Beacon. A validação e avaliação foi por meio de prova de conceito, variando o tempo de inter-contato da comunicação. Os resultados mostraram a corretude e o comportamento do protocolo até sete veículos/RSUs, para as comunicações V2I e V2V. Portanto, OSDP é um novo protocolo capaz de descobrir serviços em redes veiculares e possui os diferenciais de ser independente da conexão com à Internet, com a utilização das técnicas store-andforward e da comunicação oportunística, e também pode ser considerado um protocolo light-weight, pela razão do uso de somente mensagens tipo beacon, que normalmente são de pequeno tamanho e não exigem muito tempo de processamento.

- Um dos problemas de redes veiculares é manter a privacidade do usuário sem comprometer a disponibilidade da informação da localização do veículo. Neste estudo, foi demonstrado a eficácia do uso da criptografia simétrica aplicada nas partes do beacon que contém a posição geográfica e a identidade do veículo. Desta maneira, foi garantido o anonimato do usuário e, se necessário, inferência da posição do veículo em determinado momento. Adicionalmente, o protocolo proposto é capaz de reconhecer possíveis adversários da rede veicular, por exemplo, aqueles alteraram a informação da 
posição geográfica para conseguir vantagens e privilégios do sistema de transporte. O protocolo foi validado e avaliado por simulação e experimento em ambientes reais. $\mathrm{O}$ experimento foi realizado no testbed com cinco veículos e os resultados experimentais mostraram a eficiência do protocolo, mesmo em redes espaças de três a cinco veículos.

Esta tese inova na abordagem de beaconing para resolver problemas de posicionamento, localização e provimento de serviços em redes veiculares, explorando beaconing além da proposta original para as aplicações de segurança. Ainda, a metodologia adotada no trabalho é um diferencial para preencher a necessidade de estudos que utilizam testbeds. Assim, foi demonstrado que beaconing pode ser aplicado para resolver problemas de comunicação em redes veiculares e pode ser validada e avaliada de maneira experimental em ambientes reais diferindo das conhecidas limitações de simulações.

\subsection{Dificuldades e limitações do projeto}

O projeto teve foco no método experimental em ambientes reais e por isso demandou um tempo maior para obter resultados devido à implantação e configuração do testbed, implementação e realização dos experimentos. Além disso, a escalabilidade do trabalho ficou comprometida pelo recurso financeiro limitado e o número de pessoas envolvidas no projeto. Os experimentos também sofrem com as condições do tempo e disponibilidade do local para implantação do testbed, que deve ser livre de interferência de RF e com pouco trânsito de veículos e pessoas. Considerando os softwares, existe o problema das atualizações do sistema Open WRT que alteram as versões de alguns pacotes e bibliotecas de implementação sem manter a compatibilidade com a versão anterior, por exemplo o GPSD e os drivers para modem 3G. Por fim, o erro de posicionamento do dispositivo GPS que pode afetar a análise dos resultados.

Este projeto teve limitações no número de veículos e roteadores wireless utilizados na avaliação, além do hardware utilizado não ser o padrão IEEE 802.11p. As avaliações de desempenho, em alguns casos, tiveram uma escassez de dados pelo motivo do número de veículos, a demora em realizar as medições e o custo. Adicionalmente, existem as seguintes limitações pontuais das soluções: i) a aplicação para estimar a distância pode demorar um tempo razoável para acumular as instâncias, no caso de redes esparsas e sem infraestrutura ao redor; ii) o desempenho do OSDP com relação à taxa de sucesso do usuário encontrar o serviço procurado depende do padrão de mobilidade e da densidade de veículos, uma vez que, para encontrar os serviços, o protocolo utiliza contatos oportunistas; iii) a verificação da localização do veículo pode ficar comprometida quando dois ou mais nós atacantes conseguem compartilhar o material criptográfico e possuem acesso uma rede de alta velocidade e cobertura. 


\subsection{Publicações}

- Malandrino, F.; Borgiattino, C.; Casetti, C.; Chiasserini, C.; Fiore, M.; Yokoyama, R., Verification and Inference of Positions in Vehicular Networks through Anonymous Beaconing. In: Mobile Computing, IEEE Transactions on. 2014.

- Yokoyama, R.; Kimura, B.; Moreira, E.; An Architecture for Secure Positioning in a UAV Swarm using RSSI-based distance estimation. In: SIGAPP Applied Computing Review(ACR). 2014.

- Yokoyama, R.; Kimura, B.; Jaimes, L.; Moreira, E. A beaconing-based opportunistic service discovery protocol for vehicular networks. In: Proceedings of the 28th Advanced Information Networking and Applications Workshops (WAINA'14), Victoria-CA, 2014.

- Yokoyama, R.; Kimura, B.; Moreira, E.; Secure positioning in a UAV swarm using on-board stereo cameras. In: Proceedings of the 29th Annual ACM Symposium on Applied Computing (SAC'14), 2014.

- Malandrino, F.; Casetti, C.; Chiasserini, C.; Fiore, M.; Yokoyama, R.; Borgiattino, C. A-VIP: Anonymous verification and inference of positions in vehicular networks. In: Proceedings of the 32rd Annual IEEE International Conference on Computer Communications, IEEE Connference on, (INFOCOM'13), p. 105-109, Turin-IT, 2013.

- Yokoyama, R.; Kimura, B.; Jaimes, L.; Moreira, E. V-beacon: Uma plataforma experimental para redes veiculares sem fio. In: Anais do III Simpósio Brasileiro de Engenharia de Sistemas Computacionais (SBESC'13), Niterói-RJ Brasil. Nov. 2013.

- Kimura, B.; Yokoyama, R.; Guardia, H.; Moreira, E.; Secure Connection Re-establishment for Session-Based IP Mobility. In: Proceedings of the Second Brazilian Conference on Critical Embedded Systems (CBSEC'12), Campinas-SP, p.58-63, 2012.

- Moreira, E.; Yokoyama, R; Vanni, R.; Kimura, B.; Technologies to Improve the Quality of Handovers: Ontologies, Contexts and Mobility Management. In: Handbook of Research on Mobility and Computing: Evolving Technologies and Ubiquitous Impacts. New York: IGI Global, p.522-538, 2011.

- Kimura, B.; Yokoyama, R.; Lopes, R.; Guardia, H.; Moreira, E. Prototyping applications to handle connection disruptions in end-to-end host mobility. In:Proceedings of the Seventh International Conference on Wireless Ondemand Network Systems and Services (WONS'10), Kranjska Gora. v.1, p.1-8, 2010. 


\subsection{Sugestões de trabalhos futuros}

Alguns trabalhos pontuais podem ser realizados sobre as soluções propostas. A aplicação de estimação da distância pode ser explorada com outros algoritmos e novos parâmetros para representar as distâncias em função do RSSI, com o objetivo de aumentar a precisão da distância. O protocolo de descoberta de serviços ainda permite modificações e otimizações, poderia ser explorado com base na localização do usuário uma transmissão de múltiplos saltos para disseminar melhor os serviços em caso de rede veicular esparsa.

Em uma visão mais ampla, novos trabalhos com beaconing poderão ser com o objetivo de sensoriamento com redes veiculares (Lee e Gerla, 2010), aplicar beacons de rede veicular no paradigma de IoT (Internet of Things) (Bontu et al., 2014). A utilização de beaconing também pode ser expandida para melhorar a comunicação V2I auxiliando no procedimento de handovers (Zhu et al., 2011). 


\section{Referências Bibliográficas}

Abrougui, K.; Boukerche, A.; Pazzi, R. An efficient fault tolerant location based service discovery protocol for vehicular networks. In: Proceedings of the Global Telecommunications, IEEE Conference on, (GLOBECOM 2010), 2010, p. 1-6.

Antolino Rivas, D.; Guerrero-Zapata, M. Chains of trust in vehicular networks: A secure points of interest dissemination strategy. Ad Hoc Network, Elsevier Journal on, v. 10, n. 6 , p. 1115-1133, 2012.

Ardagna, C.; Cremonini, M.; Vimercati, S.; Samarati, P. An obfuscation-based approach for protecting location privacy. Dependable and Secure Computing, IEEE Transactions on, v. 8, n. 1, p. 13-27, 2011.

Bahl, P.; Padmanabhan, V. RADAR: An in-building RF-based user location and tracking system. In: Proceedings of the Nineteenth Annual Joint Conference of the IEEE Computer and Communications Societies. IEEE Conference on, (INFOCOM 2000), 2000, p. $775-784$.

Bai, F.; Stancil, D. D.; KRishnan, H. Toward understanding characteristics of dedicated short range communications (DSRC) from a perspective of vehicular network engineers. In: Proceedings of the Sixteenth Annual International Conference on Mobile Computing and Networking, ACM Conference on, (MobiCom10), 2010, p. 329-340.

Bontu, C.; Periyalwar, S.; Pecen, M. Wireless wide-area networks for internet of things: An air interface protocol for iot and a simultaneous access channel for uplink iot communication. Vehicular Technology Magazine, IEEE, v. 9, n. 1, p. 54-63, 2014.

Boukerche, A.; Abrougui, K.; Werner Nelem Pazzi, R. Context-aware and location-based service discovery protocol for vehicular networks. In: Proceedings of the 6th ACM Symposium on Performance Evaluation of Wireless Ad Hoc, Sensor, and Ubiquitous Networks, ACM Conference on, (PE-WASUN'09), ACM, 2009, p. 93-100.

Campolo, C.; Vinel, A.; Molinaro, A.; Koucheryavy, Y. Modeling broadcasting in IEEE 802.11p/WAVE vehicular networks. Communications Letters, IEEE, v. 15, n. 2, p. 199-201, 2011.

Capkun, S.; Hubaux, J.-P. Secure positioning in wireless networks. Selected Areas in Communications, IEEE Journal on, v. 24, n. 2, p. 221-232, 2006. 
Cesana, M.; Fratta, L.; Gerla, M.; Giordano, E.; Pau, G. C-VeT the UCla campus vehicular testbed: Integration of VANET and mesh networks. In: Proceedings of Wireless Conference, IEEE Conference on, (EW'2010 European), 2010, p. 689-695.

Cespedes, S.; Lu, N.; Shen, X. VIP-WAVE: On the feasibility of IP communications in 802.11p vehicular networks. Intelligent Transportation Systems, IEEE Transactions on, v. 14, n. 1, p. 82-97, 2013.

Chiang, J. T.; HaAs, J. J.; HU, Y.-C. Secure and precise location verification using distance bounding and simultaneous multilateration. In: Proceedings of the Second ACM Conference on Wireless Network Security, ACM Conference on, (WiSec'09), 2009, p. 181192.

Daniel, A.; Popescu, D.; Olariu, S. A study of beaconing mechanism for vehicle-toinfrastructure communications. In: Communications (ICC), 2012 IEEE International Conference on, 2012, p. 7146-7150.

Denby, B.; Oussar, Y.; Ahriz, I.; Dreyfus, G. High-performance indoor localization with full-band GSM fingerprints. In: Proceedings of Communications Workshops. IEEE Conference on, (ICC Workshops'09), 2009, p. 1-5.

Deshpande, P.; Das, S. R. Brave: Bit-rate adaptation in vehicular environments. In: Proceedings of the Ninth ACM International Workshop on Vehicular Inter-networking, Systems, and Applications, ACM Conference on, (VANET'12), 2012, p. 33-42.

Dias, J.; Cardote, A.; Neves, F.; Sargento, S.; Ollveira, A. Seamless horizontal and vertical mobility in VANET. In: Proceedings of the Vehicular Networking Conference (VNC), 2012 IEEE, 2012, p. 226-233.

Dikaiakos, M.; Florides, A.; NAdeem, T.; Iftode, L. Location-aware services over vehicular ad-hoc networks using car-to-car communication. Selected Areas in Communications, IEEE Journal on, v. 25, n. 8, p. 1590-1602, 2007.

E-SECurity, T. Thales e-security. disponível em: www.thales-esecurity.com. acesso em: 25-02-2014. 2014.

ETSI-TS Intelligent transport systems (ITS) - vehicular communications - basic set of applications - part 2: Specification of cooperative awareness basic service. Relatório Técnico, 2011.

Gerla, M.; Weng, J.-T.; Giordano, E.; PAU, G. Vehicular testbeds; validating models and protocols before large scale deployment. In: Proceedings of the Computing, Networking and Communications, IEEE Conference on, (ICNC'12), 2012, p. 665-669.

Ghafoor, K.; Lloret, J.; Bakar, K.; SAdiQ, A.; Mussa, S. Beaconing approaches in vehicular ad hoc networks: A survey. Wireless Personal Communications, v. 73, n. 3, p. 885-912, 2013.

Hartenstein, H.; Laberteaux, K. A tutorial survey on vehicular ad hoc networks. Communications Magazine, IEEE, v. 46, n. 6, p. 164-171, 2008. 
Hong, K.; Xing, D.; RAI, V.; Kenney, J. Characterization of DSRC performance as a function of transmit power. In: Proceedings of the Sixth ACM International Workshop on VehiculAr InterNETworking, ACM Conference on, (VANET'09), 2009, p. 63-68.

Hull, B.; Bychkovsky, V.; Zhang, Y.; Chen, K.; Goraczko, M.; Miu, A.; Shin, E.; Balakrishnan, H.; Madden, S. Cartel: A distributed mobile sensor computing system. In: Proceedings of the 4th International Conference on Embedded Networked Sensor Systems, ACM Conference on, (SenSys'06), 2006, p. 125-138.

IEEE-802.11 Standard for information technology-telecommunications and information exchange between systems local and metropolitan area networks-specific requirements part 11: Wireless LAN medium access control (MAC) and physical layer (PHY) specifications. IEEE Standards, 2012.

IEEE-802.11P 802.11p-2010 - IEEE standard for information technology - local and metropolitan area networks - specific requirements-part 11: Wireless LAN medium access control (MAC) and physical layer (PHY) specifications amendment 6: Wireless access in vehicular environments. IEEE Standards, 2010.

Jiang, D.; Chen, Q.; Delgrossi, L. Optimal data rate selection for vehicle safety communications. In: Proceedings of the Fifth ACM International Workshop on VehiculAr Inter-NETworking, ACM Conference on, (VANET'08), 2008, p. 30-38.

JiAng, D.; Delgrossi, L. Ieee 802.11p: Towards an international standard for wireless access in vehicular environments. In: Proceedings of the Vehicular Technology Conference, IEEE Conference on (VTC Spring'08), 2008, p. 2036-2040.

Joerer, S.; Sommer, C.; Dressler, F. Toward reproducibility and comparability of IVC simulation studies: a literature survey. Communications Magazine, IEEE, v. 50, n. 10, p. $82-88,2012$.

Kaemarungsi, K.; Krishnamurthy, P. Properties of indoor received signal strength for WLAN location fingerprinting. In: Proceedings onf the The First Annual International Mobile and Ubiquitous Systems: Networking and Services, IEEE Conference on, (MOBIQUITOUS'04), 2004, p. 14-23.

Karagiannis, G.; Altintas, O.; Ekici, E.; Heijenk, G.; Jarupan, B.; Lin, K.; WEIL, T. Vehicular networking: A survey and tutorial on requirements, architectures, challenges, standards and solutions. Communications Surveys Tutorials, IEEE, v. 13, n. 4, p. 584-616, 2011.

Kurose, J. F.; Ross, K. W. Redes de computadores e a Internet. Uma abordagem topdown. 5 ed. Sao Paulo:Person, 2010.

Ladd, A. M.; Bekris, K. E.; Rudys, A.; Marceau, G.; Kavraki, L. E.; Wallach, D. S. Robotics-based location sensing using wireless ethernet. In: Proceedings of the 8th Annual International Conference on Mobile Computing and Networking, ACM Conference on, (MobiCom'02), 2002, p. 227-238.

Lamarca, A.; Chawhthe, Y.; Consolvo, S.; Hightower, J.; Smith, I.; Scott, J.; Sohn, T.; Howard, J.; Hughes, J.; Potter, F.; Tabert, J.; Powledge, P.; Borriello, G.; Schilit, B. Place lab: Device positioning using radio beacons in the 
wild. In: Gellersen, H.-W.; Want, R.; Schmidt, A., eds. Pervasive Computing, v. 3468 de Lecture Notes in Computer Science, Springer Berlin Heidelberg, p. 116-133, 2005.

Lee, K.; Lee, S.-H.; Cheung, R.; Lee, U.; Gerla, M. First experience with cartorrent in a real vehicular ad hoc network testbed. In: 2007 Mobile Networking for Vehicular Environments, 2007, p. 109-114.

LeE, U.; Gerla, M. A survey of urban vehicular sensing platforms. Computer Network, Elsevier, v. 54, n. 4, p. 527-544, 2010.

Liénard, M.; Bétrencourt, S.; Degauque, P. Propagation in road tunnels: a statistical analysis of the field distribution and impact of the traffic. Annales Des Télécommunications, v. 55, n. 11-12, p. 623-631, 2000.

Lu, R.; Lin, X.; Zhu, H.; Ho, P.-H.; Shen, X. Ecpp: Efficient conditional privacy preservation protocol for secure vehicular communications. In: Proceedings of the 27th Conference on Computer Communications. IEEE Conference on, (INFOCOM'08), 2008, p. 1-9.

Mahajan, R.; Zahorjan, J.; Zill, B. Understanding WiFi-based connectivity from moving vehicles. In: Proceedings of the 7th ACM SIGCOMM Conference on Internet Measurement, ACM Conference on (IMC'07), 2007, p. 321-326.

Malandrino, F.; Borgiattino, C.; Casetti, C.; Chiasserini, C.; Fiore, M.; SaDAO YOKOYAMA, R. Verification and inference of positions in vehicular networks through anonymous beaconing. Aceito em Mobile Computing, IEEE Transactions on, 2014.

Malandrino, F.; Casetti, C.; Chiasserini, C.; Fiore, M.; Yokoyama, R.; BorGiattino, C. A-VIP: Anonymous verification and inference of positions in vehicular networks. In: Proceedings of the 32rd Annual IEEE International Conference on Computer Communications, IEEE Connference on, (INFOCOM'13), 2013, p. 105-109.

Marfia, G.; Roccetti, M.; Amoroso, A.; Pau, G. Safe driving in la: Report from the greatest intervehicular accident detection test ever. Vehicular Technology, IEEE Transactions on, v. 62, n. 2, p. 522-535, 2013.

Martelli, F.; Elena Renda, M.; Resta, G.; Santi, P. A measurement-based study of beaconing performance in IEEE 802.11p vehicular networks. In: Proceedings of the 31rd Annual IEEE International Conference on Computer Communications, IEEE Connference on, (INFOCOM'12), 2012, p. 1503-1511.

Nzouonta, J.; Rajgure, N.; Wang, G.; Borcea, C. VAnET routing on city roads using real-time vehicular traffic information. Vehicular Technology, IEEE Transactions on, v. 58, n. 7, p. 3609-3626, 2009.

Papadimitratos, P.; La Fortelle, A.; Evenssen, K.; Brignolo, R.; Cosenza, S. Vehicular communication systems: Enabling technologies, applications, and future outlook on intelligent transportation. Communications Magazine, IEEE, v. 47, n. 11, p. 84-95, 2009.

RAppaport, T. S. Comunicações sem fio: princípios e práticas. 2 ed. Sao Paulo:Person Prentice Hall, 2009. 
Roos, T.; Myllymäki, P.; Tirri, H.; Misikangas, P.; Sievänen, J. A probabilistic approach to WLAN user location estimation. International Journal of Wireless Information Networks, v. 9, n. 3, p. 155-164, 2002.

Rubinstein, M.; Ben Abdesslem, F.; Amorim, M.; Cavalcanti, S.; Dos Santos Alves, R.; Costa, L.; Duarte, O.; Campista, M. Measuring the capacity of in-car to in-car vehicular networks. Communications Magazine, IEEE, v. 47, n. 11, p. 128-136, 2009.

SAE-International J2735 DSRC message set dictionary. Relatório Técnico, 2009.

Sanchez, M. I.; Gramaglia, M.; Bernardos, C. J.; Oliva, A.; Calderon, M. On the implementation, deployment and evaluation of a networking protocol for VANETs: The VARON case. Ad Hoc Networks, , n. 1, p. 1 - 14, 2014.

Santa, J.; Tsukada, M.; Ernst, T.; Gomez-Skarmeta, A. Experimental analysis of multi-hop routing in vehicular ad-hoc networks. In: Proceedings of the 5th InternationalConference on Testbeds and Research Infrastructures for the Development of Networks Communities and Workshops, IEEE Conference on, (TridentCom'09), 2009, p. 1-8.

Schmidt-Eisenlohr, F.; Torrent-Moreno, M.; Mittag, J.; Hartenstein, H. Simulation platform for inter-vehicle communications and analysis of periodic information exchange. In: Proceedings of the Fourth Annual Conference on Wireless on Demand Network Systems and Services. IEEE Conference on (WONS'07)., 2007, p. 50-58.

ScHOCH, E.; KARGL, F. On the efficiency of secure beaconing in VANETs. In: Proceedings of the Third ACM Conference on Wireless Network Security, ACM Conference on, (WiSec'10), 2010, p. 111-116.

Slavik, M.; Mahgoub, I.; Alwakeel, M. Analysis of beaconing message rate in vanet multi-hop broadcast protocols. In: Proceedings of the 9th International Conference on High Capacity Optical Networks and Enabling Technologies, IEEE Conference on, (HONET'12), 2012, p. 037-041.

Sommer, C.; Tonguz, O.; Dressler, F. Adaptive beaconing for delay-sensitive and congestion-aware traffic information systems. In: Proceedings of the Vehicular Networking Conference, IEEE Conference on, (VNC'10), 2010, p. 1-8.

Soroush, H.; Baneruee, N.; Balasubramanian, A.; Corner, M. D.; Levine, B. N.; Lynn, B. Dome: A diverse outdoor mobile testbed. In: Proceedings of the 1st ACM International Workshop on Hot Topics of Planet-Scale Mobility Measurements, ACM Conference on, (HotPlanet'09), 2009, p. 2:1-2:6.

Tanenbaum, A. S.; Wetherall, D. J. Redes de computadores. 5 ed, 2011.

Tiedeke, J.; Schabel, P.; Rille, E. Vehicle distance sensor using a segmented ir laser beam. In: Proceedings of the 40th Vehicular Technology Conference, IEEE Conference on, 1990, p. 107-112.

Torrent-Moreno, M.; Mittag, J.; Santi, P.; Hartenstein, H. Vehicle-to-vehicle communication: Fair transmit power control for safety-critical information. Vehicular Technology, IEEE Transactions on, v. 58, n. 7, p. 3684-3703, 2009. 
Toutouh, J.; AlBA, E. Performance analysis of optimized vanet protocols in real world tests. In: Wireless Communications and Mobile Computing Conference (IWCMC), 2011 rth International, 2011, p. 1244-1249.

Uzcategui, R.; Acosta-Marum, G. WAVE: A tutorial. Communications Magazine, IEEE, v. 47, n. 5, p. 126-133, 2009.

Vandenberghe, W.; Moerman, I.; Demeester, P. Approximation of the IEEE 802.11p standard using commercial off-the-shelf IEEE 802.11a hardware. In: Proceedings of the 11th International Conference ITS Telecommunications (ITST'11), IEEE Conference (ITST'11), 2011, p. 21-26.

VSC-CONSORTIUM Vehicle safety communications project task 3 - final report: Indentify intelligent vehicle safety applications enables by dsrc. In: Relatório Técnico., 2005.

Widmann, D.; Balac, K.; Taddeo, A.; Prevostini, M.; Puiatti, A. Characterization of in-tunnel distance measurements for vehicle localization. In: Proceedings of the Wireless Communications and Networking Conference, IEEE Conference on, (WCNC'13), 2013, p. 2311-2316.

Wiedersheim, B.; Ma, Z.; Kargl, F.; Papadimitratos, P. Privacy in inter-vehicular networks: Why simple pseudonym change is not enough. In: Proceedings of the Seventh International Wireless On-demand Network Systems and Services, IEEE Conference on (WONS'10), 2010, p. 176-183.

Yang, S.; Dessai, P.; Verma, M.; Gerla, M. Freeloc: Calibration-free crowdsourced indoor localization. In: Proceedings of the 32rd Annual IEEE International Conference on Computer Communications, Conference on, (INFOCOM'13), 2013, p. 2481-2489.

Ying, Y.; YuHui, Z. Technique of measuring leading vehicle distance based on digital image processing theory. In: Proceedings of the Intelligent Computation Technology and Automation, IEEE Conference on, (ICICTA'10), 2010, p. 674-677.

Yokoyama, R.; Kimura, B.; Jaimes, L.; Moreira, E. A beaconing-based opportunistic service discovery protocol for vehicular networks. In: Advanced Information Networking and Applications Workshops (WAINA), 28th International Conference on, 13-16 May, 2014.

Yokoyama, R.; Kimura, B.; Moreira, E. V-Beacon: Uma plataforma experimental para redes veiculares sem fio. In: Anais do III Simposio Brasileiro de Engenharia de Sistemas Computacionais (SBESC13), Niteroi-RJ Brasil. Pag. 1-6. Novembro., 2013.

Zeadally, S.; Hunt, R.; Chen, Y.-S.; Irwin, A.; Hassan, A. Vehicular ad hoc networks (VANETS): status, results, and challenges. Telecommunication Systems, v. 50, n. 4, p. 217-241, 2012.

Zhu, K.; Niyato, D.; Wang, P.; Hossain, E.; In Kim, D. Mobility and handoff management in vehicular networks: a survey. Wireless Communications and Mobile Computing, v. 11, n. 4, p. 459-476, 2011. 